\title{
Nucleophilic Aromatic Substitution Reactions for the Synthesis of Ferrocenyl Aryl Ethers
}

Marcus Korb, ${ }^{a}$ Pieter J. Swarts, ${ }^{b}$ Dominique Miesel, ${ }^{a}$ Alexander Hildebrandt, ${ }^{a}$ Jannie C. Swarts, ${ }^{b}$ Heinrich Lang ${ }^{a} *$

a Technische Universität Chemnitz, Faculty of Natural Sciences, Institute of Chemistry, Inorganic Chemistry, D09107 Chemnitz, Germany

b Department of Chemistry, University of the Free State, PO Box 339, Bloemfontein, South Africa

\section{SUPPORTING INFORMATION}




\section{TABLE OF CONTENTS}

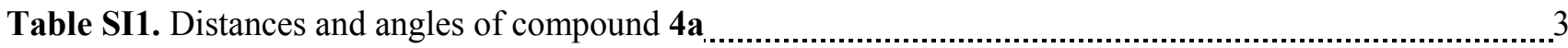

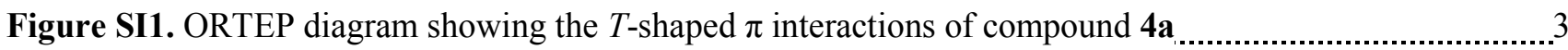

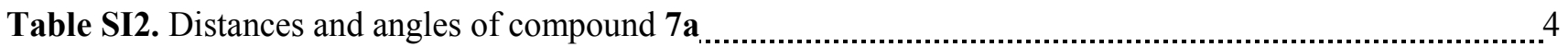

Figure SI2a. ORTEP diagrams of compound 7a

Figure SI2b. ORTEP diagrams of compound 7a

Table SI3. Distances and angles of the intermolecular $T$-shaped $\pi$ interactions of compound $7 \mathbf{b} \ldots \ldots \ldots \ldots \ldots \ldots \ldots$

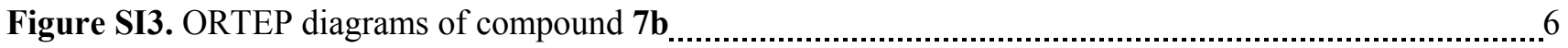

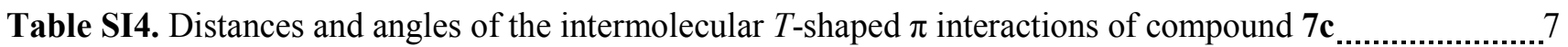

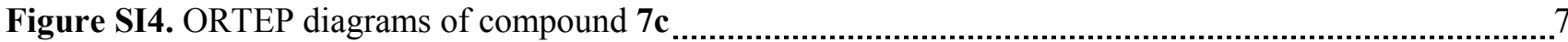

Table SI5. Distances and angles within the sum of the van der Waals radii and of the intermolecular $T$-shaped $\pi$ interactions of compound $\mathbf{8}$

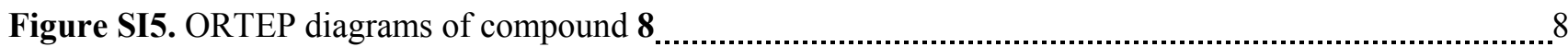

Table SI6. Distances and angles within the sum of the van der Waals radii and of the intermolecular

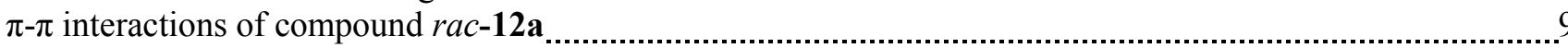

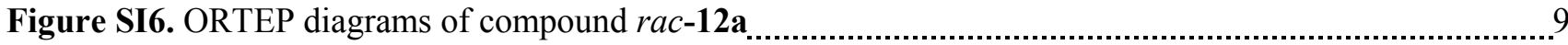

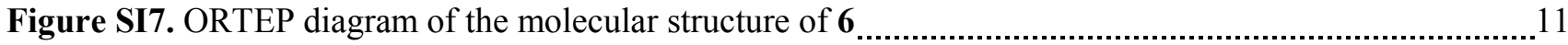

Table SI7. Selected bond distances, angles and torsion angles of $\mathbf{4 a}, \mathbf{b}, \mathbf{7} \mathbf{a}-\mathbf{c}, \mathbf{8}$ and $\mathrm{rac}-\mathbf{1 2 a} \ldots \ldots \ldots \ldots \ldots \ldots \ldots . . . . . . . . . .11$

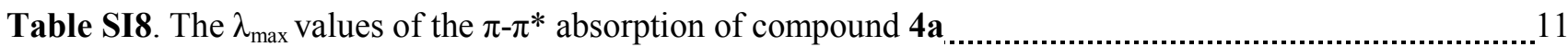

Figure SI8. Cyclic voltammograms and square wave voltammograms of 9, 10, rac-11c, rac-11d and 17

Figure SI9. Cyclic voltammograms and square wave voltammograms of $\mathbf{4 a}$ and $\mathbf{4 b}$ 12

Figure SI10. Cyclic voltammograms and square wave voltammograms of $r a c-11 b, r a c-12 a$ and $r a c-$ $13 \mathbf{a}$

Figure SI11. Cyclic voltammograms and square wave voltammograms of $7 \mathbf{a}-\mathbf{c}$ and $\mathbf{8}$ 13

${ }^{1} \mathrm{H},{ }^{13} \mathrm{C}\left\{{ }^{1} \mathrm{H}\right\},{ }^{29} \mathrm{Si}$ and ${ }^{31} \mathrm{P}\left\{{ }^{1} \mathrm{H}\right\}$ NMR spectra of $\mathbf{2 b}-\mathbf{d}, \mathbf{g}, \mathbf{h}, \mathbf{4 a}, \mathbf{b}, \mathbf{7 a}-\mathbf{c}, \mathbf{8}$, rac-11a, $\mathbf{b}$, rac-12a, rac-13a and 16a,b 


\section{$\underline{\text { Single Crystal Diffraction Analysis - Remarks and intermolecular Interactions }}$}

Intermolecular interactions between the centroids $(=\mathrm{Ct})$ of aromatic rings and within the sum of the van der Waals radii are summarized in Tables SI1-6 and Figures SI1-6

\section{Compound 4a}

Table SI1. Distances and angles of the intermolecular $T$-shaped $\pi$ interactions of compound $4 \mathbf{a}$ referring to Figure SI1.

\begin{tabular}{lcccc}
\hline & \multicolumn{1}{c}{$\mathbf{C t}^{\cdots}{ }^{\cdots} \mathbf{C t}$} & Distance $^{(\AA)}$ & Angle $\left.^{1)} \mathbf{(}^{\circ}\right)$ & Symmetry Code \\
\hline I1 (blue) & $\mathrm{Ct}(\mathrm{C} 11-\mathrm{C} 16){ }^{\cdots} \mathrm{Ct}(\mathrm{C} 17-\mathrm{C} 21)$ & $4.9185(19)$ & $88.68(17)$ & $1-\mathrm{x}, 1-\mathrm{y}, 1-\mathrm{z}$ \\
$\mathbf{I 2}$ (green) & $\mathrm{Ct}(\mathrm{C} 27-\mathrm{C} 32)^{\cdots} \mathrm{Ct}(\mathrm{C} 6-\mathrm{C} 10)$ & $4.527(2)$ & $88.70(17)$ & $1-\mathrm{x}, 1-\mathrm{y},-\mathrm{z}$ \\
$\mathbf{I 3}$ (pink) & $\mathrm{Ct}(\mathrm{C} 22-\mathrm{C} 26){ }^{\cdots} \mathrm{Ct}(\mathrm{C} 6-\mathrm{C} 10)$ & $4.570(2)$ & $84.4(2)$ & $\mathrm{x}, \mathrm{y}, \mathrm{z}$ \\
\hline
\end{tabular}

1) The angle $\alpha$ is described by the intersection of the involved $\mathrm{C}_{5} \mathrm{H}_{5}, \mathrm{C}_{5} \mathrm{H}_{4}$ and $\mathrm{C}_{6} \mathrm{H}_{3}$ planes.

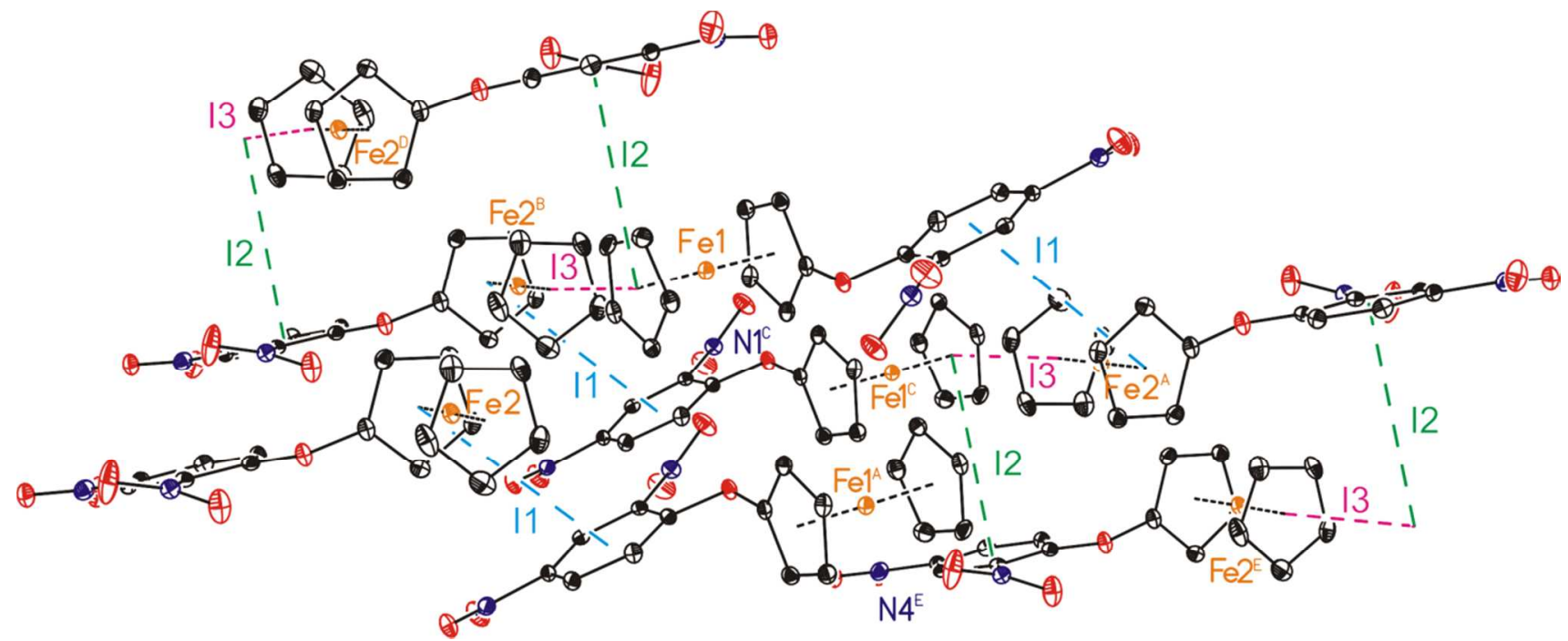

Figure SI1. ORTEP diagram (30\% probability level) showing the $T$-shaped $\pi$ interactions of compound 4 a. Hydrogen atoms have been omitted for clarity. Symmetry transformations used to generate equivalent atoms: $\mathrm{A}=2-\mathrm{x}, 1-\mathrm{y}, 1-\mathrm{z} ; \mathrm{B}=\mathrm{x}-1, \mathrm{y}, \mathrm{z} ; \mathrm{C}=1-\mathrm{x}, 1-\mathrm{y}, 1-\mathrm{z} ; \mathrm{D}=2-\mathrm{x}, 1-\mathrm{y},-\mathrm{z} ; \mathrm{E}=\mathrm{x}-1, \mathrm{y}, 1+\mathrm{z}$.

The packing of compound $\mathbf{4 a}$ is completed by intermolecular $T$-shaped $\pi$ interactions between the $\mathrm{C}_{6} \mathrm{H}_{3}$ rings of both molecules of the asymmetric unit and the $\mathrm{C}_{5} \mathrm{H}_{5}$ moiety of the Fel labeled and the $\mathrm{C}_{5} \mathrm{H}_{5}$ and $\mathrm{C}_{5} \mathrm{H}_{4}$ cyclopentadienyls of the Fe2 labeled ferrocenyls. The complex 3-D structure consists of cyclic structures involving three molecules, which are interacting via two I2 (green) and I3 (pink) interactions (Figure SI1) and are connected by the I1 (blue, Figure SI1). The structure refinement includes a twinning (TWIN-Matrix: $1.000 .000 .00-0.47-$ $1.000 .00-0.160 .00-1.00)$ of 2 components $(\mathrm{BASF}=0.40413)$. 


\section{Compound 7a}

Table SI2. Distances and angles within the sum of the van der Waals radii and of the intra- and intermolecular $T$ shaped $\pi$ interactions of compound 7a referring to Figure SI2.

\begin{tabular}{|c|c|c|c|c|}
\hline & $\mathrm{X} 1{ }^{\cdots} \mathrm{X}_{2} / \mathrm{Ct}^{\cdots} \mathrm{Ct}$ & Distance $(\AA)$ & Angle ( $\left.{ }^{\circ}\right)$ & Symmetry Code \\
\hline I1 (violet) & $\mathrm{O} 1 \cdots \mathrm{C} 5$ & $3.112(11)$ & $82.1(6)^{1)}$ & $1-\mathrm{x},-1 / 2+\mathrm{y}, 2-\mathrm{z}$ \\
\hline $\mathbf{I 2}$ (pale green) & $\begin{array}{c}\mathrm{O} 3{ }^{\cdots} \mathrm{N} 1 \\
\mathrm{O} 3{ }^{\cdots} \mathrm{O}^{2)}\end{array}$ & $\begin{array}{l}2.912(11) \\
2.975(10)\end{array}$ & $\begin{array}{l}105.4(6)^{1)} \\
126.0(6)^{1)}\end{array}$ & $-\mathrm{x}, 1 / 2+\mathrm{y}, 2-\mathrm{z}$ \\
\hline I3 (blue) & $\mathrm{Ct}(\mathrm{C} 12-\mathrm{C} 16){ }^{\cdots} \mathrm{Ct}(\mathrm{C} 17-\mathrm{C} 21)$ & $4.898(6)$ & $82.8(6)^{3)}$ & - \\
\hline I4 (green) & $\mathrm{Ct}(\mathrm{C} 22-\mathrm{C} 26){ }^{\cdots} \mathrm{Ct}(\mathrm{C} 7-\mathrm{C} 11)$ & $4.646(6)$ & $85.6(6)^{3)}$ & $-1+x, 1+y, z$ \\
\hline I5 (pink) & $\mathrm{Ct}(\mathrm{C} 12-\mathrm{C} 16){ }^{\cdots} \mathrm{Ct}(\mathrm{C} 17-\mathrm{C} 21)$ & $4.983(6)$ & $82.8(6)^{3)}$ & $1+\mathrm{x}, \mathrm{y}, \mathrm{z}$ \\
\hline I6 (yellow) & $\mathrm{Ct}(\mathrm{C} 7-\mathrm{C} 11)^{\cdots} \mathrm{Ct}(\mathrm{C} 22-\mathrm{C} 26)$ & $4.633(6)$ & $85.6(6)^{3)}$ & $\mathrm{x},-1+\mathrm{y}, \mathrm{z}$ \\
\hline
\end{tabular}

1) The $\mathrm{N}-\mathrm{X} 1^{\cdots} \mathrm{X} 2$ angle is reported. 2) Not shown in Figure SI2. 3) The angle $\alpha$ is described by the intersection of the involved $\mathrm{C}_{5} \mathrm{H}_{5}, \mathrm{C}_{5} \mathrm{H}_{4}$ and $\mathrm{C}_{6} \mathrm{H}_{3}$ planes.
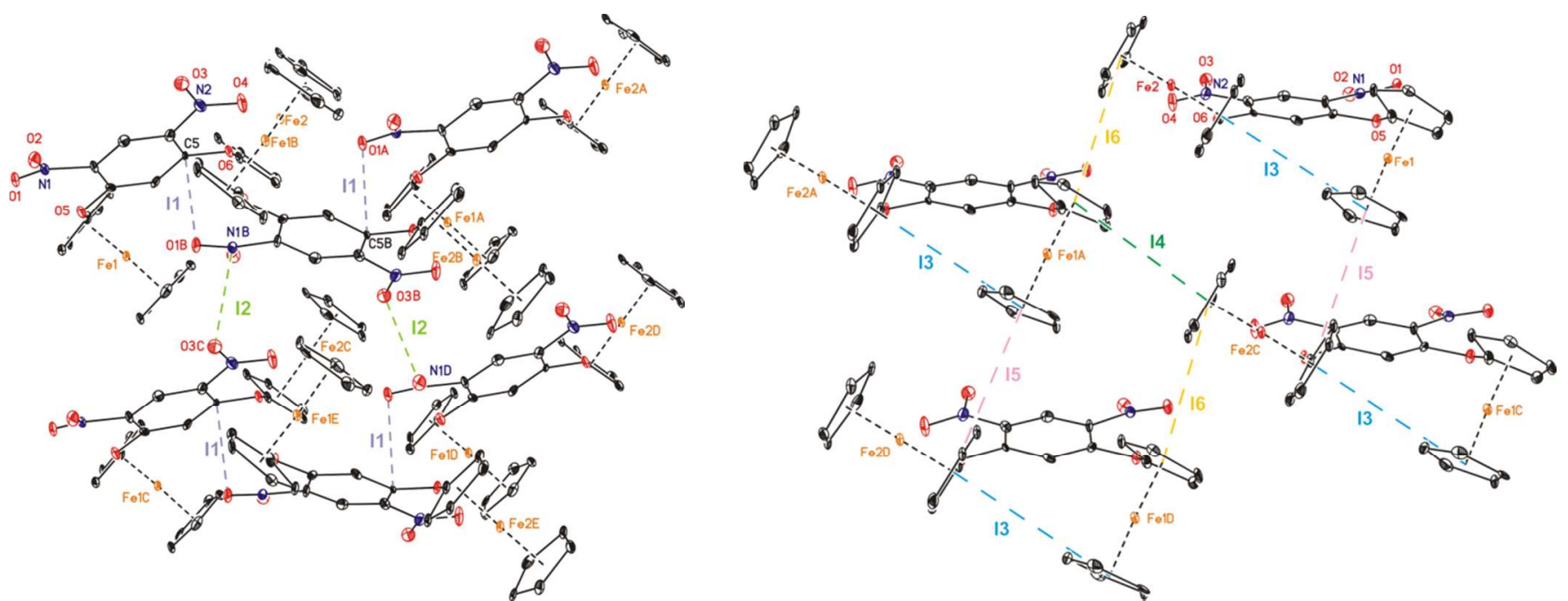

Figure SI2a. ORTEP diagrams (30\% probability level) showing interactions within the sum of the van der Waals radii (left), intra- (I3) and intermolecular (I4-6) $T$-shaped $\pi$ interactions (right) of the packing of compound 7a. Hydrogen atoms have been omitted for clarity. Symmetry transformations used to generate equivalent atoms: $\mathrm{A}=$ $\mathrm{x}, 1+\mathrm{y}, \mathrm{z} ; \mathrm{B}=1-\mathrm{x}, \mathrm{y}+1 / 2,-\mathrm{z} ; \mathrm{C}=1+\mathrm{x}, \mathrm{y}, \mathrm{z} ; \mathrm{D}=1+\mathrm{x}, 1+\mathrm{y}, \mathrm{z}$. 


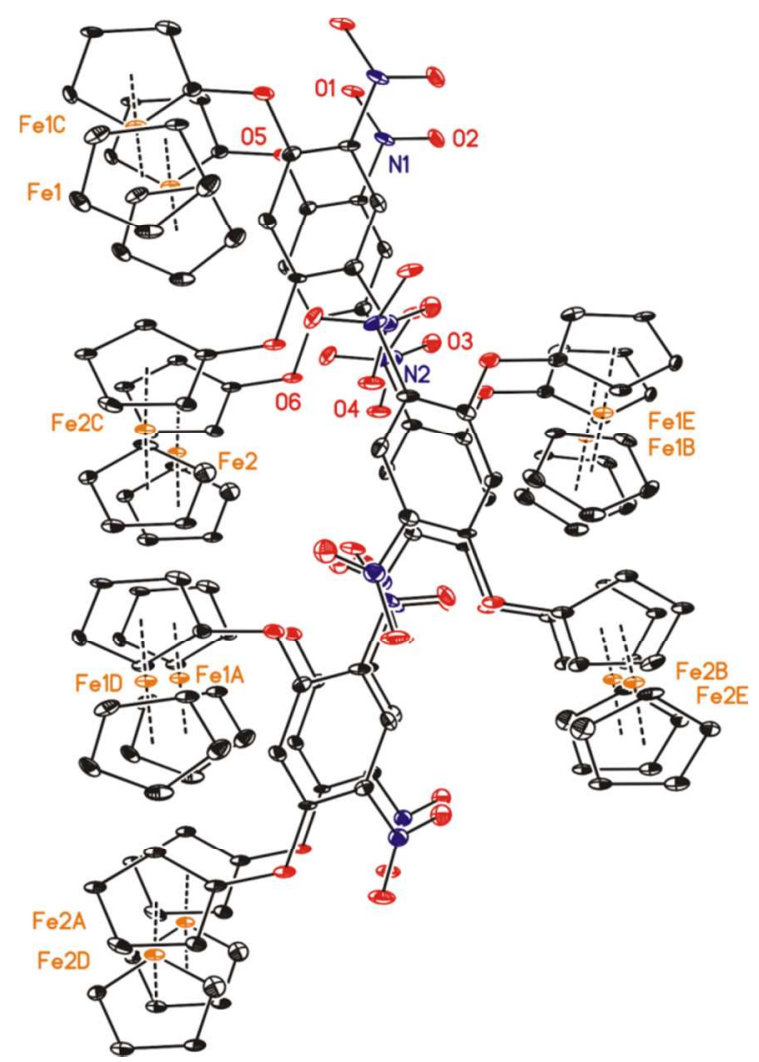

Figure SI2b. ORTEP diagrams (30\% probability level) showing the packing along the a axis of compound 7a. Hydrogen atoms have been omitted for clarity. Symmetry transformations used to generate equivalent atoms: $\mathrm{A}=$ $\mathrm{x}, 1+\mathrm{y}, \mathrm{z} ; \mathrm{B}=1-\mathrm{x}, \mathrm{y}+1 / 2,-\mathrm{z} ; \mathrm{C}=1+\mathrm{x}, \mathrm{y}, \mathrm{z} ; \mathrm{D}=1+\mathrm{x}, 1+\mathrm{y}, \mathrm{z} ; \mathrm{E}=2-\mathrm{x}, \mathrm{y}+1 / 2,-\mathrm{z}$.

Compound 7a forms a layer-type packing parallel to (001) (Figure SI2, top-right). The layers itself are built up of three parts. The two outer layers consist of the ferrocenyl moieties interacting by intra- and intermolecular $T$ shaped $\pi$ interactions forming a two dimensional network (Figure SI2, bottom). The middle layer contains the benzene parts of 7a in a $\pi$-stacking within the sum of the van der Waals radii including the $\mathrm{NO}_{2}$ groups and the $\mathrm{C} 5$ atom of the phenyl $\mathrm{C}_{6}$ entity (Figure SI2, top-left). 


\section{Compound 7b}

Table SI3. Distances and angles of the intermolecular $T$-shaped $\pi$ interactions of compound $7 \mathbf{b}$ referring to Figure SI3.

\begin{tabular}{|c|c|c|c|}
\hline $\mathrm{X} 1{ }^{\cdots} \mathrm{X} 2 / \mathrm{Ct}^{\cdots} \mathrm{Ct}$ & Distance $(\AA)$ & Angle ( $\left.{ }^{\circ}\right)$ & Symmetry Code \\
\hline $\mathrm{F} 1 \cdots \mathrm{O} 9$ & $2.886(2)$ & $130.15(15)^{1)}$ & - \\
\hline $\mathrm{F} 2 \cdots \mathrm{O} 8$ & $2.923(2)$ & $105.84(14)^{1)}$ & $\mathrm{x}, 1+\mathrm{y}, \mathrm{z}$ \\
\hline $\mathrm{N} 4{ }^{\cdots} \mathrm{O} 4$ & $2.915(3)$ & $107.42(16)^{2)}$ & $\mathrm{x}, 1+\mathrm{y}, \mathrm{z}$ \\
\hline $\mathrm{Ct}(\mathrm{C} 6-\mathrm{C} 10){ }^{\cdots} \mathrm{Ct}(\mathrm{C} 22-\mathrm{C} 26)$ & $4.5078(17)$ & $87.13(17)^{3)}$ & $\mathrm{X},-1+\mathrm{y}, 1+\mathrm{z}$ \\
\hline $\mathrm{Ct}(\mathrm{C} 22-\mathrm{C} 26){ }^{\cdots} \mathrm{Ct}(\mathrm{C} 6-\mathrm{C} 10)$ & $4.7767(17)$ & $87.13(17)^{3)}$ & $\mathrm{X}, \mathrm{y},-1+\mathrm{z}$ \\
\hline $\mathrm{Ct}(\mathrm{C} 11-\mathrm{C} 16){ }^{\cdots} \mathrm{Ct}(\mathrm{C} 22-\mathrm{C} 26)$ & $4.9281(18)$ & $85.30(15)^{3)}$ & $1 / 2-x,-1 / 2+y, 1 / 2-z$ \\
\hline $\mathrm{Ct}(\mathrm{C} 27-\mathrm{C} 32) \cdots \mathrm{Ct}(\mathrm{C} 6-\mathrm{C} 10)$ & $4.5842(16)$ & $88.86(14)^{3)}$ & $-\mathrm{x}, 1-\mathrm{y}, 1-\mathrm{z}$ \\
\hline
\end{tabular}

1) The $\mathrm{C}-\mathrm{X} 1{ }^{\cdots} \mathrm{X} 2$ angle is reported. 1) The $\mathrm{N} 4 \cdots \mathrm{O} 4-\mathrm{N} 2$ angle is reported. 3) The angle $\alpha$ is described by the intersection of the involved $\mathrm{C}_{5} \mathrm{H}_{5}, \mathrm{C}_{5} \mathrm{H}_{4}$ and $\mathrm{C}_{6} \mathrm{H}_{3}$ planes.
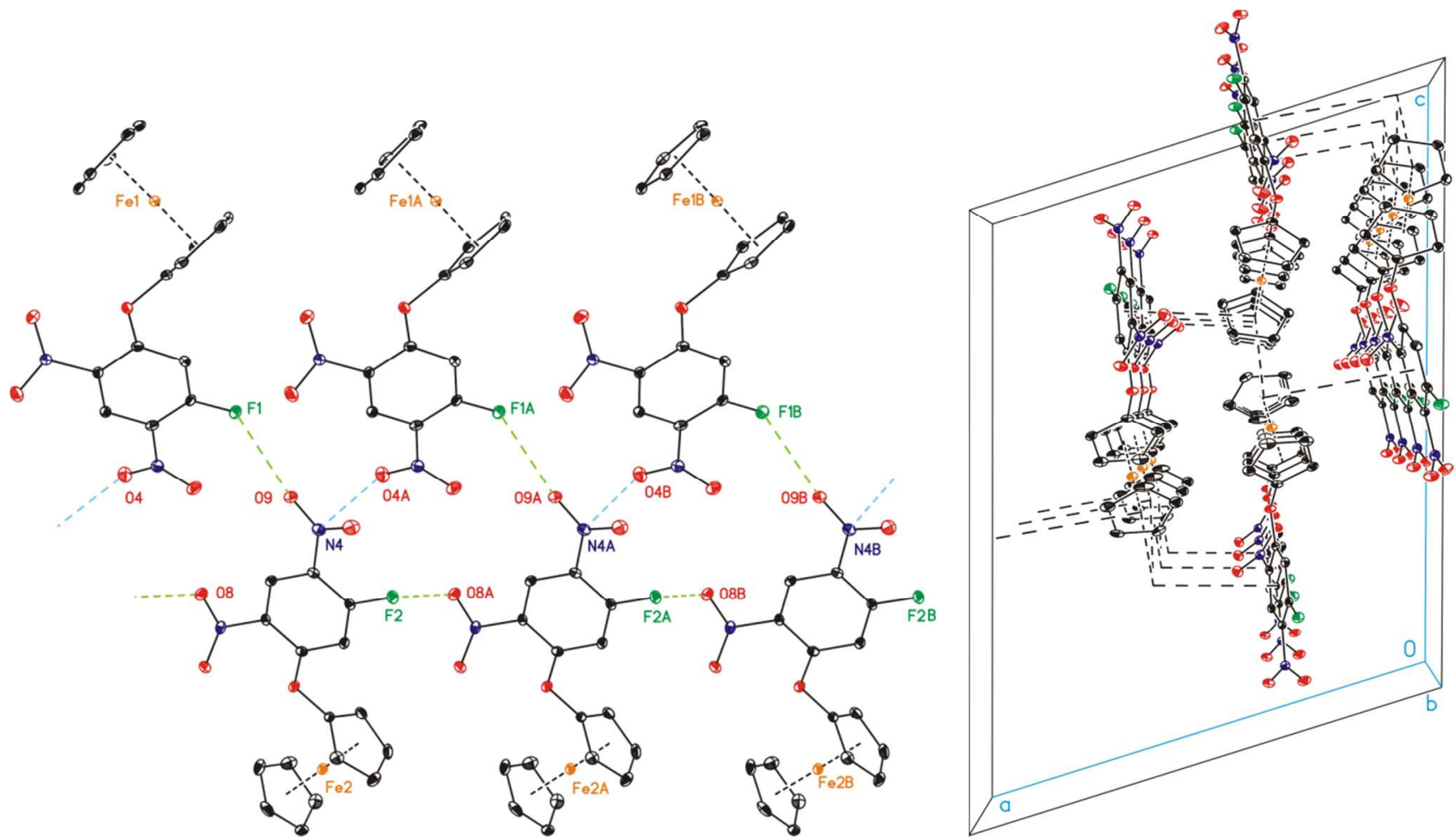

Figure SI3. ORTEP diagrams (30\% probability level) showing interactions within the sum of the van der Waals radii (top) and $T$-shaped $\pi$ interactions (bottom) of compound $\mathbf{7 b}$. Hydrogen atoms have been omitted for clarity. Symmetry transformations used to generate equivalent atoms: $A=x, y+1, z ; B=x, y+2, z$.

Compound $\mathbf{7 b}$ is stabilized by a three dimensional network including short $\mathrm{F} 1{ }^{\cdots} \mathrm{O} 9$ and $\mathrm{F} 2{ }^{\cdots} \mathrm{O} 8$ and electrostatic $\mathrm{N} 4 \cdots \mathrm{O} 4$ distances within the sum of the van der Waals radii (Figure SI3, top) forming one-dimensional strands within the [010] direction. Furthermore, $T$-shaped $\pi$ interactions between the $\mathrm{C}_{5} \mathrm{H}_{5}$ rings connect these strands to a layer-type network (Figure SI3, bottom). These layers are packed parallelly to (004), connected via $T$-shaped $\pi$ interactions between the $\mathrm{C}_{5} \mathrm{H}_{5}$ rings and the phenyl moieties of the adjacent layer, finalizing the three-dimensional network in the [100] direction. 


\section{Compound 7c}

Table SI4. Distances and angles within the sum of the van der Waals radii and of the intermolecular $T$-shaped $\pi$ interactions of compound 7c referring to Figure SI4.

\begin{tabular}{cccc}
\hline $\mathbf{X} 1{ }^{\cdots} \mathbf{X} 2 / \mathbf{C t}^{\cdots} \mathbf{C t}$ & Distance $(\mathbf{\AA})$ & Angle $^{\left({ }^{\circ}\right)}$ & Symmetry Code \\
\hline $\mathrm{O} 4 \cdots \mathrm{O} 1$ & $3.004(12)$ & $154.4(7)^{1)}$ & $1 / 2+\mathrm{x}, 3 / 2-\mathrm{y}, 1-\mathrm{z}$ \\
$\mathrm{O} 4 \cdots \mathrm{N} 1$ & $2.919(13)$ & $133.4(7)^{1)}$ & $1 / 2+\mathrm{x}, 3 / 2-\mathrm{y}, 1-\mathrm{z}$ \\
$\mathrm{O} 4{ }^{\cdots} \mathrm{C} 2$ & $3.090(14)$ & $109.5(7)^{1)}$ & $1 / 2+\mathrm{x}, 3 / 2-\mathrm{y}, 1-\mathrm{z}$ \\
$\mathrm{Ct}(\mathrm{C} 12-\mathrm{C} 16){ }^{\cdots} \mathrm{Ct}(\mathrm{C} 7-\mathrm{C} 11)$ & $4.804(8)$ & $79.7(7)^{2)}$ & $1-\mathrm{x},-1 / 2+\mathrm{y}, 1 / 2-\mathrm{z}$ \\
\hline
\end{tabular}

1) The N2-O4 ' X2 angle is reported. 2) The angle $\alpha$ is described by the intersection of the involved $\mathrm{C}_{5} \mathrm{H}_{5}$ and $\mathrm{C}_{5} \mathrm{H}_{4}$ planes.
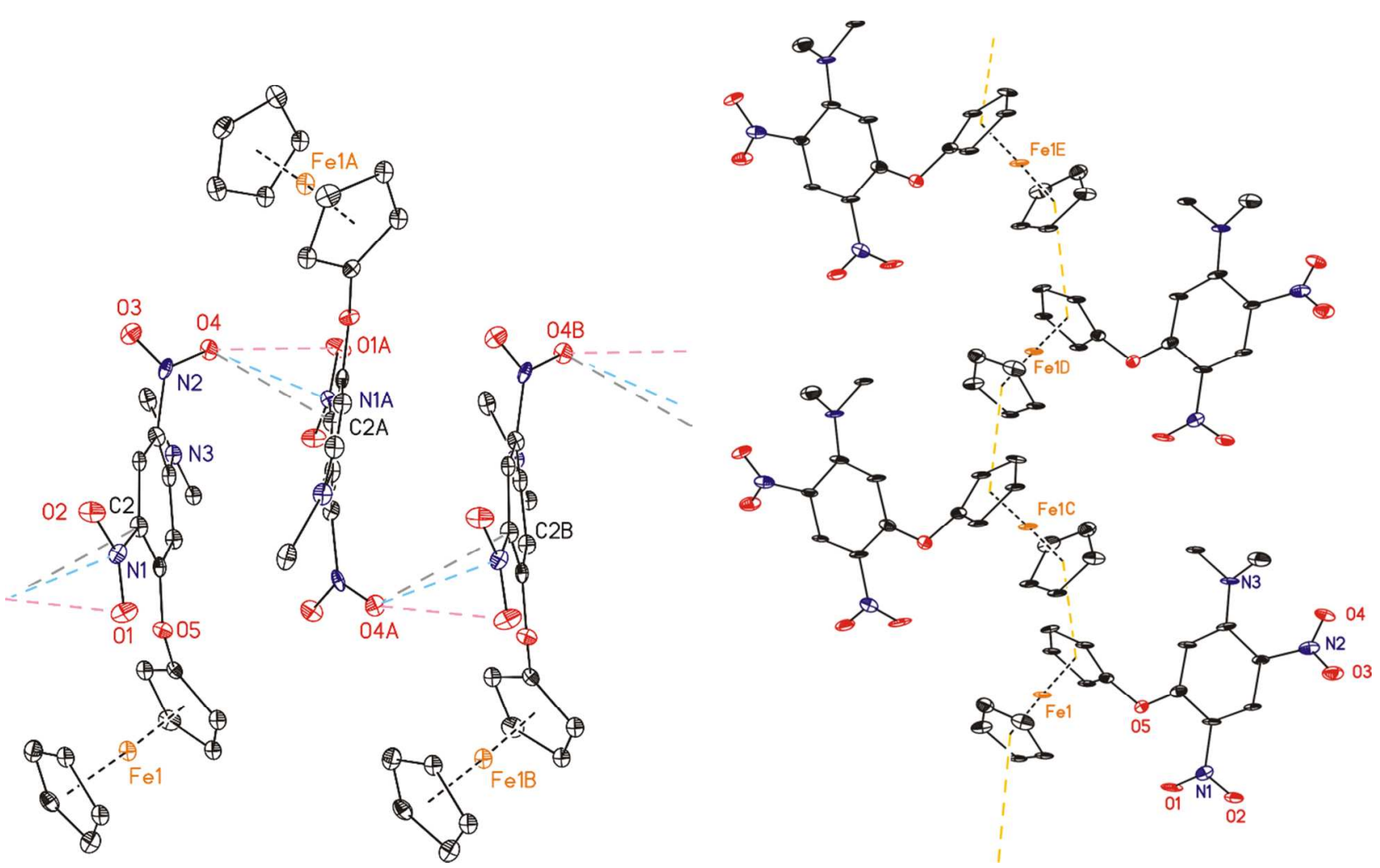

Figure SI4. ORTEP diagrams (probability level: $30 \%$ left; $50 \%$ right) showing interactions within the sum of the van der Waals radii (left) and $T$-shaped $\pi$ interactions (right) of compound 7c. Hydrogen atoms have been omitted for clarity. Symmetry transformations used to generate equivalent atoms: $A=1 / 2+x, 3 / 2-y, 1-z ; B=x+1, y, z ; C=$ $1-\mathrm{x}, 1 / 2+\mathrm{y}, 1 / 2-\mathrm{z} ; \mathrm{D}=\mathrm{x}, \mathrm{y}+1, \mathrm{z} ; \mathrm{E}=1-\mathrm{x}, \mathrm{y}+3 / 2,1 / 2-\mathrm{z}$.

The packing of compound 7c reveals a 3-dimensional network. Along to the direction of the a axis [100], intermolecular short contacts within the sum of the van der Waals radii between the $\mathrm{O} 4$ atom, acting as an electron donor, and the positively charged $\mathrm{N} 2$, as well as the $\mathrm{C} 2$ and $\mathrm{O} 1$ atoms of the adjacent molecules, are present, forming an one-dimensional chain (Figure SI4, left). Within these chains the ferrocenyls are directed alternatingly into opposite directions. The latter ones interact via one-dimensional intermolecular $T$-shaped $\pi$ interactions parallel to the $b$ axis [010] (Figure SI4, right), whereas the benzene moieties are also alternatingly directed to opposite directions, which resembles to the 3D-network present in compound $7 \mathbf{c}$. 


\section{Compound $\mathbf{8}$}

Table SI5. Distances and angles within the sum of the van der Waals radii and of the intermolecular $T$-shaped $\pi$ interactions of compound $\mathbf{8}$ referring to Figure SI5.

\begin{tabular}{cccc}
\hline $\mathbf{X} 1{ }^{\cdots} \mathbf{X} 2 / \mathbf{C t}^{\cdots} \mathbf{C t}$ & Distance $(\mathbf{\AA})$ & Angle $\left({ }^{\circ}\right)$ & Symmetry Code \\
\hline O6 ${ }^{\cdots} \mathrm{C} 6$ & $3.0163(2)$ & $124.92(1)^{1)}$ & $1-\mathrm{x}, 1-\mathrm{y},-\mathrm{z}$ \\
$\mathrm{Ct}(\mathrm{C} 1-\mathrm{C} 6){ }^{\cdots} \mathrm{Ct}(\mathrm{C} 22-\mathrm{C} 26)$ & $4.8515(2)$ & $86(1)^{2)}$ & $\mathrm{x}, 1+\mathrm{y}, \mathrm{z}$ \\
\hline
\end{tabular}

1) The N2-O6 “ C6 angle is reported. 2) The angle $\alpha$ is described by the intersection of the involved $\mathrm{C}_{5} \mathrm{H}_{5}$ and $\mathrm{C}_{5} \mathrm{H}_{4}$ planes.
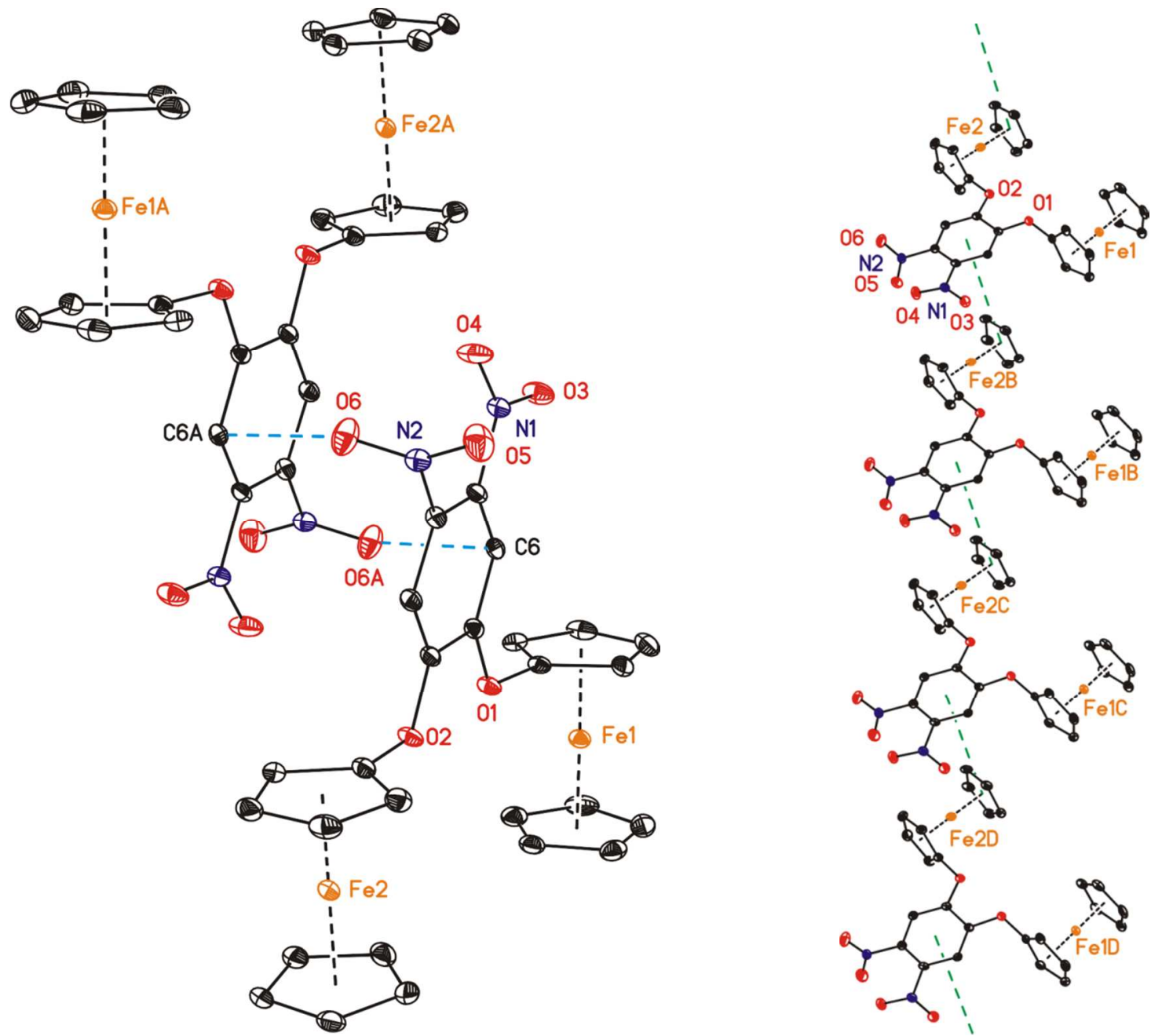

Figure SI5. ORTEP diagrams (30\% probability level) showing interactions within the sum of the van der Waals radii (left) and $T$-shaped $\pi$ interactions (right) of compound $\mathbf{8}$. Hydrogen atoms have been omitted for clarity. Symmetry transformations used to generate equivalent atoms: $A=1-x, 1-y,-z ; B=x, y+1, z ; C=x, y+2, z ; D=$ $\mathrm{x}, \mathrm{y}+3, \mathrm{z}$.

Within the packing of compound $\mathbf{8}$ intermolecular short distances within the sum of the van der Waals radii are present between the $\mathrm{O} 6$ and the $\mathrm{C} 6$ atoms of the adjacent molecule, forming a dimeric structure (Figure SI5, left). Furthermore, an one-dimensional chain based on $T$-shaped $\pi$ interactions along [010] (Figure SI5, right) is present, resembling in an two-dimensional network. 


\section{Compound 12a}

Table SI6. Distances and angles within the sum of the van der Waals radii and of the intermolecular $\pi-\pi$ interactions of compound $\mathrm{rac}-\mathbf{1 2 a}$ referring to Figure SI6.

\begin{tabular}{cccc}
\hline $\mathbf{X} 1{ }^{\cdots} \mathbf{X} 2 / \mathbf{C t}^{\cdots} \mathbf{C t}$ & Distance $(\AA)$ & Angle $\left(^{\circ}\right)$ & Symmetry Code \\
\hline $\mathrm{F} 2 \cdots \mathrm{F} 2$ & $2.726(2)$ & $163.21(18)^{1)}$ & $2-\mathrm{x}, 1-\mathrm{y}, 1-\mathrm{z}$ \\
$\mathrm{Ct}(\mathrm{C} 11-\mathrm{C} 16) \cdots \mathrm{Ct}(\mathrm{C} 11-\mathrm{C} 16)$ & $3.6528(2)$ & $1.482 \AA^{2)}$ & $1-\mathrm{x},-\mathrm{y},-\mathrm{z}$ \\
$\mathrm{C} 11{ }^{\cdots} \mathrm{C} 13$ & $3.334(3)$ & $91.39(11)^{3)}$ & $1-\mathrm{x},-\mathrm{y},-\mathrm{z}$ \\
$\mathrm{C} 12 \cdots \mathrm{Ct}(\mathrm{C} 11-\mathrm{C} 16)$ & $3.345(2)$ & $91.59(11)^{3)}$ & $1-\mathrm{x},-\mathrm{y},-\mathrm{z}$ \\
\hline
\end{tabular}

1) The N2-O6 " C6 angle is reported. 2) The slippage between the centroids is reported. 3) The angle $\alpha$ is described by the intersection of the involved $\mathrm{C}_{6} \mathrm{H}_{3}$ moiety.

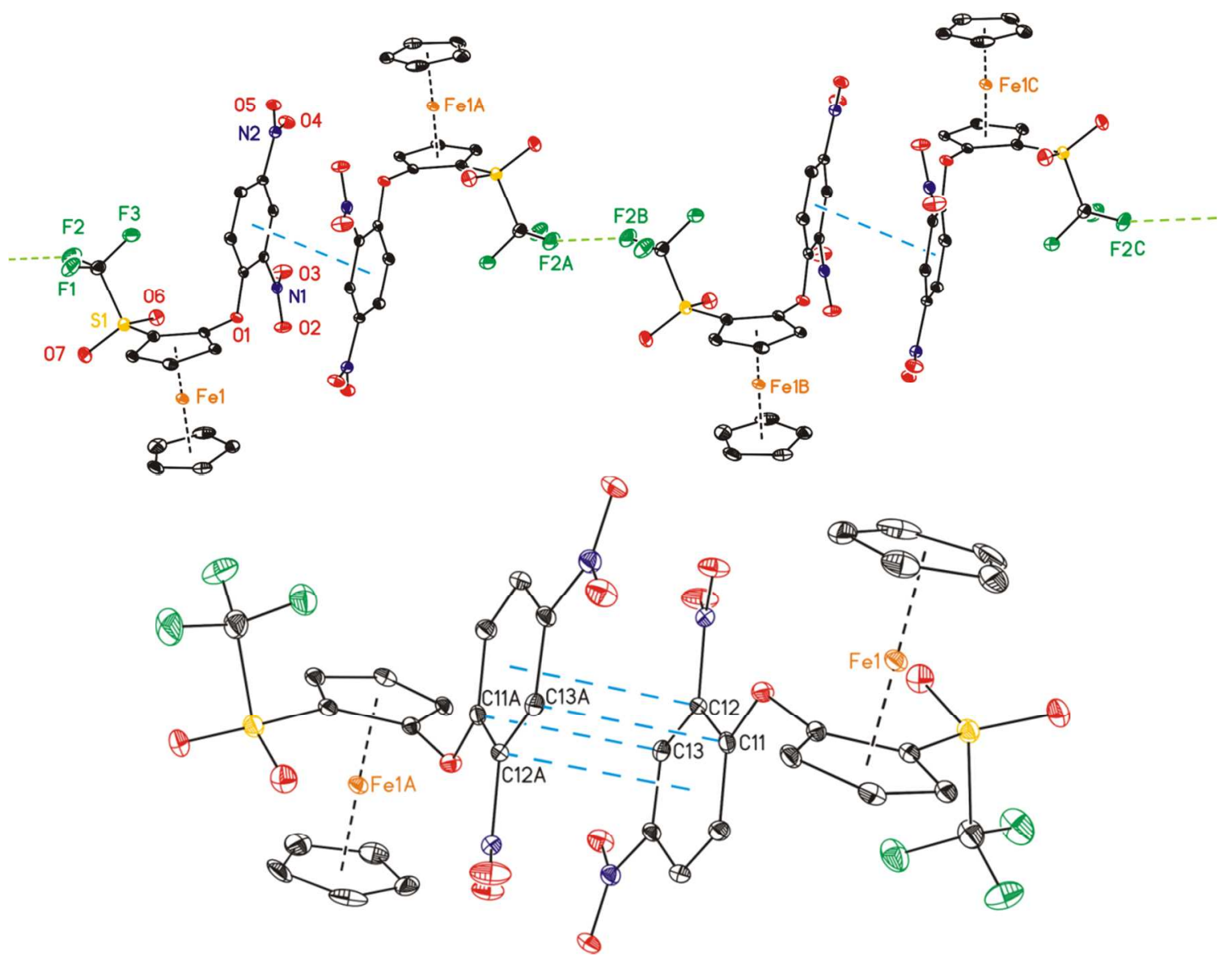

Figure SI6. ORTEP diagrams (30\% probability level) showing interactions within the sum of the van der Waals radii (green) and parallel displaced $\pi-\pi$ interactions (blue, top) of compound rac-12a and the shortest distances between two phenyl rings (bottom). Hydrogen atoms have been omitted for clarity. Symmetry transformations used to generate equivalent atoms: $A=1-x,-y,-z ; B=x-1, y-1, z-1 ; C=2-x,-y+1,1-z$.

Compound rac-12a exhibits a one-dimensional network parallel to [111]. It consists of short distances within the sum of the van der Waals radii between F2 and its symmetry generated equivalent of the adjacent molecule (Table SI6, Figure SI6) and parallel displaced $\pi-\pi$ interactions between the phenyl rings. The shortest distances are observed between $\mathrm{C} 11$ and $\mathrm{C} 13 \mathrm{~A}$, the $\mathrm{C} 12$ atom and the centroid of the phenyl ring of a symmetry generated molecule of rac-12a. 


\section{$\underline{\text { Molecular Structure of compound } 6}$}

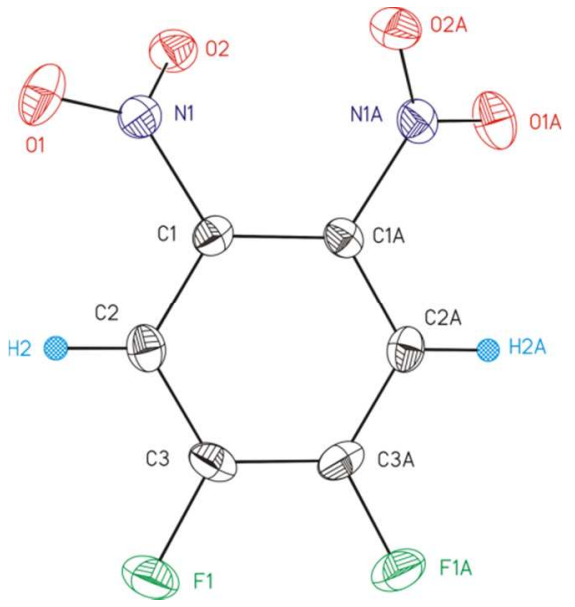

Figure SI7. ORTEP diagram (50\% probability level) of the molecular structure of 6 with the atom numbering scheme. Symmetry transformations used to generate equivalent atoms: $A=y, x,-z+2$.

Suitable single crystals were grown from a hexane solution containing 6 at ambient temperature.

Crystal Data for 6: $\mathrm{C}_{6} \mathrm{H}_{2} \mathrm{~F}_{2} \mathrm{~N}_{2} \mathrm{O}_{4}, M=204.10 \mathrm{~g} \mathrm{~mol}^{-1}$, tetragonal, $P 4_{3} 22_{1} 2, \lambda=0.71073 \AA, a=5.8849(2) \AA, c=$ 21.4266(9) $\AA, V=742.05(6) \AA^{3}, Z=4, \rho_{\text {calcd }}=1.827 \mathrm{Mg} \mathrm{m}^{-3}, \mu=0.185 \mathrm{~mm}^{-1}, T=110(5) \mathrm{K}, \theta$ range $3.590-24.998^{\circ}, 3024$ reflections collected, 647 independent reflections $\left(R_{\text {int }}=0.0694\right),{ }^{52} R_{1}=0.0362, w R_{2}=$ $0.0810(I>2 \sigma(I))$, absolute structure parameter $-1.3(10)$. 
Table SI7. Selected bond distances $(\AA)$, angles $\left(^{\circ}\right)$ and torsion angles $\left(^{\circ}\right)$ of $\mathbf{4 a}, \mathbf{b}, \mathbf{7 a}-\mathbf{c}, \mathbf{8}$ and $\mathrm{rac}-\mathbf{1 2 a}$.

\begin{tabular}{|c|c|c|c|c|c|c|c|}
\hline $\begin{array}{l}\text { Compound } \\
\text { CCDC }\end{array}$ & $\begin{array}{c}\mathbf{4 a} \\
1446860 \\
\end{array}$ & $\begin{array}{c}\mathbf{4 b} \\
1446861 \\
\end{array}$ & $\begin{array}{c}7 \mathbf{a} \\
1446863 \\
\end{array}$ & $\begin{array}{c}\mathbf{7 b} \\
1446864 \\
\end{array}$ & $\begin{array}{c}\mathbf{7 c} \\
1446865 \\
\end{array}$ & $\begin{array}{c}\mathbf{8} \\
1446866 \\
\end{array}$ & $\begin{array}{l}r a c-12 a \\
1446867 \\
\end{array}$ \\
\hline $\mathrm{Ct}\left(\mathrm{C}_{5} \mathrm{H}_{4}\right) \cdots \mathrm{Fe}$ & $\begin{array}{l}1.6358(5) \\
1.6328(5)\end{array}$ & $1.6456(6)$ & $\begin{array}{l}1.640(19) \\
1.627(18)\end{array}$ & $\begin{array}{l}1.6326(4) \\
1.6369(4)\end{array}$ & $1.6296(15)$ & $\begin{array}{l}1.6410(3) \\
1.6480(3)\end{array}$ & $1.6258(3)$ \\
\hline $\mathrm{Ct}\left(\mathrm{C}_{5} \mathrm{H}_{5}\right) \cdots \mathrm{Fe}$ & $\begin{array}{l}1.6448(5) \\
1.6441(5)\end{array}$ & $1.6403(6)$ & $\begin{array}{l}1.642(18) \\
1.648(18)\end{array}$ & $\begin{array}{l}1.6519(4) \\
1.6433(4)\end{array}$ & $1.6340(15)$ & $\begin{array}{l}1.6538(4) \\
1.6510(3)\end{array}$ & $1.6565(3)$ \\
\hline $\mathrm{O}-\mathrm{C}_{\mathrm{Fc}}$ & $\begin{array}{l}1.404(4) \\
1.404(4)\end{array}$ & $1.406(4)$ & $\begin{array}{l}1.392(10) \\
1.382(10)\end{array}$ & $\begin{array}{l}1.409(3) \\
1.400(3)\end{array}$ & $1.416(14)$ & $\begin{array}{l}1.397(3) \\
1.398(3)\end{array}$ & \\
\hline $\mathrm{O}-\mathrm{C}_{\mathrm{C} 6 \mathrm{H} 3 / 4}$ & $\begin{array}{l}1.356(4) \\
1.350(4)\end{array}$ & $1.373(4)$ & $\begin{array}{c}1.361(10) \\
1.353(9)\end{array}$ & $\begin{array}{l}1.348(3) \\
1.346(3)\end{array}$ & $1.325(15)$ & $\begin{array}{l}1.363(3) \\
1.352(3)\end{array}$ & \\
\hline $\begin{array}{c}\text { Torsion } \\
\mathrm{C}_{5} \mathrm{H}_{4} \cdots \mathrm{C}_{5} \mathrm{H}_{5}\end{array}$ & $\begin{array}{l}0.1(2) \\
2.9(3)\end{array}$ & $0.8(3)$ & $\begin{array}{l}4.9(7) \\
0.4(7)\end{array}$ & $\begin{array}{c}2.62(16) \\
1.2(2)\end{array}$ & $7.8(8)$ & $\begin{array}{l}3.28(18) \\
5.97(18)\end{array}$ & $22.7(2)$ \\
\hline $\mathrm{Ct}-\mathrm{Fe}-\mathrm{Ct}$ & $\begin{array}{l}178.93(3) \\
179.47(3)\end{array}$ & $179.49(4)$ & $\begin{array}{c}176.9(14) \\
177.4(2)\end{array}$ & $\begin{array}{l}178.38(2) \\
178.31(3)\end{array}$ & $176.41(11)$ & $\begin{array}{l}179.06(3) \\
179.80(3)\end{array}$ & $178.22(3)$ \\
\hline $\mathrm{Fc}-\mathrm{O}-\mathrm{Ar}$ & $117.0(2)$ & $117.2(2)$ & $\begin{array}{l}118.8(7) \\
122.2(7)\end{array}$ & $118.66(19)$ & $121.3(9)$ & $\begin{array}{l}116.60(17) \\
116.14(18)\end{array}$ & $117.50(17)$ \\
\hline & \multicolumn{7}{|c|}{ Plane intersections } \\
\hline $\mathrm{C}_{5} \mathrm{H}_{3 / 4} \cdots \mathrm{C}_{6} \mathrm{H}_{4-2}$ & $\begin{array}{l}69.90(10) \\
85.71(11)\end{array}$ & $82.00(11)$ & $\begin{array}{l}42.7(4) \\
62.8(3)\end{array}$ & $\begin{array}{c}65.60(9) \\
88.74(10)\end{array}$ & $52.1(4)$ & $\begin{array}{l}85.65(8) \\
86.13(8)\end{array}$ & $85.76(8)$ \\
\hline $\mathrm{NO}_{2} \cdots \mathrm{C}_{6} \mathrm{H}_{4-2}$ & $\begin{array}{l}30.6(2) \\
19.9(5) \\
24.0(3) \\
10.0(6)\end{array}$ & $0.4(4)$ & $\begin{array}{l}19.9(8) \\
6.3(15)\end{array}$ & $\begin{array}{c}40.78(12) \\
25.97(7) \\
39.94(14) \\
20.72(19)\end{array}$ & $\begin{array}{c}9.6(6) \\
37.0(5) \\
25.2(6)\end{array}$ & $\begin{array}{c}76.2(3) \\
6.7(3)\end{array}$ & $\begin{array}{l}21.5(2) \\
13.2(4)\end{array}$ \\
\hline rms C $_{6}$-Phenyl & 0.0020 & 0.0045 & 0.0072 & 0.0025 & 0.0381 & 0.0031 & 0.0143 \\
\hline
\end{tabular}

The centroids $(\mathrm{Ct})$ of the respective rings are calculated by the indexed number of carbon atoms.

$\underline{\text { Solvatochromic Measurements }}$

Table SI8. The $\lambda_{\max }$ values of the $\pi-\pi^{*}$ absorption of compound 4a.

\begin{tabular}{cc}
\hline solvent & $\lambda_{\max }{ }^{\mathrm{a}}[\mathrm{nm}]$ \\
\hline hexane & 281 \\
toluene & 284 \\
isopropanol & 285 \\
dmf & 289 \\
ethanol & 291 \\
acetone & 293
\end{tabular}

The maximum refers to the $\pi-\pi^{*}$ absorption of compound $4 \mathbf{a}$. 


\section{Electrochemistry}

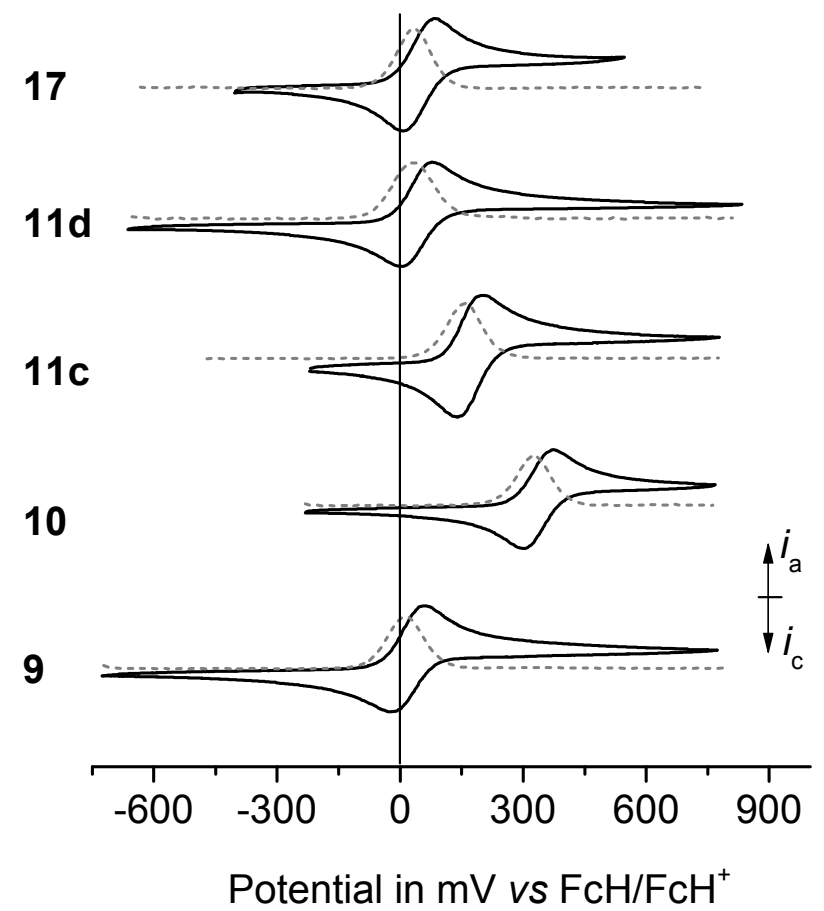

Figure SI8. Cyclic voltammograms (solid lines) and square wave voltammograms (dashed lines) of 9, 10, 11c, rac-11d and 17; scan rate: $100 \mathrm{mV} \cdot \mathrm{s}^{-1}$; in dichloromethane solutions $\left(1.0 \mathrm{mmol} \cdot \mathrm{L}^{-1}\right)$ at $25{ }^{\circ} \mathrm{C}$, supporting electrolyte $0.1 \mathrm{~mol} \cdot \mathrm{L}^{-1}\left[\mathrm{~N}^{n} \mathrm{Bu}_{4}\right]\left[\mathrm{B}\left(\mathrm{C}_{6} \mathrm{~F}_{5}\right)_{4}\right]$, working electrode: glassy carbon electrode.
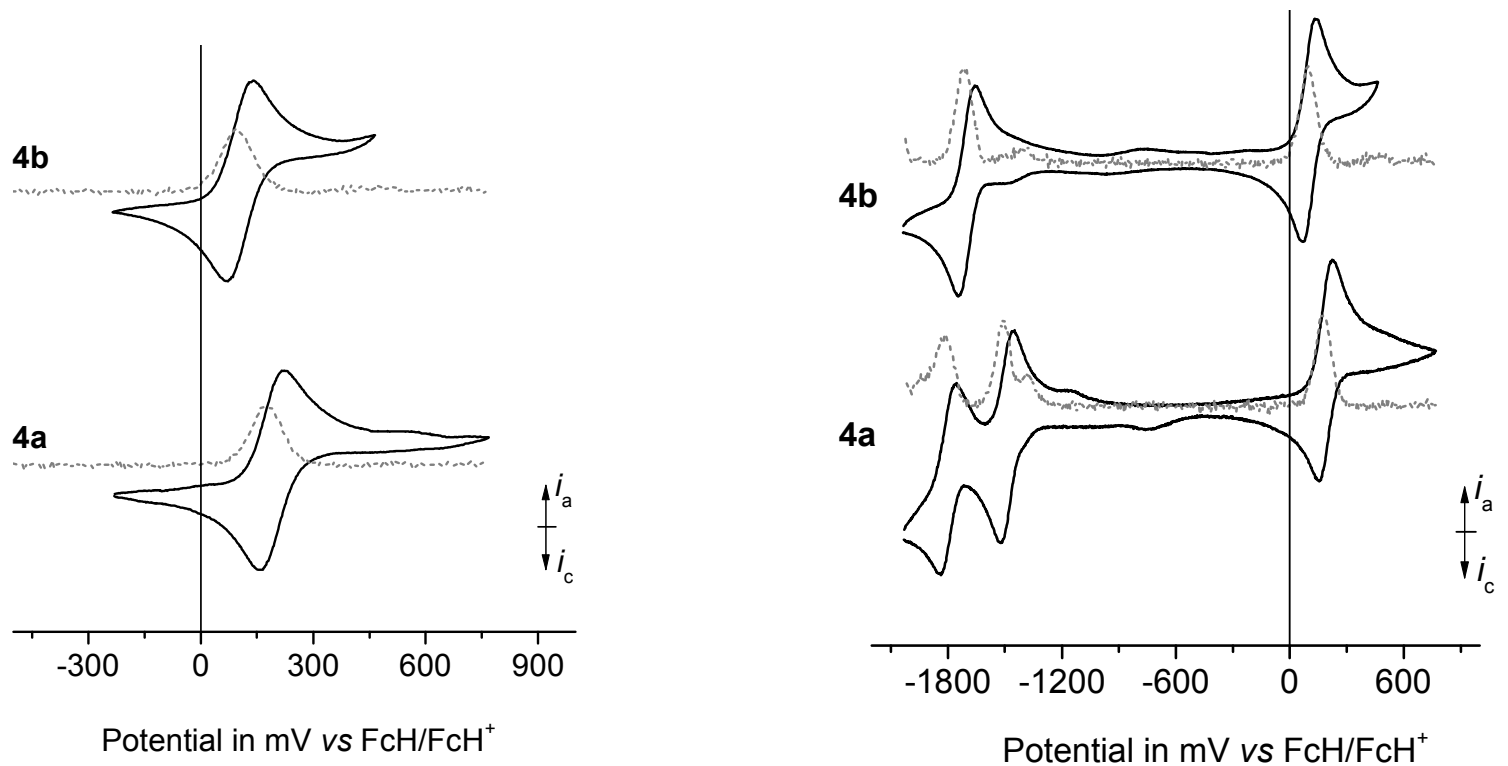

Figure SI9. Cyclic voltammograms (solid lines) and square wave voltammograms (dashed lines) of $\mathbf{4 a}$ and $\mathbf{4 b}$; scan rate: $100 \mathrm{mV} \cdot \mathrm{s}^{-1}$; in dichloromethane solutions $\left(1.0 \mathrm{mmol} \cdot \mathrm{L}^{-1}\right)$ at $25^{\circ} \mathrm{C}$, supporting electrolyte $0.1 \mathrm{~mol} \cdot \mathrm{L}^{-1}$ $\left[\mathrm{N}^{n} \mathrm{Bu}_{4}\right]\left[\mathrm{B}\left(\mathrm{C}_{6} \mathrm{~F}_{5}\right)_{4}\right]$, working electrode: glassy carbon electrode. 

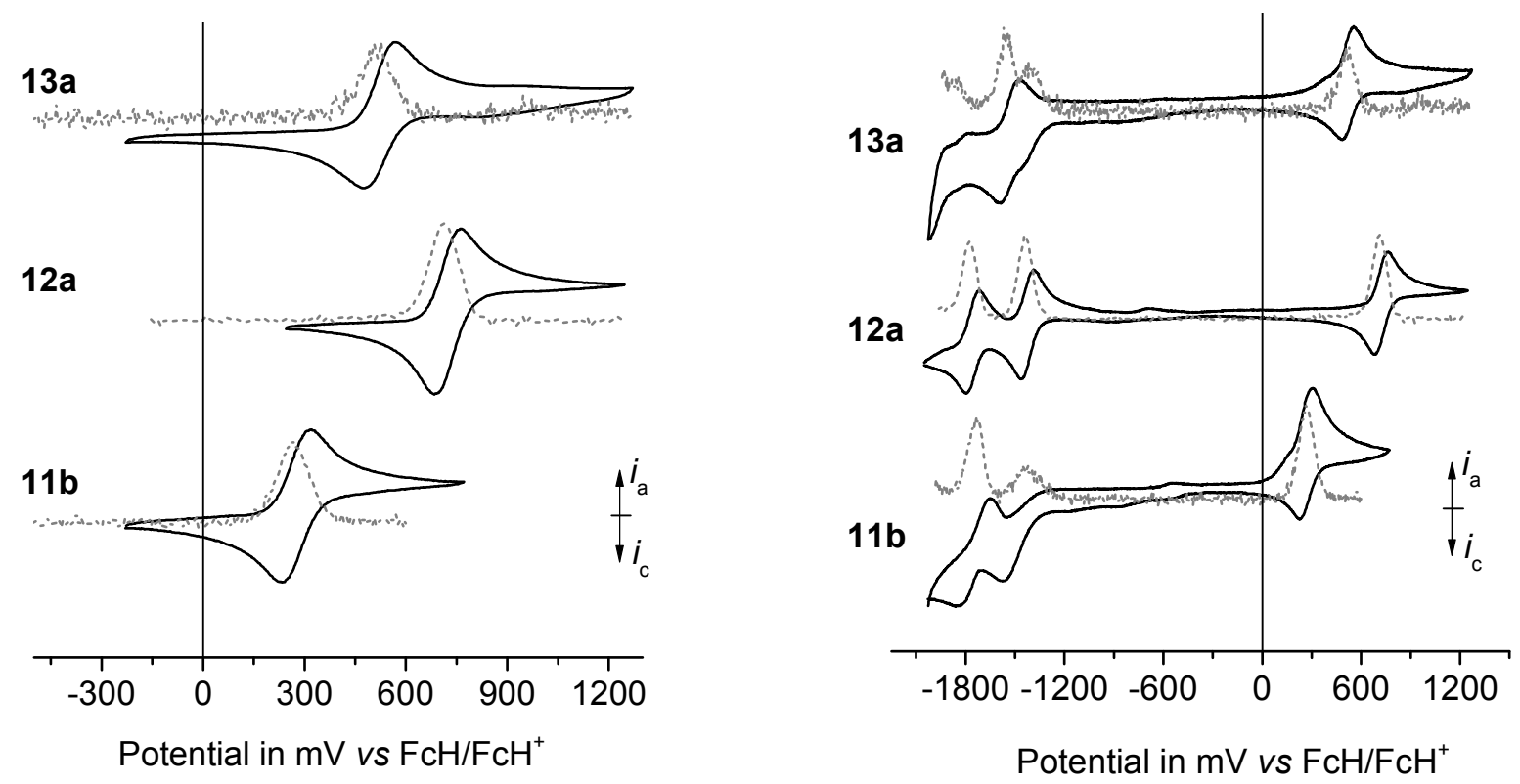

Figure SI10. Cyclic voltammograms (solid lines) and square wave voltammograms (dashed lines) of rac-11b, rac12a and $\mathrm{rac}-13 \mathrm{a}$; scan rate: $100 \mathrm{mV} \cdot \mathrm{s}^{-1}$; in dichloromethane solutions $\left(1.0 \mathrm{mmol} \cdot \mathrm{L}^{-1}\right)$ at $25{ }^{\circ} \mathrm{C}$, supporting electrolyte $0.1 \mathrm{~mol} \cdot \mathrm{L}^{-1}\left[\mathrm{~N}^{n} \mathrm{Bu}_{4}\right]\left[\mathrm{B}\left(\mathrm{C}_{6} \mathrm{~F}_{5}\right)_{4}\right]$, working electrode: glassy carbon electrode.

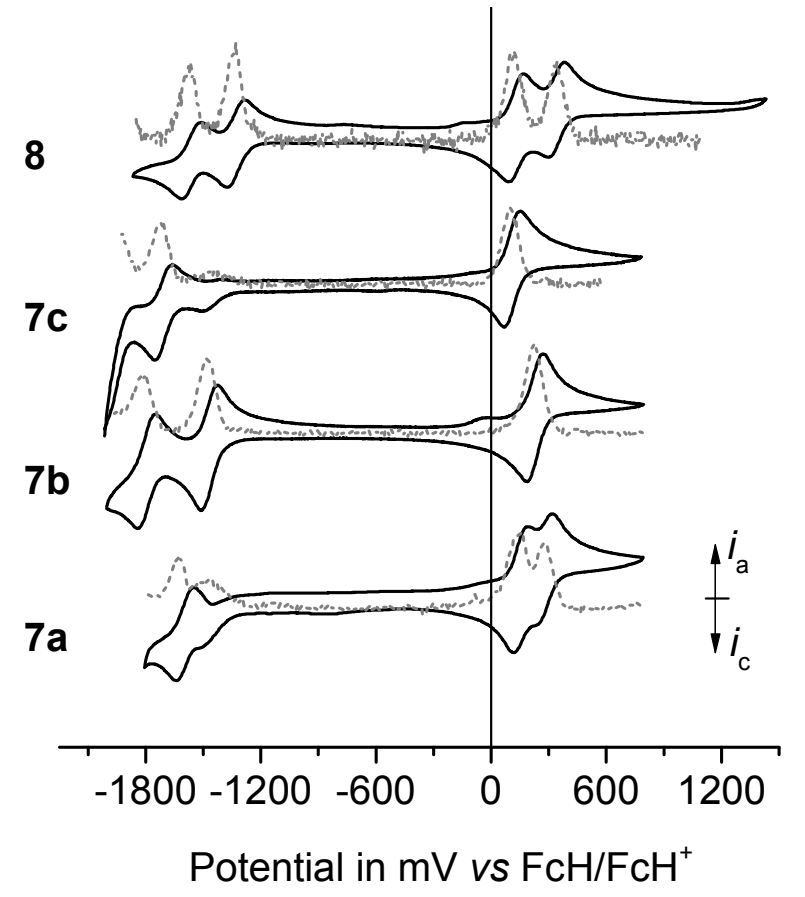

Figure SI11. Cyclic voltammograms (solid lines) and square wave voltamograms (dashed lines) of 7a-c and 8; scan rate: $100 \mathrm{mV} \cdot \mathrm{s}^{-1}$; in dichloromethane solutions $\left(1.0 \mathrm{mmol} \cdot \mathrm{L}^{-1}\right)$ at $25^{\circ} \mathrm{C}$, supporting electrolyte $0.1 \mathrm{~mol} \cdot \mathrm{L}^{-1}$ $\left[\mathrm{N}^{n} \mathrm{Bu}_{4}\right]\left[\mathrm{B}\left(\mathrm{C}_{6} \mathrm{~F}_{5}\right)_{4}\right]$, working electrode: glassy carbon electrode. 


\section{${ }^{1} \mathrm{H},{ }^{13} \mathrm{C}\left\{{ }^{1} \mathrm{H}\right\},{ }^{29} \mathrm{Si}$ and ${ }^{31} \mathrm{P}\left\{{ }^{1} \mathrm{H}\right\}$ NMR spectra of $2 \mathrm{~b}-\mathrm{d}, \mathrm{g}, \mathrm{h}, 4 \mathrm{a}, \mathrm{b}, 7 \mathrm{a}-\mathrm{c}, 8,11 \mathrm{a}, \mathrm{b}, 12 \mathrm{a}, 13 \mathrm{a}$ and $16 \mathrm{a}, \mathrm{b}$.}

\section{Figure SI12. ${ }^{1} \mathrm{H}$ NMR spectra of $2 \mathrm{~b}$}

\section{MK-357-2}

PROTON CDCl3 \{C:|Bruker|TOPSPIN\} korbm 35

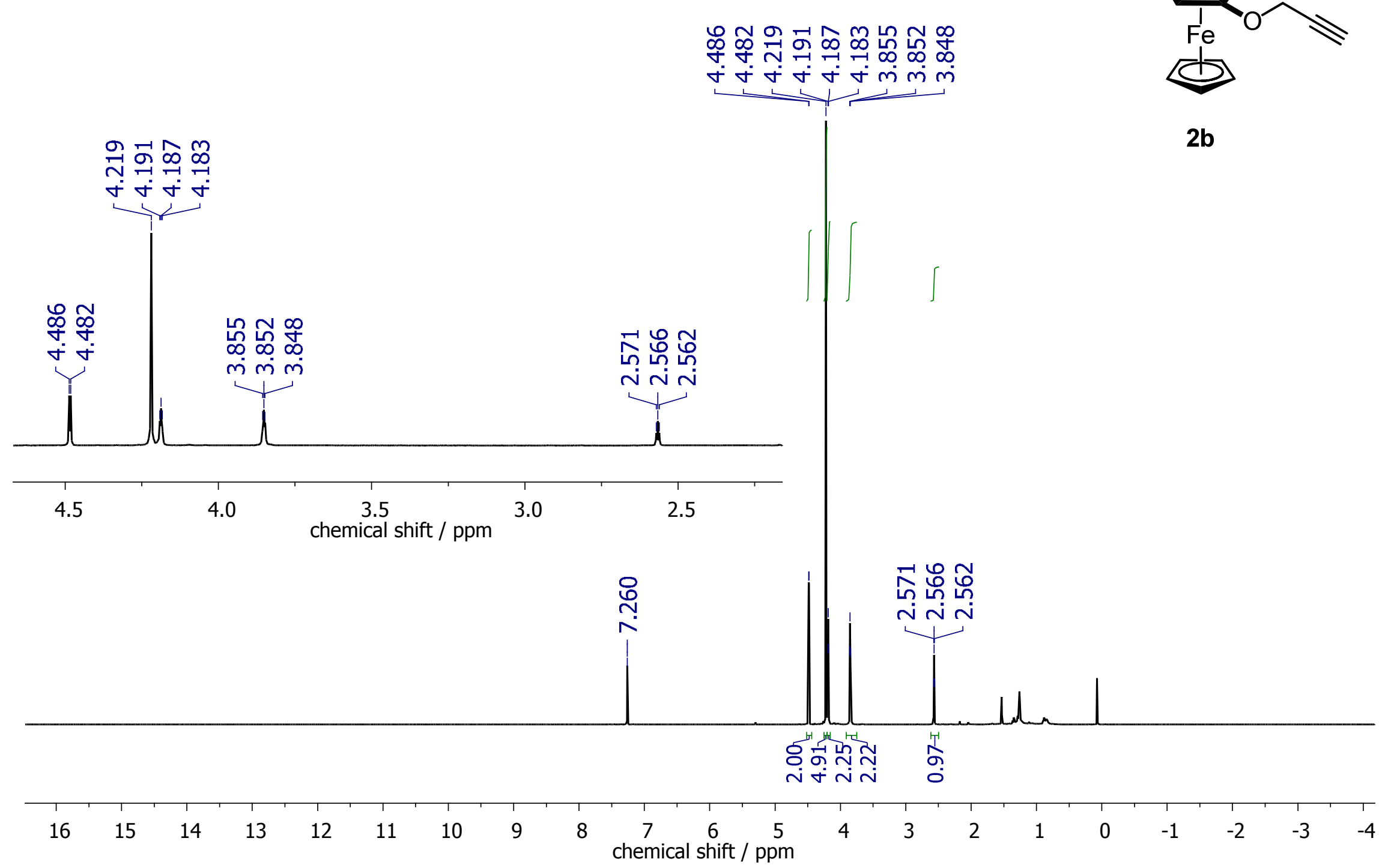




\section{Figure SI13. ${ }^{13} \mathrm{C}\left\{{ }^{1} \mathrm{H}\right\}$ NMR spectra of $2 \mathrm{~b}$}

\section{MK-357-2}

C13CPD CDCI3 \{C:|Bruker|TOPSPIN\} korbm 35
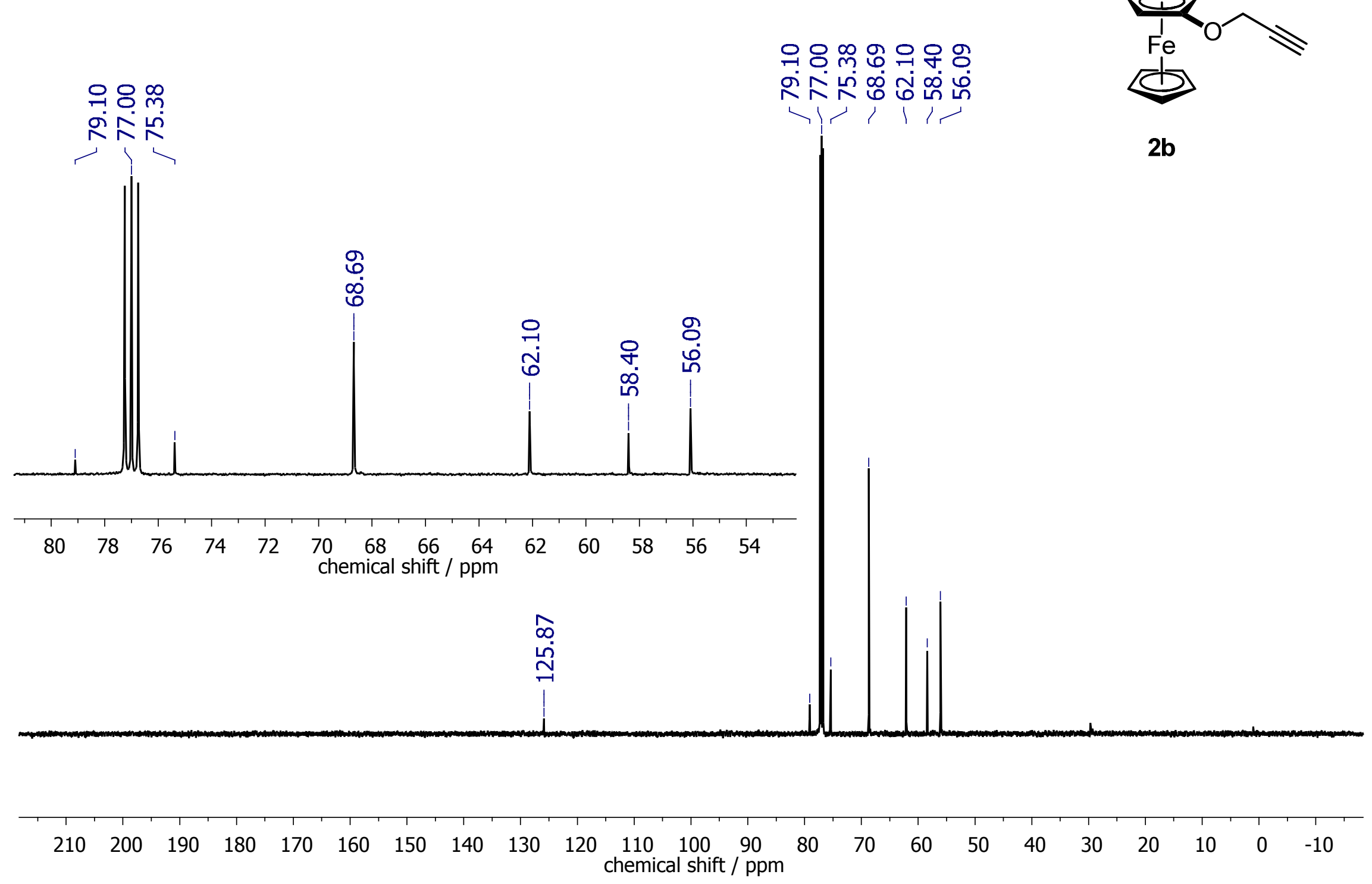


\section{Figure SI14. ${ }^{1} \mathrm{H}$ NMR spectra of $2 \mathrm{c}$}

\section{MK-364-3-2}

PROTON CDCl3 \{C:|Bruker|TOPSPIN\} korbm 41

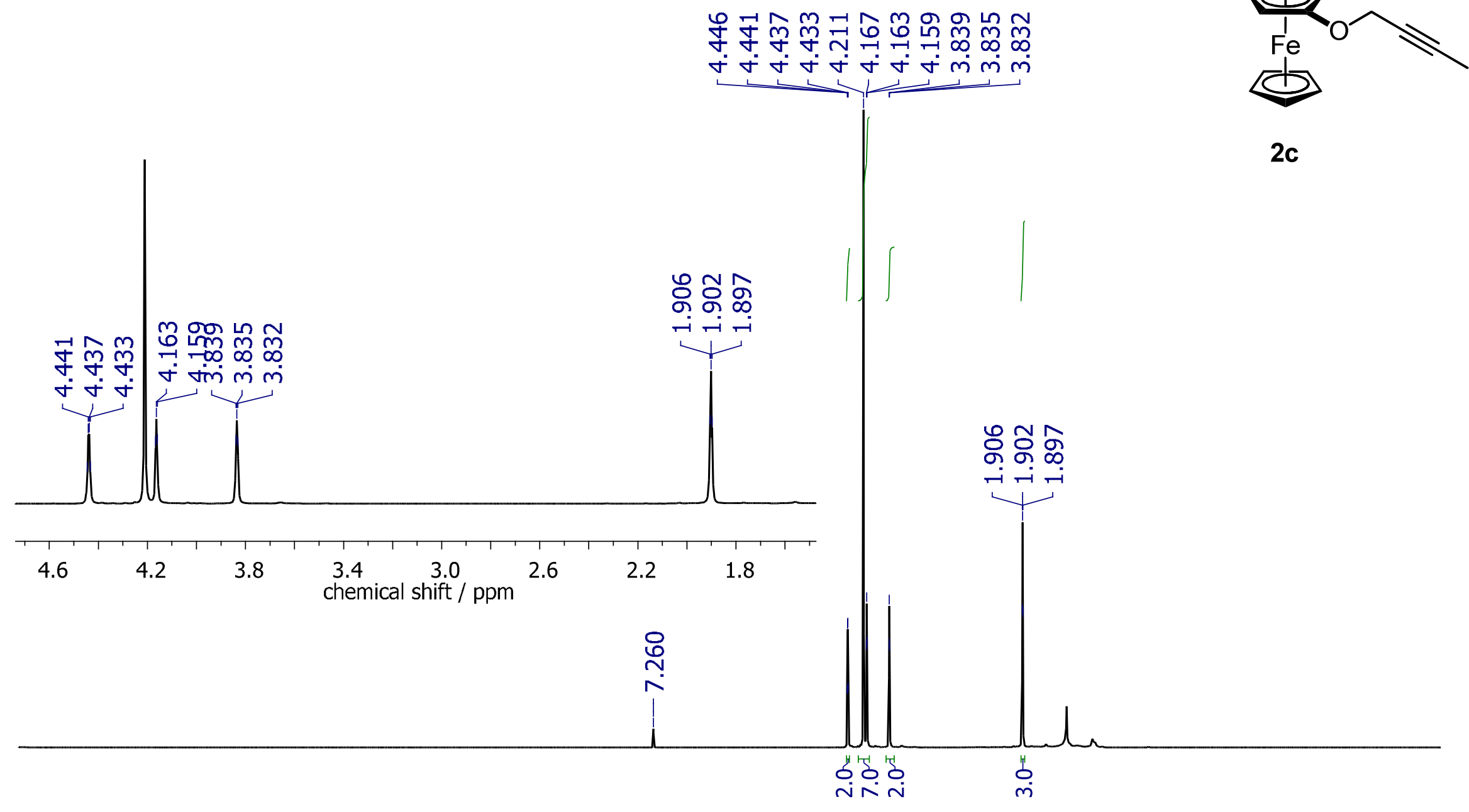

守守

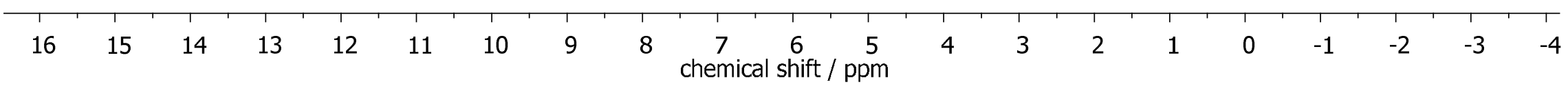




\section{Figure SI15. ${ }^{13} \mathrm{C}\left\{{ }^{1} \mathrm{H}\right\}$ NMR spectra of $2 \mathrm{c}$}

MK-364-3-2

C13CPD CDCI3 \{C:|Bruker|TOPSPIN\} korbm 41

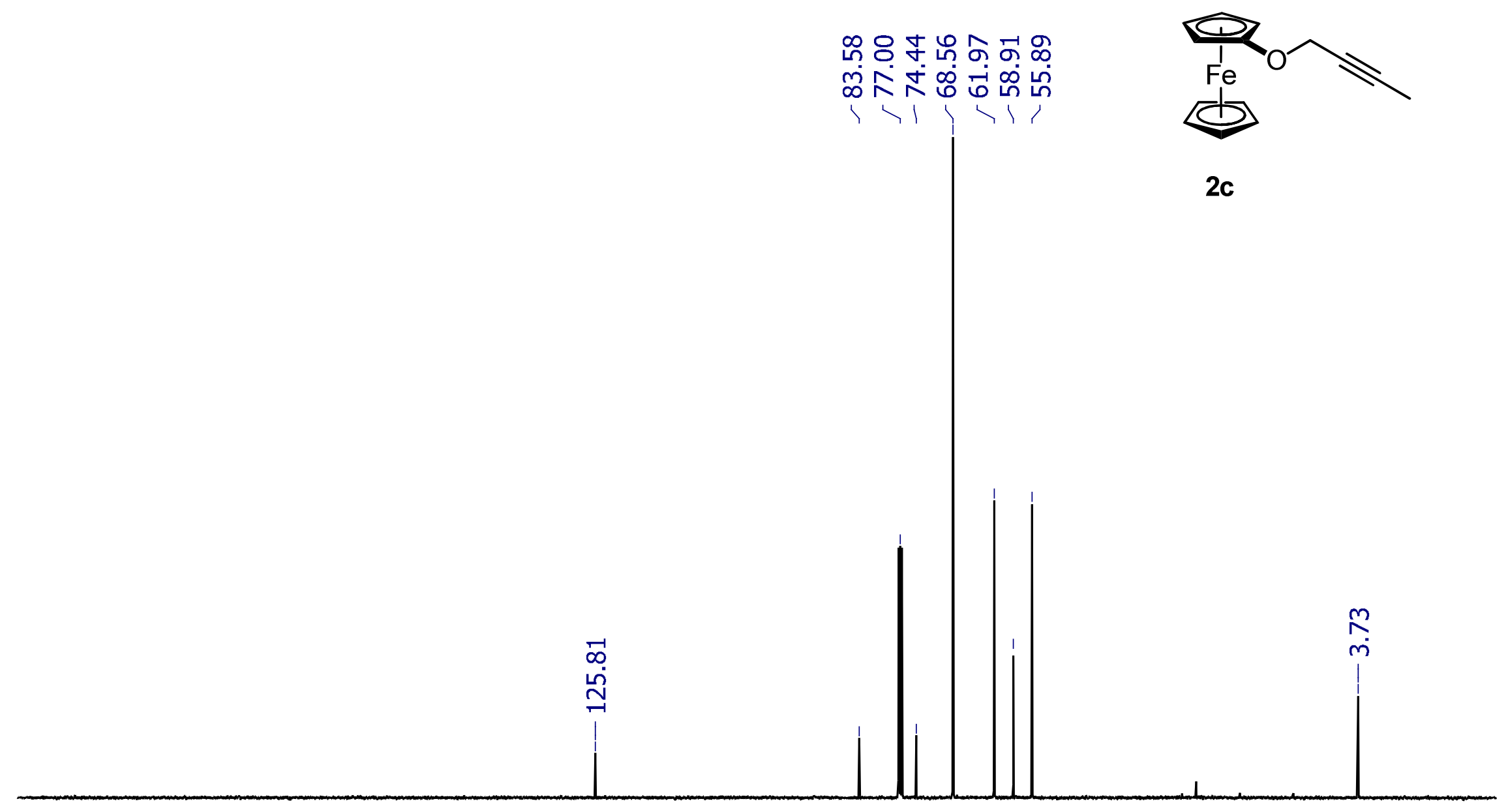

$\begin{array}{lllllllllllllllllllll}210 & 200 & 190 & 180 & 170 & 160 & 150 & 140 & 130 & 120 & \begin{array}{c}110 \\ \text { chemical shift } / \text { ppm }\end{array} & 100 & 70 & 60 & 50 & 40 & 30 & 20 & 10 & 0 & -10\end{array}$ 


\section{Figure SI16. ${ }^{1} \mathrm{H}$ NMR spectra of $2 \mathrm{~d}$}

MK-355

PROTON CDCl3 \{C:\Bruker\TOPSPIN\} korbm 28
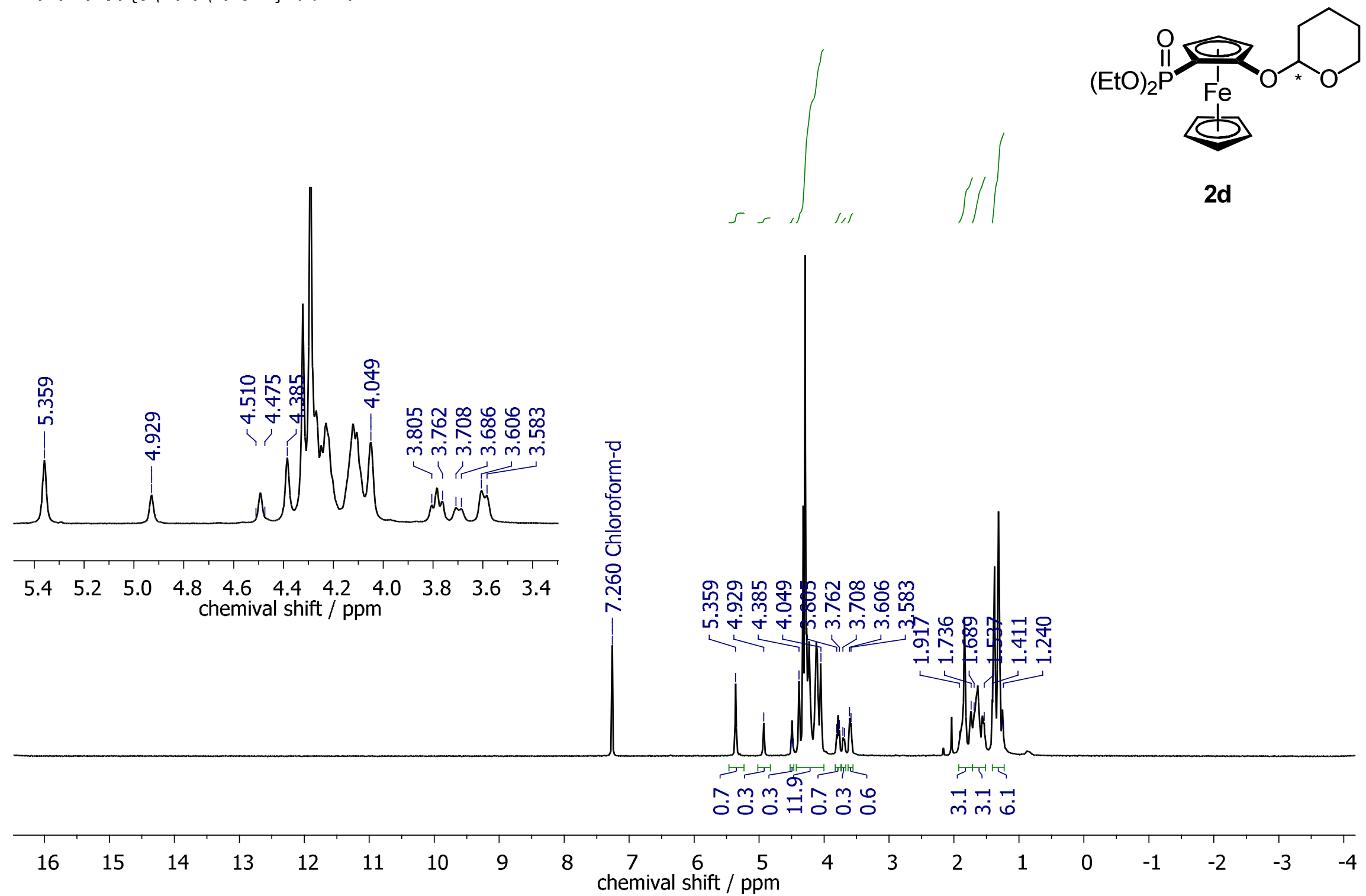


\section{Figure SI17. ${ }^{13} \mathrm{C}\left\{{ }^{1} \mathrm{H}\right\}$ NMR spectra of $2 \mathrm{~d}$}

MK-355

C13CPD CDCl3 \{C:|Bruker|TOPSPIN\} korbm 28

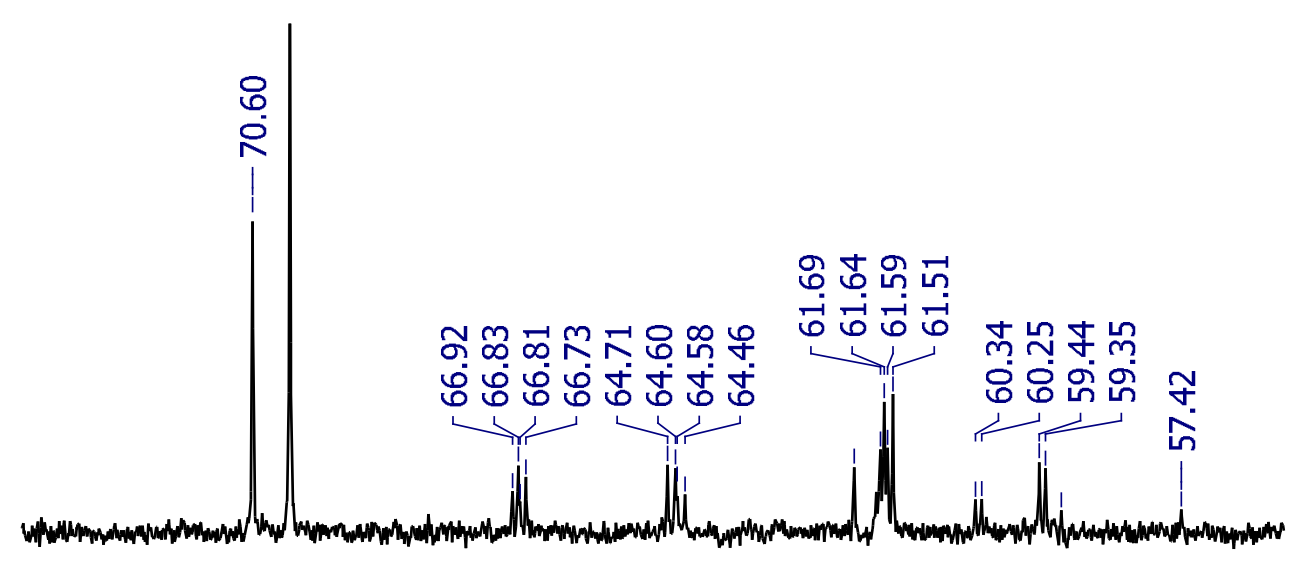

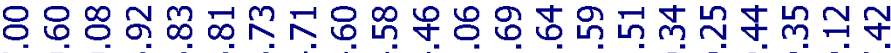

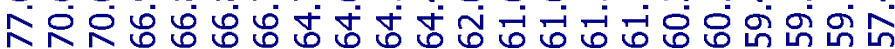
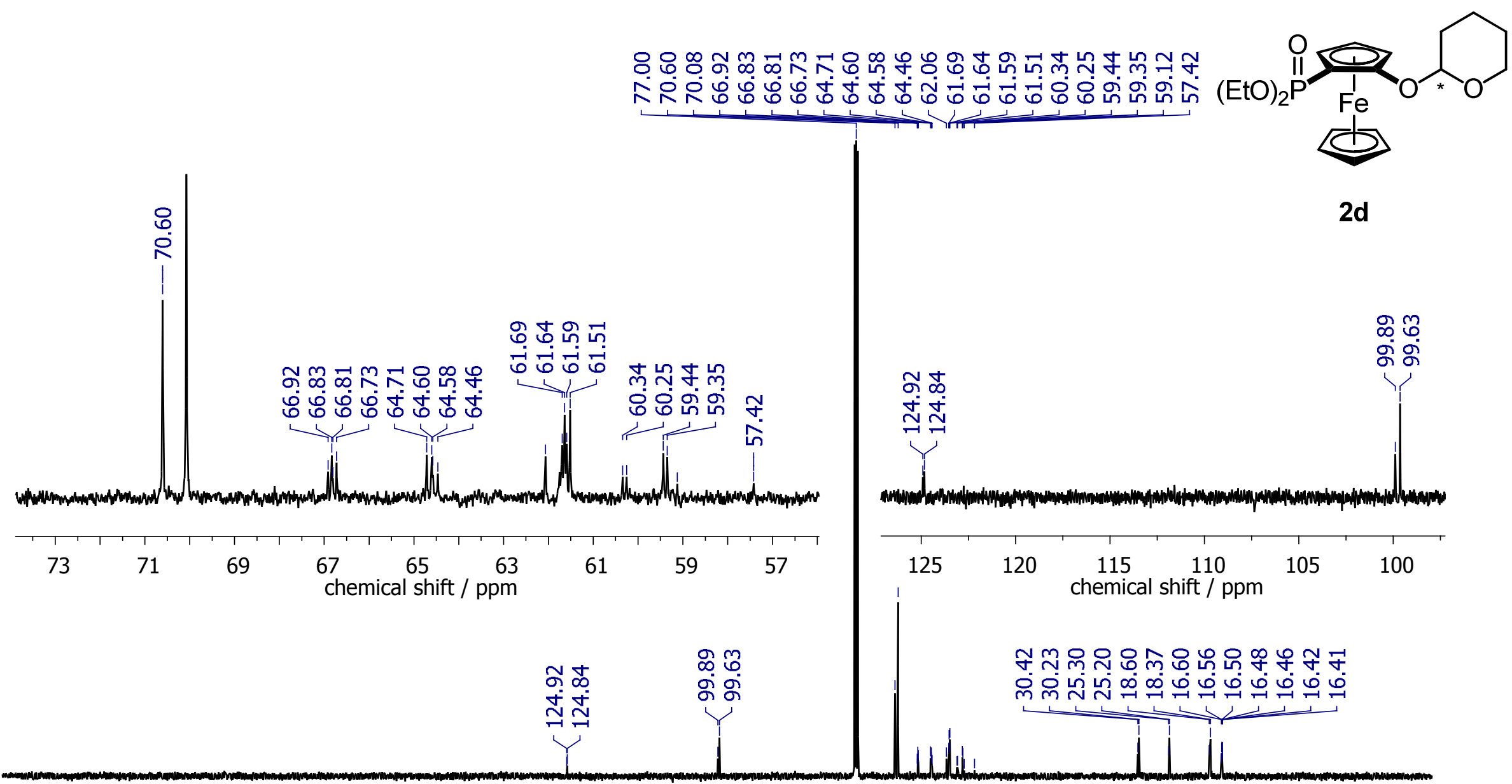

210 
Figure SI18. ${ }^{31} \mathbf{P}\left\{{ }^{1} \mathrm{H}\right\}$ NMR spectra of 2d

MK-355

P31CPD CDCl3 \{C:|Bruker|TOPSPIN $\}$ korbm 28

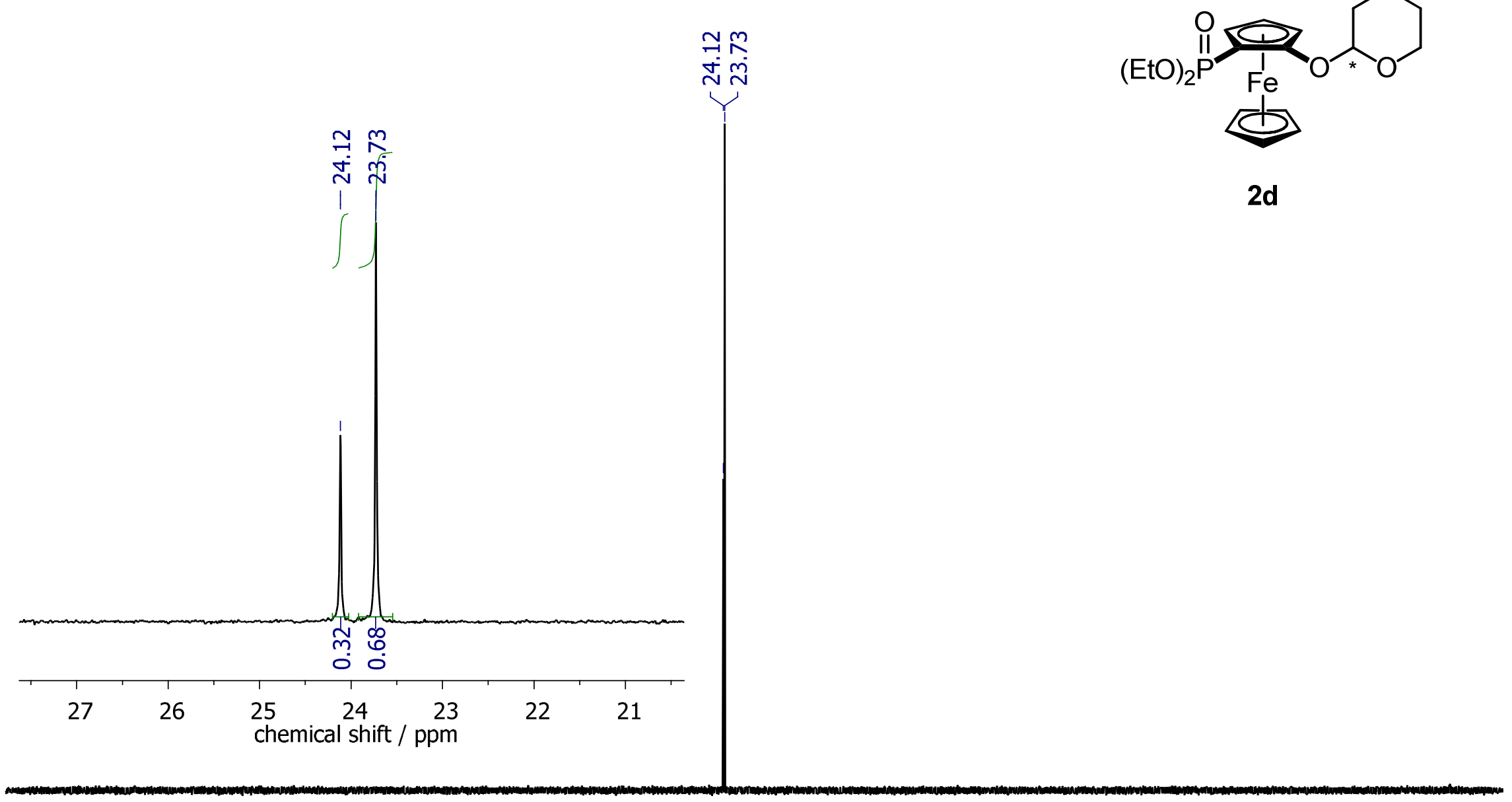

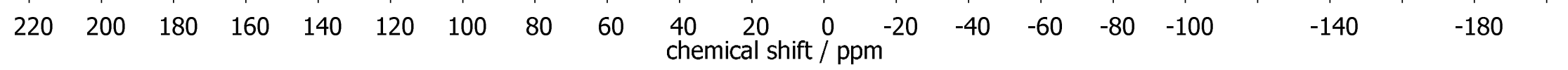




\section{Figure SI19. ${ }^{1} \mathrm{H}$ NMR spectra of $\mathrm{rac}-2 \mathrm{~g}$}

MK-346-F2

PROTON CDCl3 \{C:|Bruker|TOPSPIN\} korbm 39

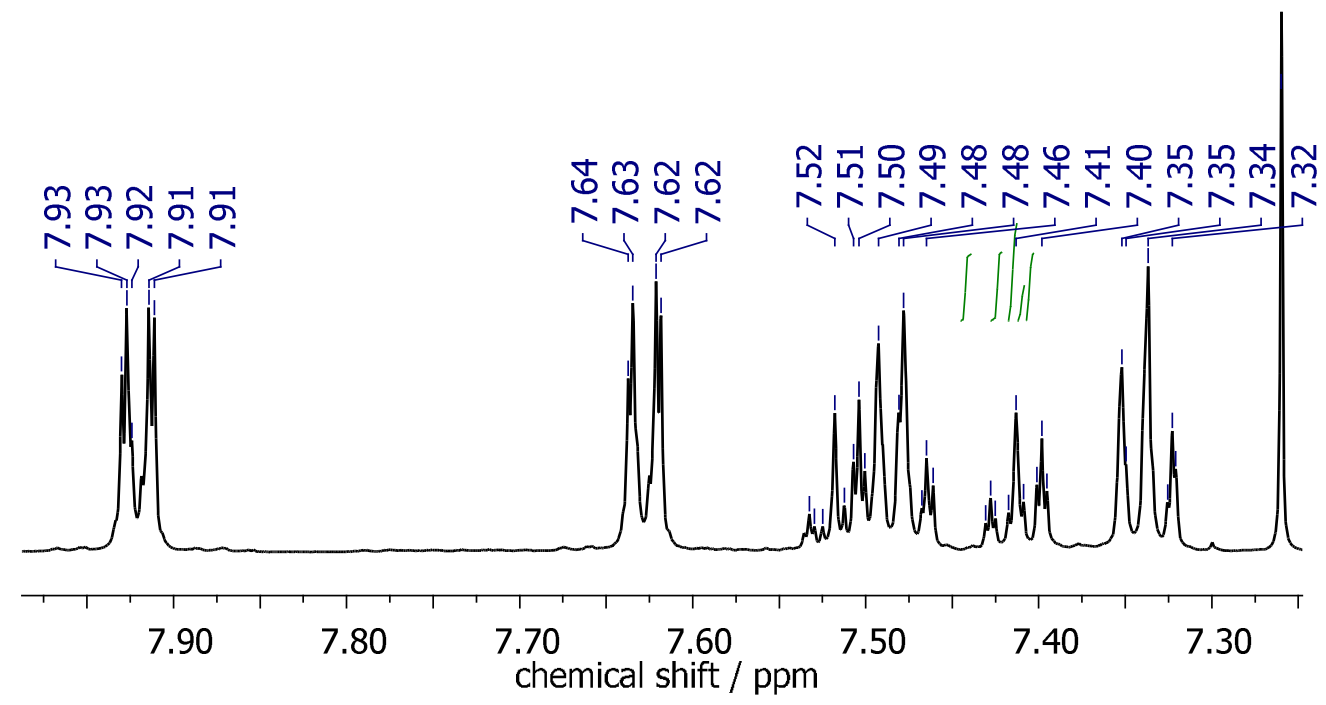

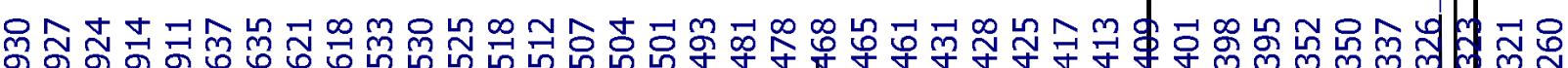

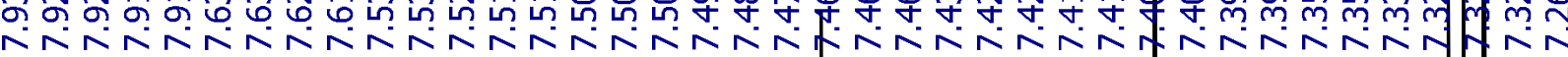

$(\mathrm{EtO})_{2} \mathrm{P}$

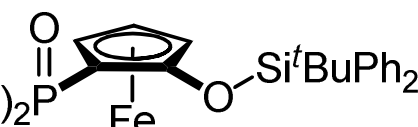

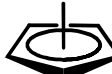

rac-2g

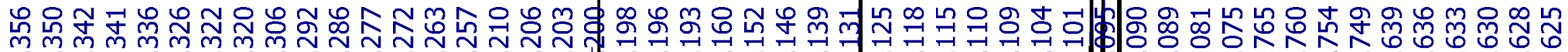

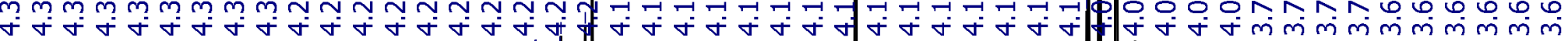

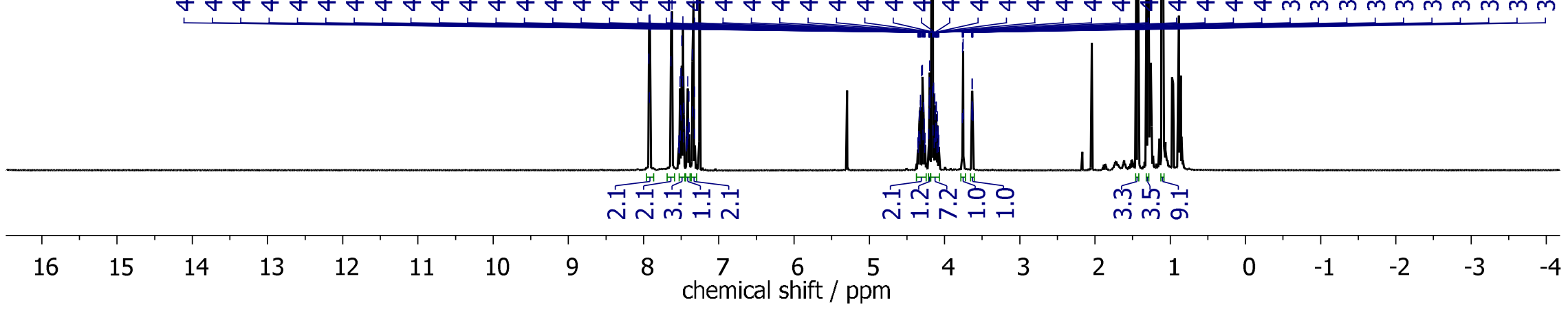




\section{Figure SI20. ${ }^{13} \mathrm{C}\left\{{ }^{1} \mathrm{H}\right\},{ }^{29} \mathrm{Si}$ and ${ }^{31} \mathrm{P}\left\{{ }^{1} \mathrm{H}\right\}$ NMR spectra of rac-2g}

MK-346-F2

C13CPD CDCl3 \{C:|Bruker|TOPSPIN\} korbm 39

MK-346-F2

P31CPD CDCI3 \{C:|Bruker|TOPSPIN\} korbm 39
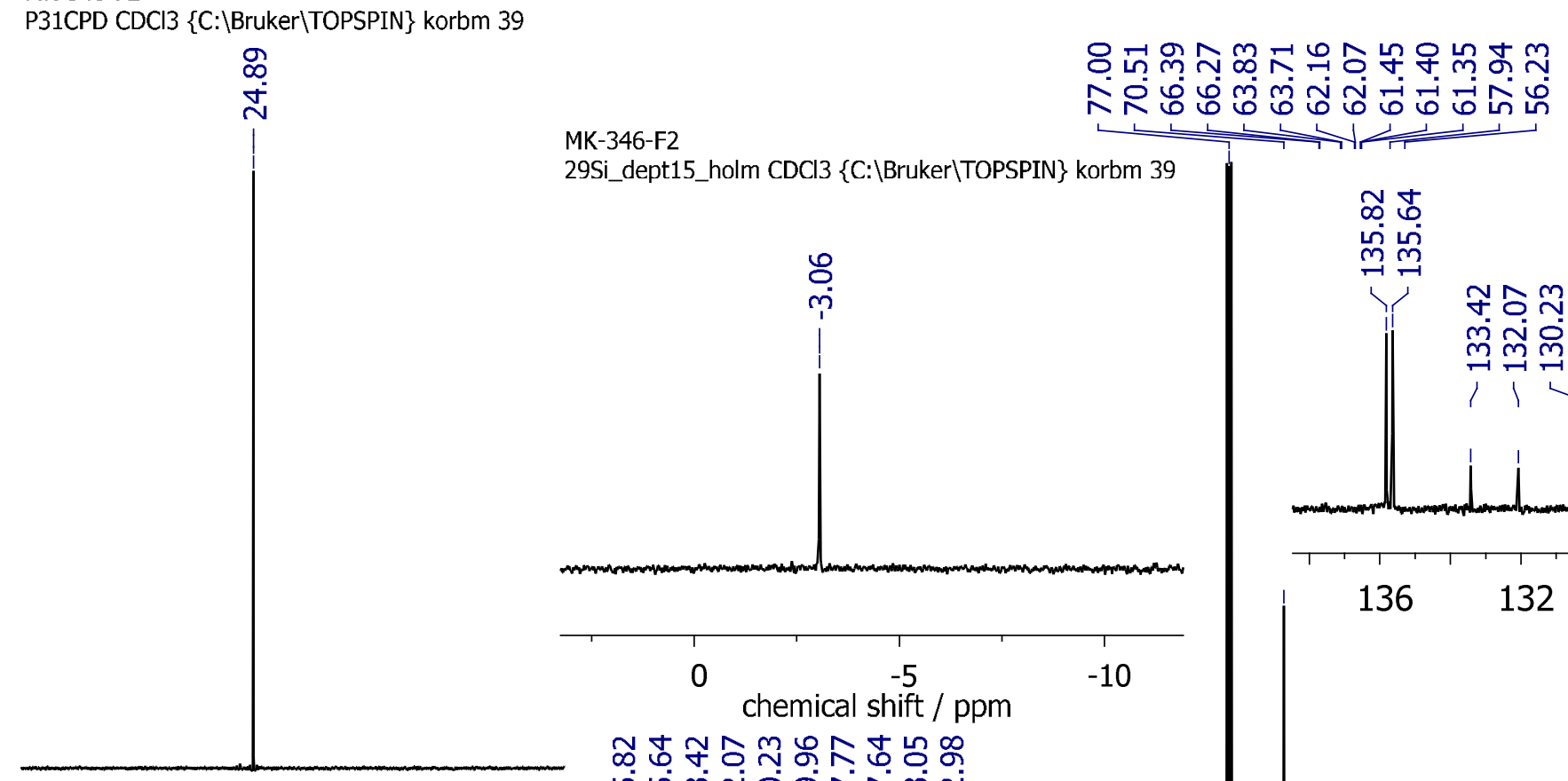

$(\mathrm{EtO})_{2}$

${ }_{2} \mathrm{P}_{\mathrm{O}}-\mathrm{Si}^{\mathrm{t}} \mathrm{BuPh}_{2}$

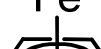

29Si_dept15_holm CDCl3 \{C:〈Bruker\TOPSPIN\} korbm 39

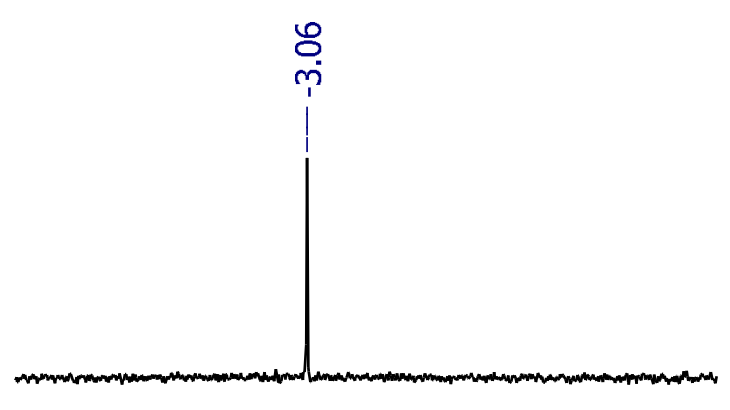

0

$-5$

chemical shift / ppm

$-10$

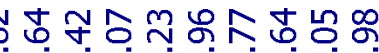

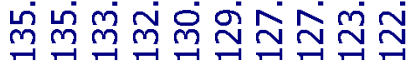
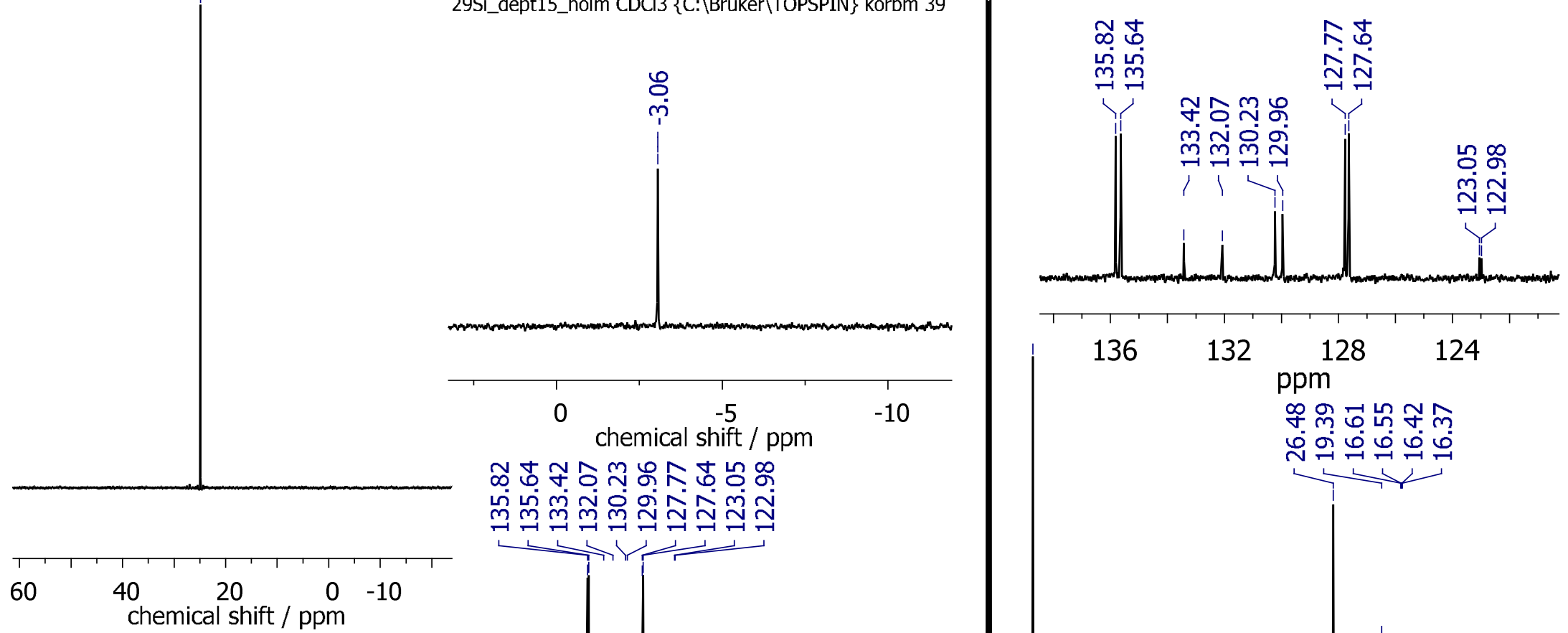

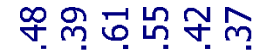

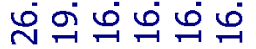

chemical shift / ppm

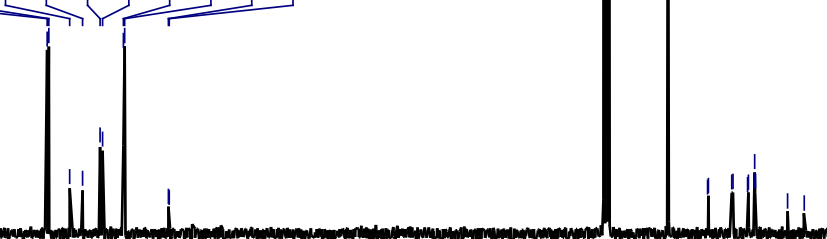

$\begin{array}{lllllllllllllll}210 & 190 & 170 & 150 & 130 & \begin{array}{c}110 \\ \text { chemical shift } / \mathrm{ppm}\end{array} & 70 & 60 & 50 & 40 & 30 & 20 & 10 & 0 & 80\end{array}$




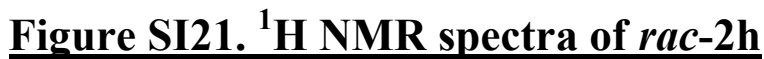

MK-347

PROTON CDCl3 \{C:|Bruker|TOPSPIN\} korbm 52

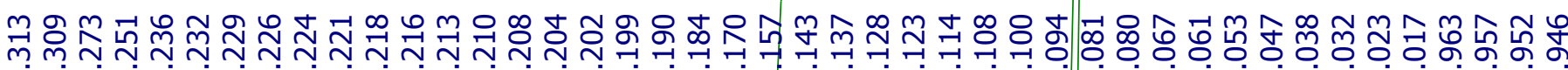

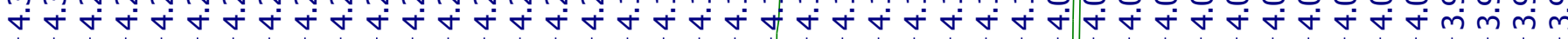
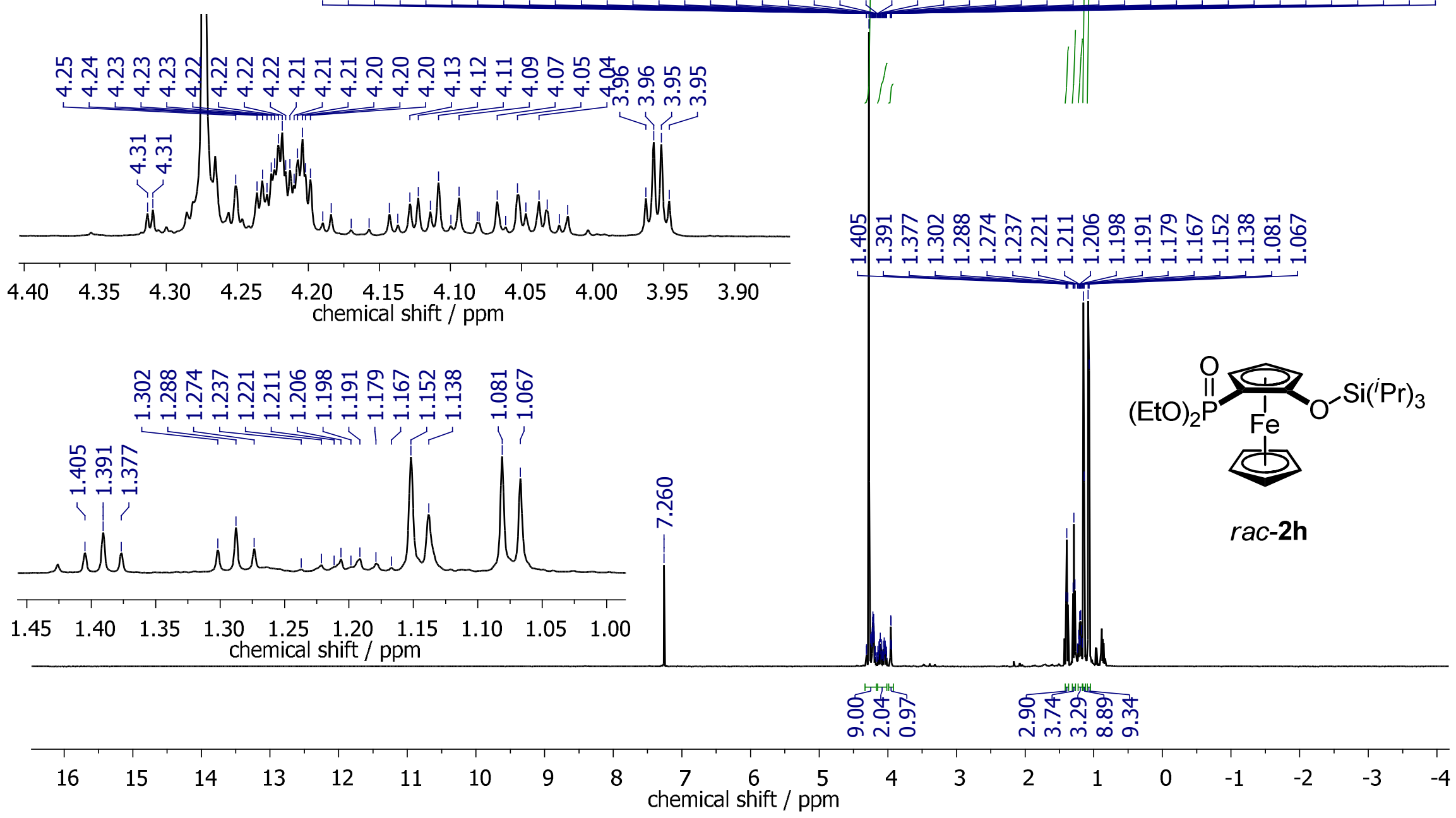


\section{Figure SI22. ${ }^{13} \mathrm{C}\left\{{ }^{1} \mathrm{H}\right\}$ NMR spectra of rac-2h}

MK-347

C13CPD CDCl3 \{C:\Bruker\TOPSPIN\} korbm 52

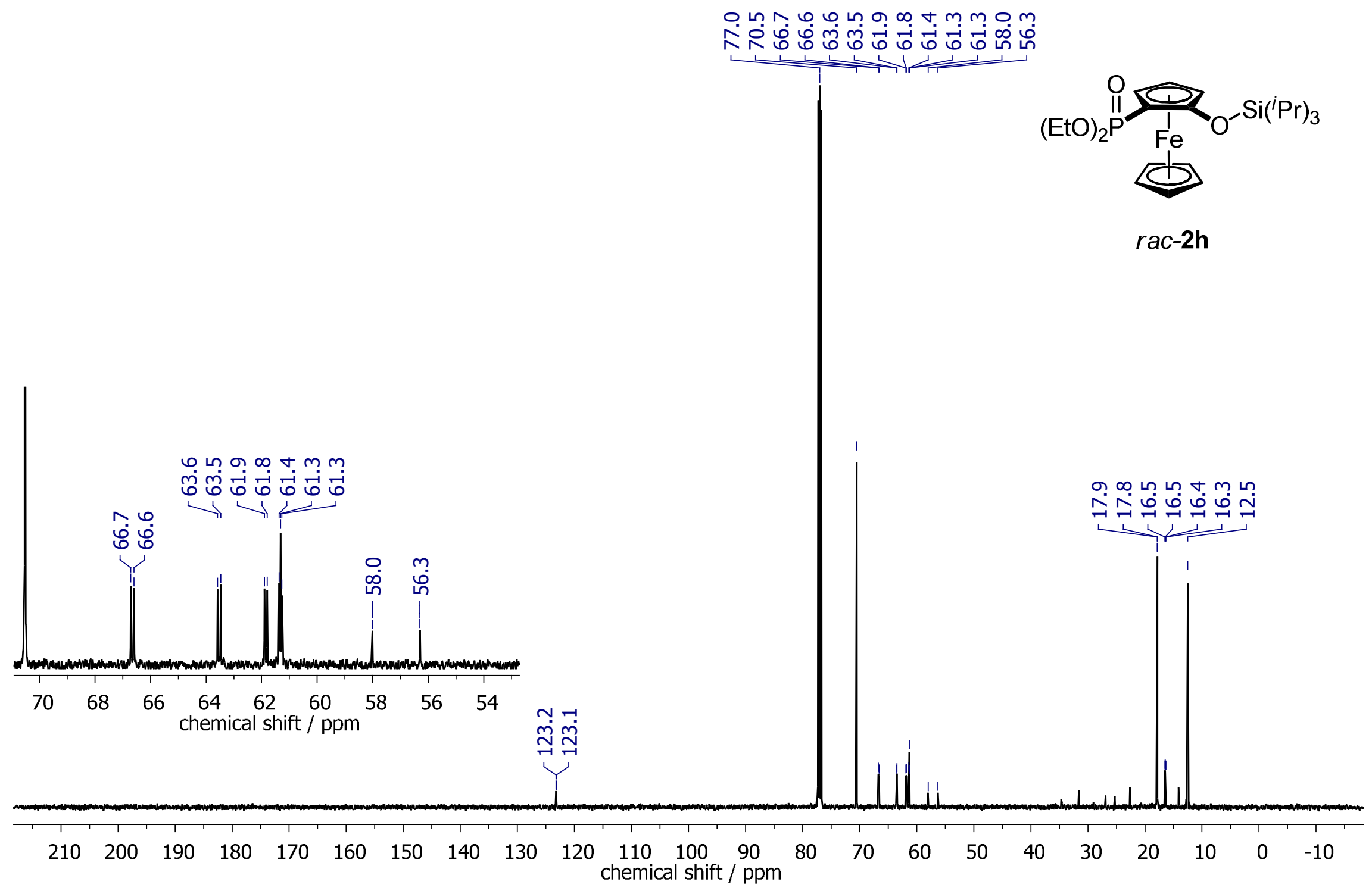




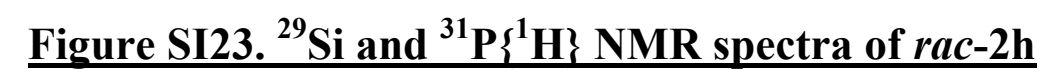

MK-347

P31CPD CDCl3 \{C:|Bruker|TOPSPIN\} korbm 52

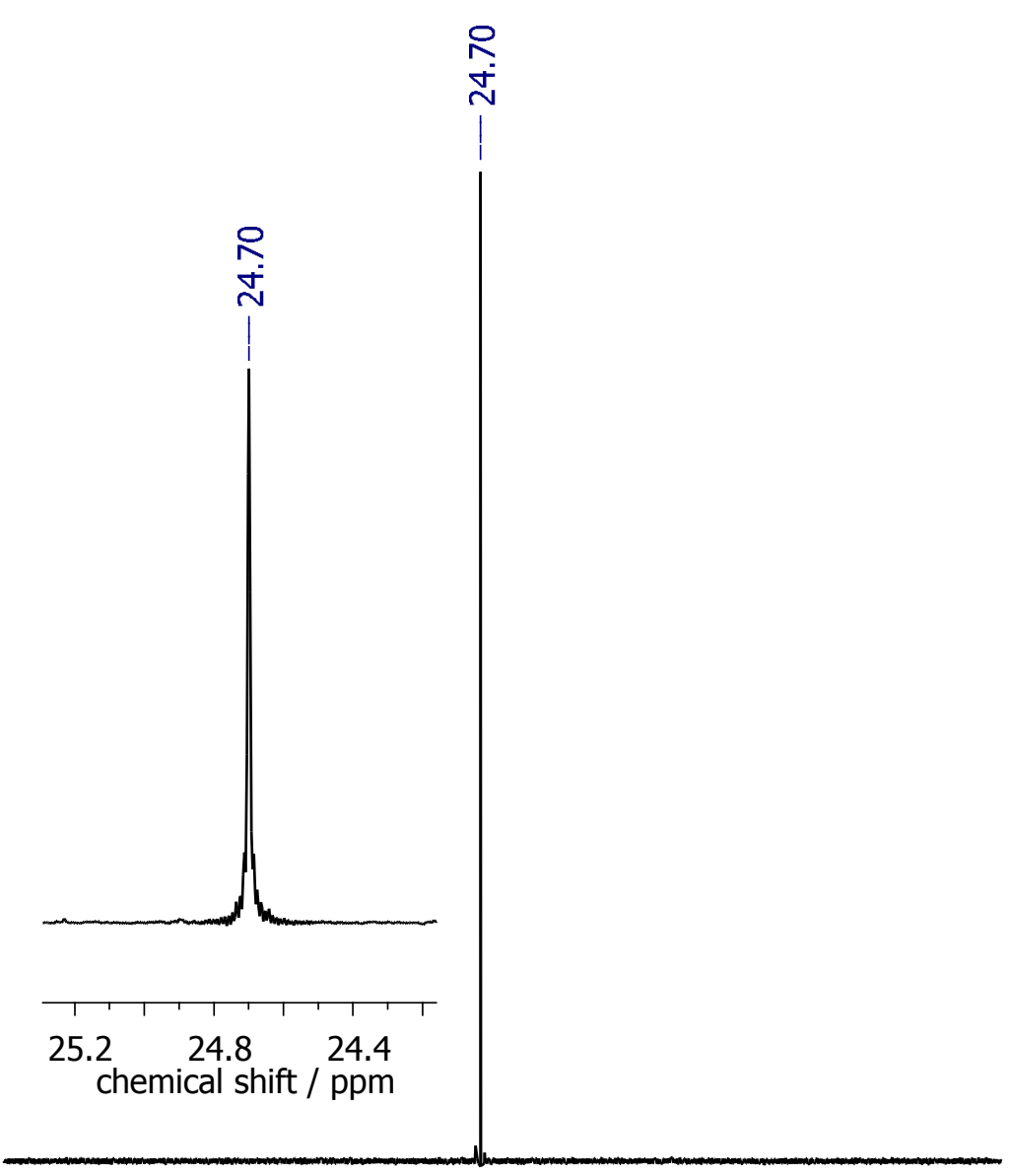

MK-347

29Si dept15 holm CDCl3 \{C:|Bruker|TOPSPIN\} korbm 52

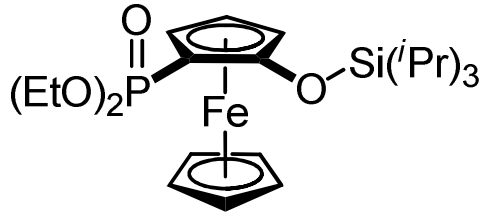

rac-2h

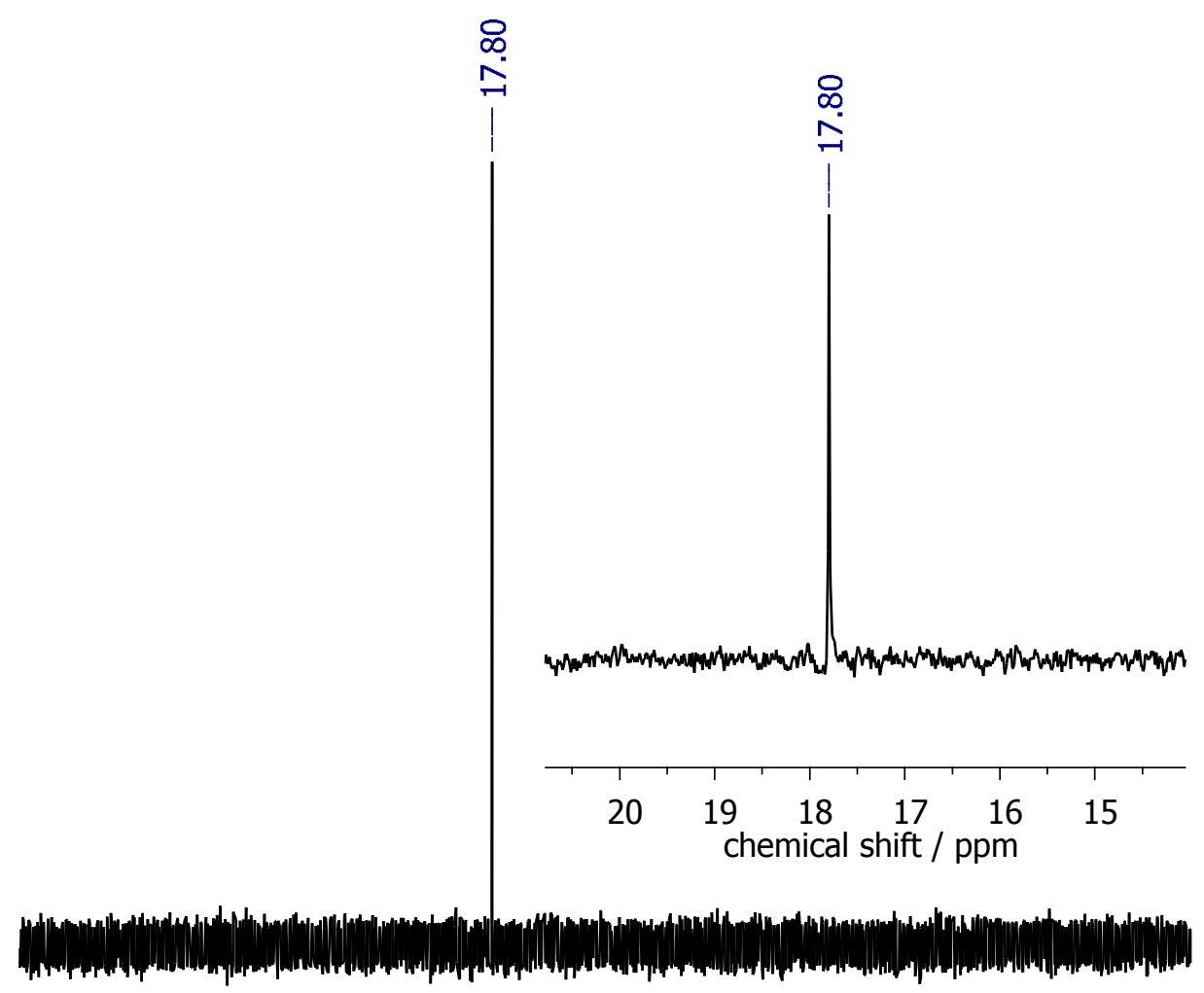




\section{Figure SI24. ${ }^{1} \mathrm{H}$ NMR spectra of $4 \mathrm{a}$}

MK-380-2-F2

PROTON CDCl3 \{C:|Bruker|TOPSPIN\} korbm 48

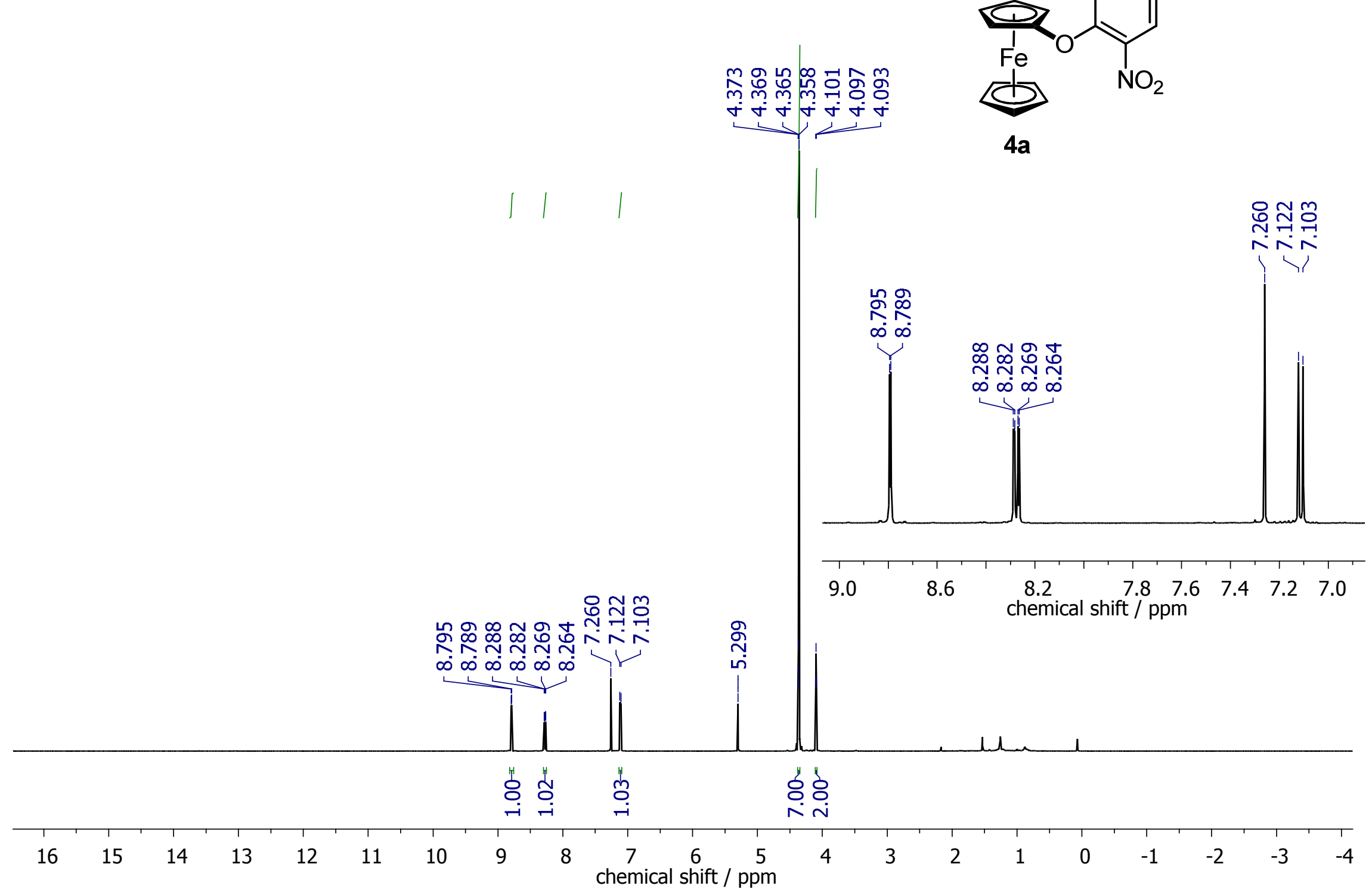




\section{Figure SI25. ${ }^{13} \mathrm{C}\left\{{ }^{1} \mathrm{H}\right\}$ NMR spectra of $4 \mathrm{a}$}

MK-380-2-F2

C13CPD CDCl3 \{C:|Bruker|TOPSPIN\} korbm 48

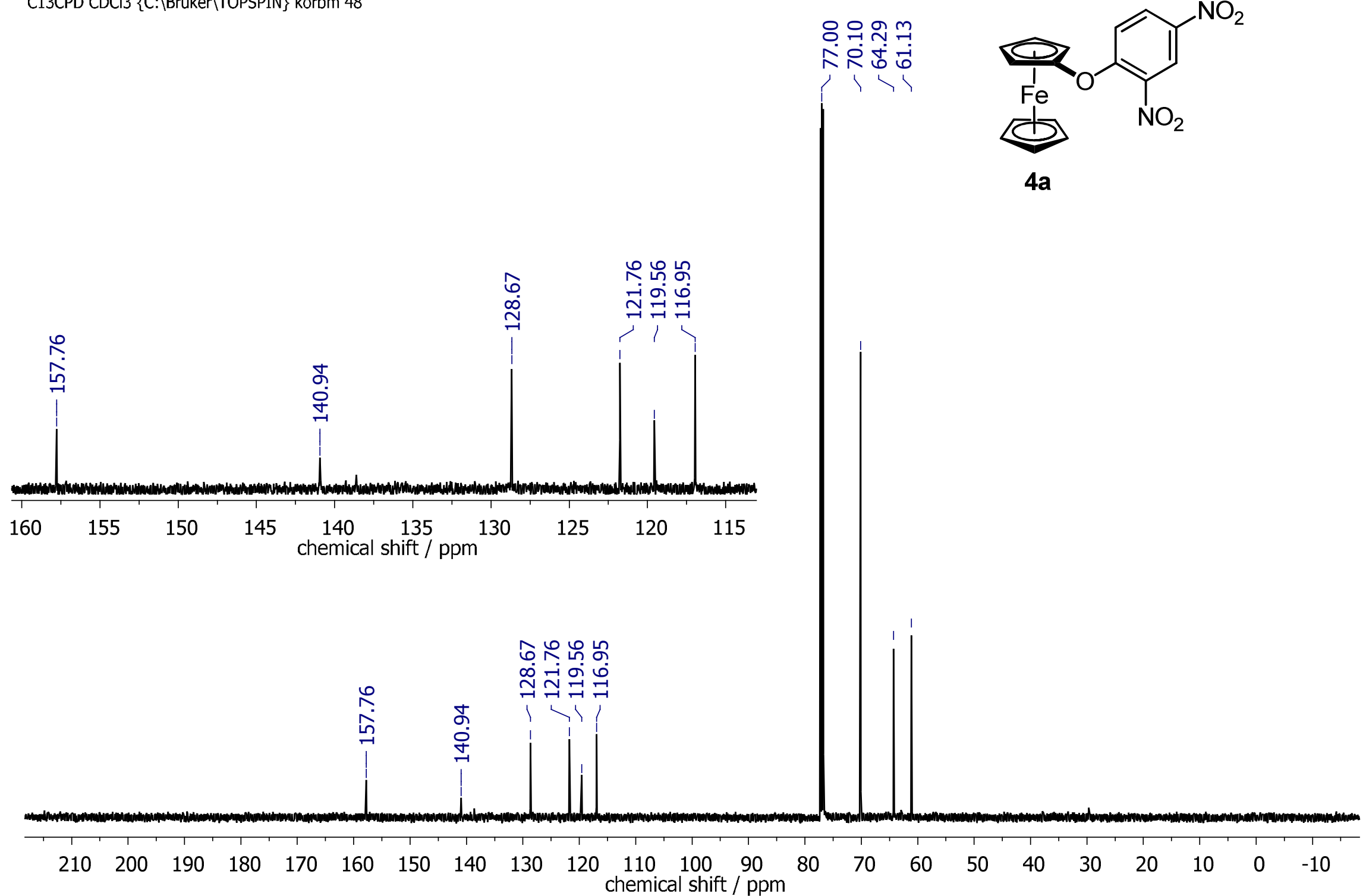




\section{Figure SI26. ${ }^{1} \mathrm{H}$ NMR spectra of $4 \mathrm{~b}$}

MK-383

PROTON CDCl3 \{C:\Bruker\TOPSPIN\} korbm 34

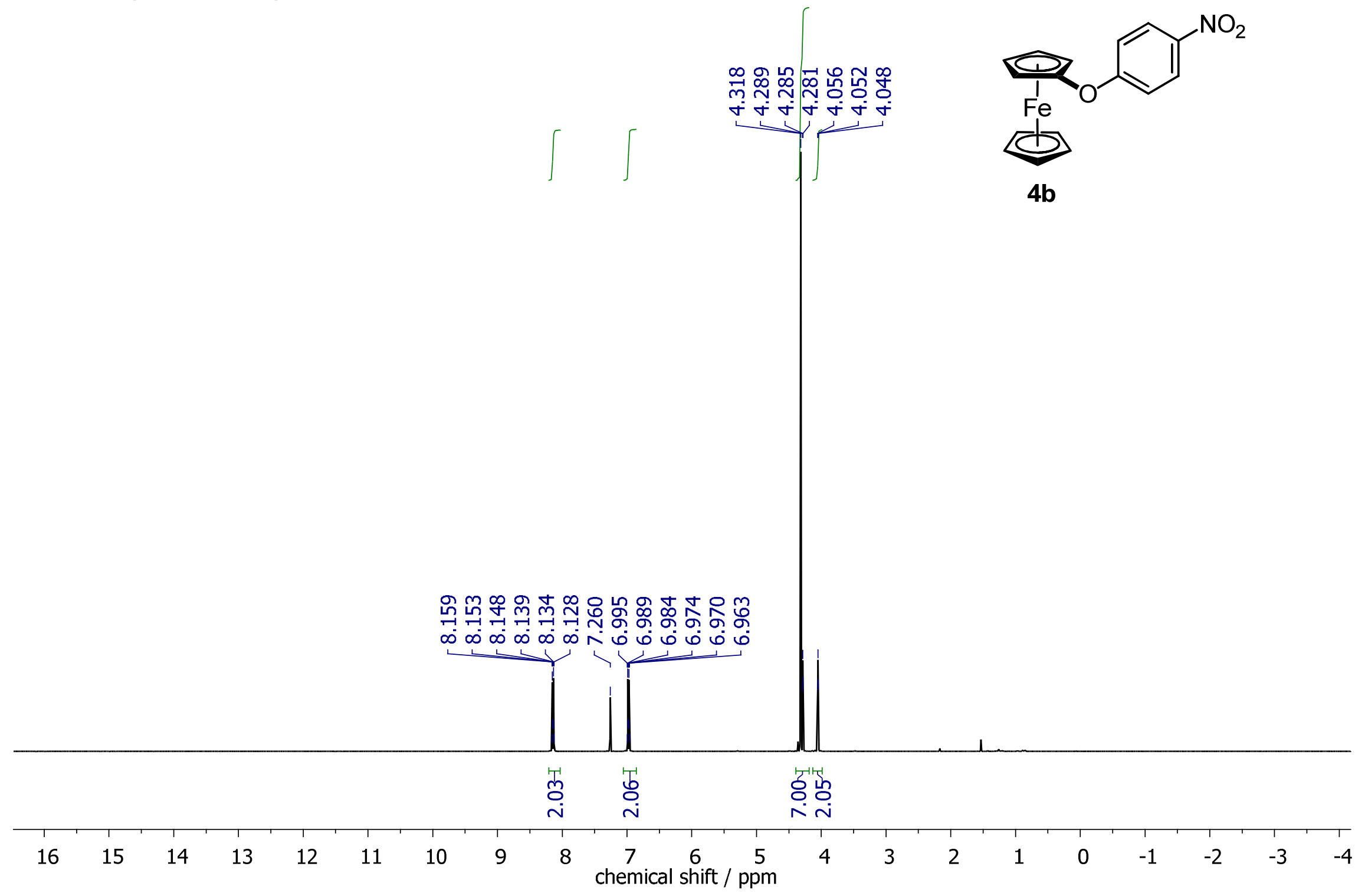




\section{$\underline{\text { Figure SI27. }{ }^{13} \mathrm{C}\left\{{ }^{1} \mathrm{H}\right\} \text { NMR spectra of } 4 \mathrm{~b}}$}

MK-383

C13CPD CDCl3 \{C:|Bruker〈TOPSPIN\} korbm 34

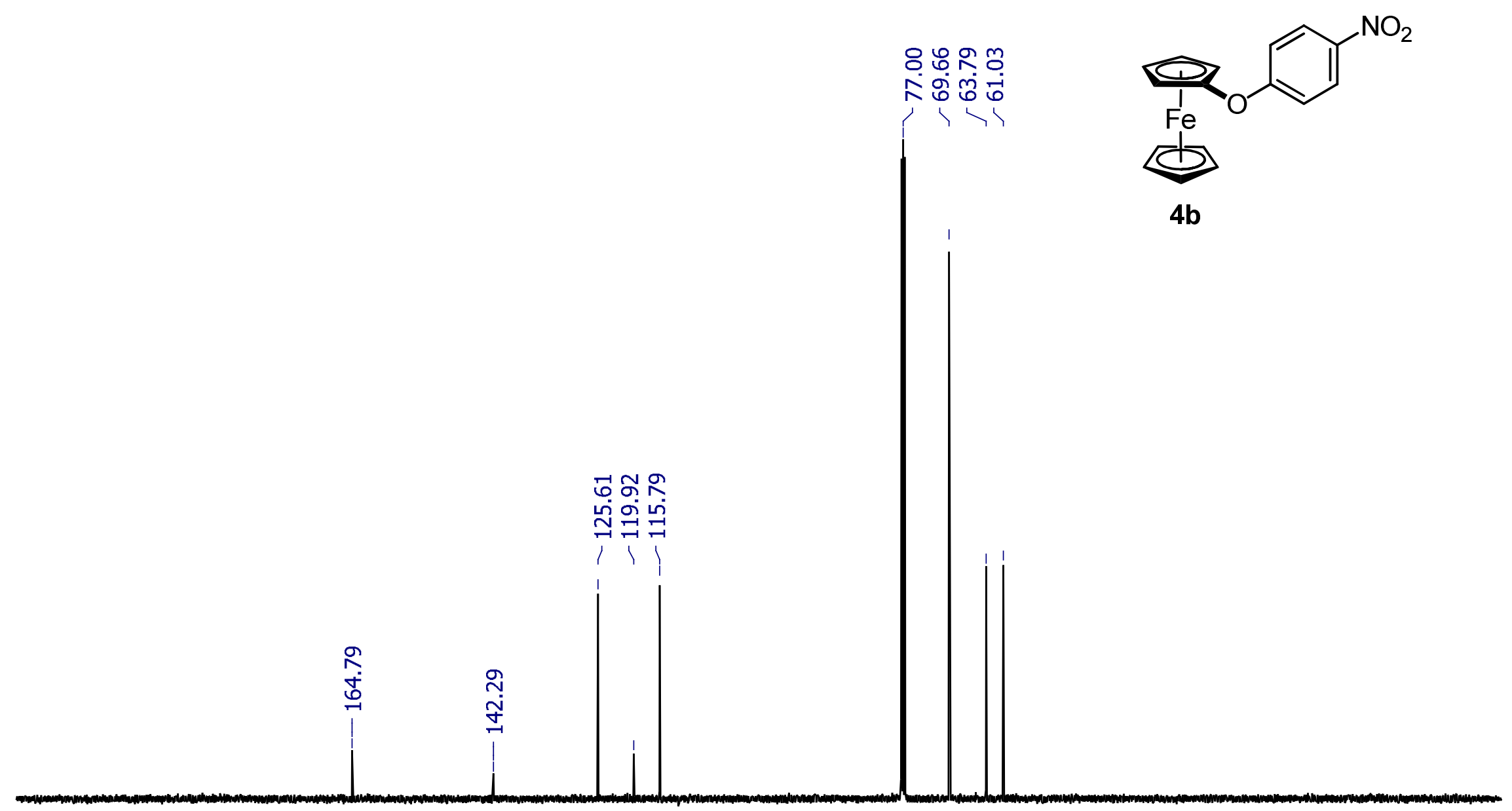

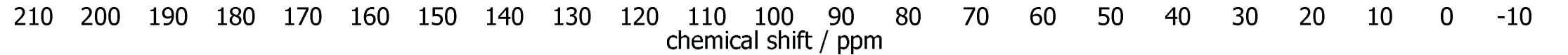




\section{Figure SI28. ${ }^{1} \mathrm{H}$ NMR spectra of $7 \mathrm{a}$}

MK-384-F4-F1

PROTON CDCl3 \{C:|Bruker\TOPSPIN\} korbm 34

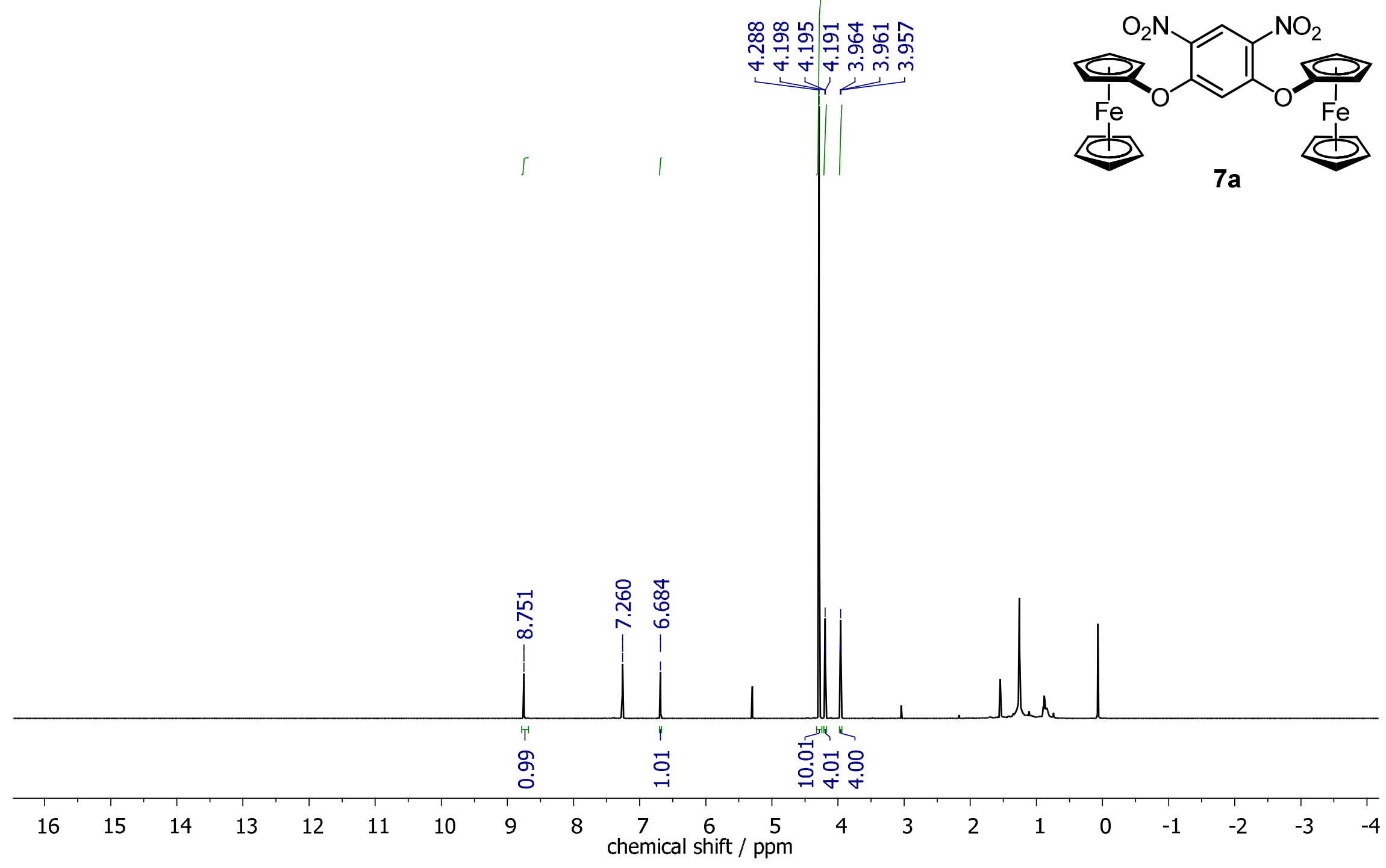


Figure SI29. ${ }^{13} \mathrm{C}\left\{{ }^{1} \mathrm{H}\right\}$ NMR spectra of 7a

MK-384-F4-F1

C13CPD CDCI3 \{C:|Bruker〈TOPSPIN\} korbm 34

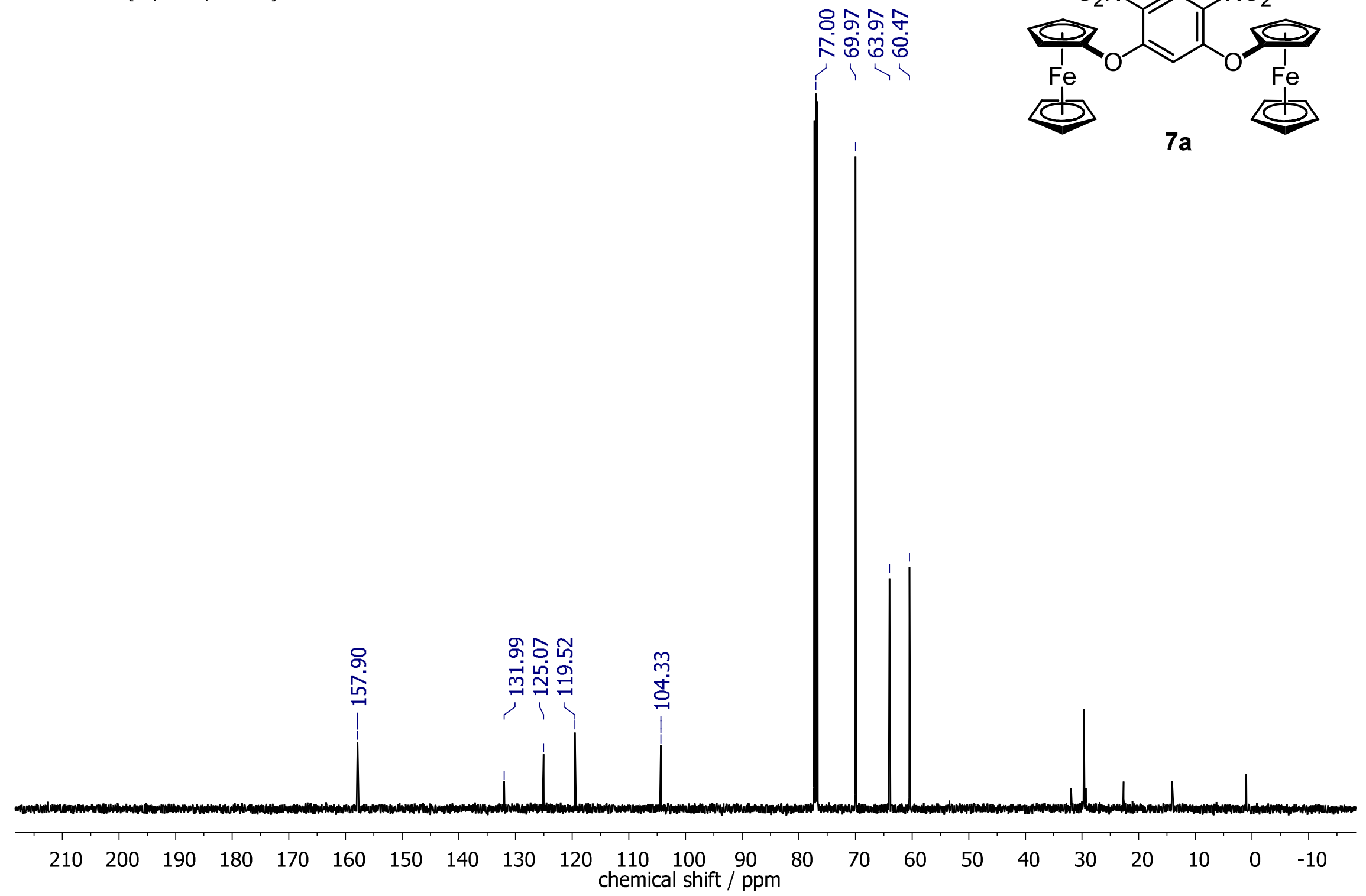




\section{Figure SI30. ${ }^{1} \mathrm{H}$ NMR spectra of $7 \mathrm{~b}$}

MK-384-F1-N

PROTON CDCl3 \{C:|Bruker|TOPSPIN\} korbm 59

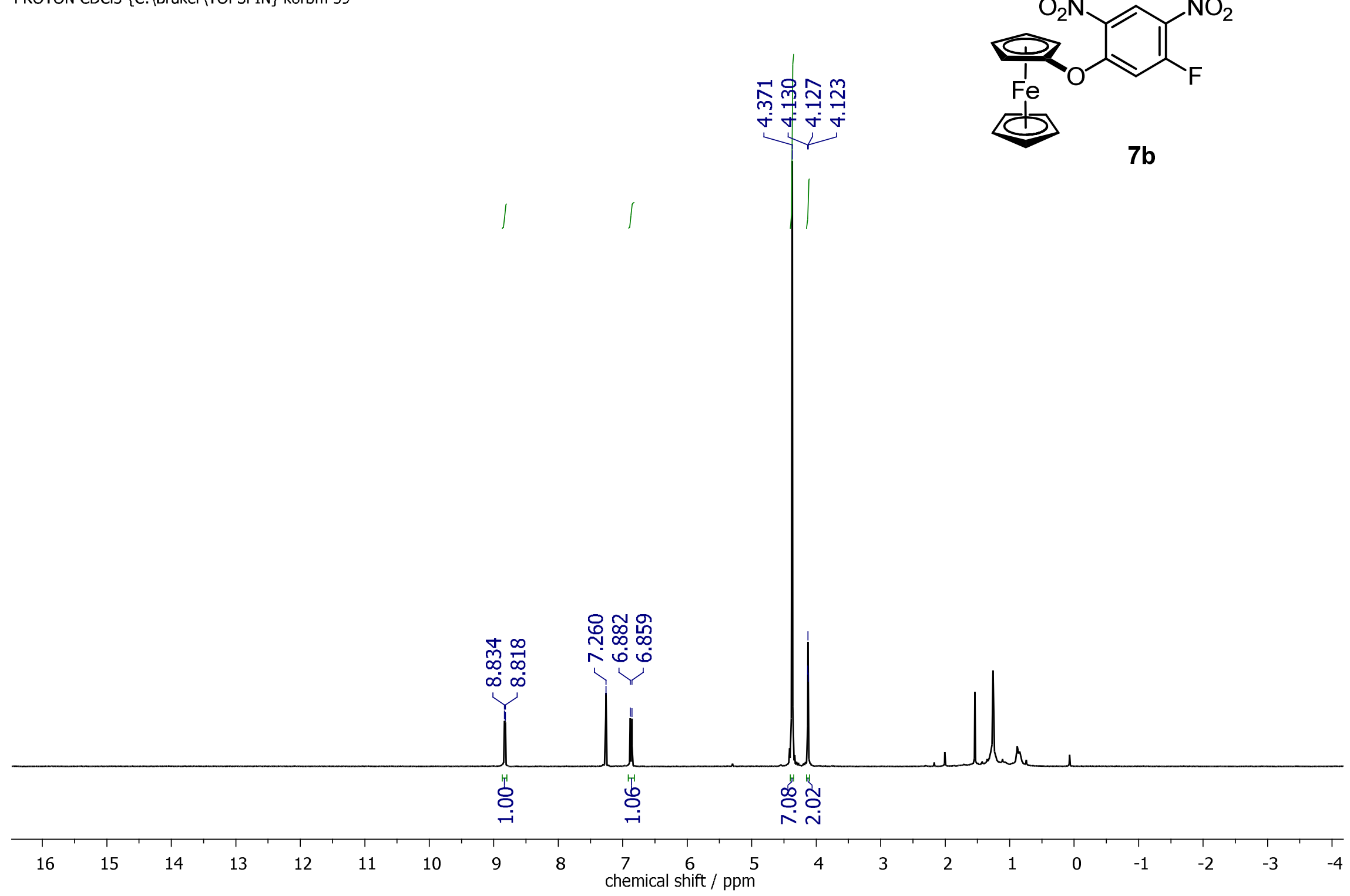


Figure SI31. ${ }^{13} \mathrm{C}\left\{{ }^{1} \mathrm{H}\right\}$ NMR spectra of $7 \mathrm{~b}$

MK-384-F1-N

C13CPD CDCl3 \{C:|Bruker|TOPSPIN\} korbm 59

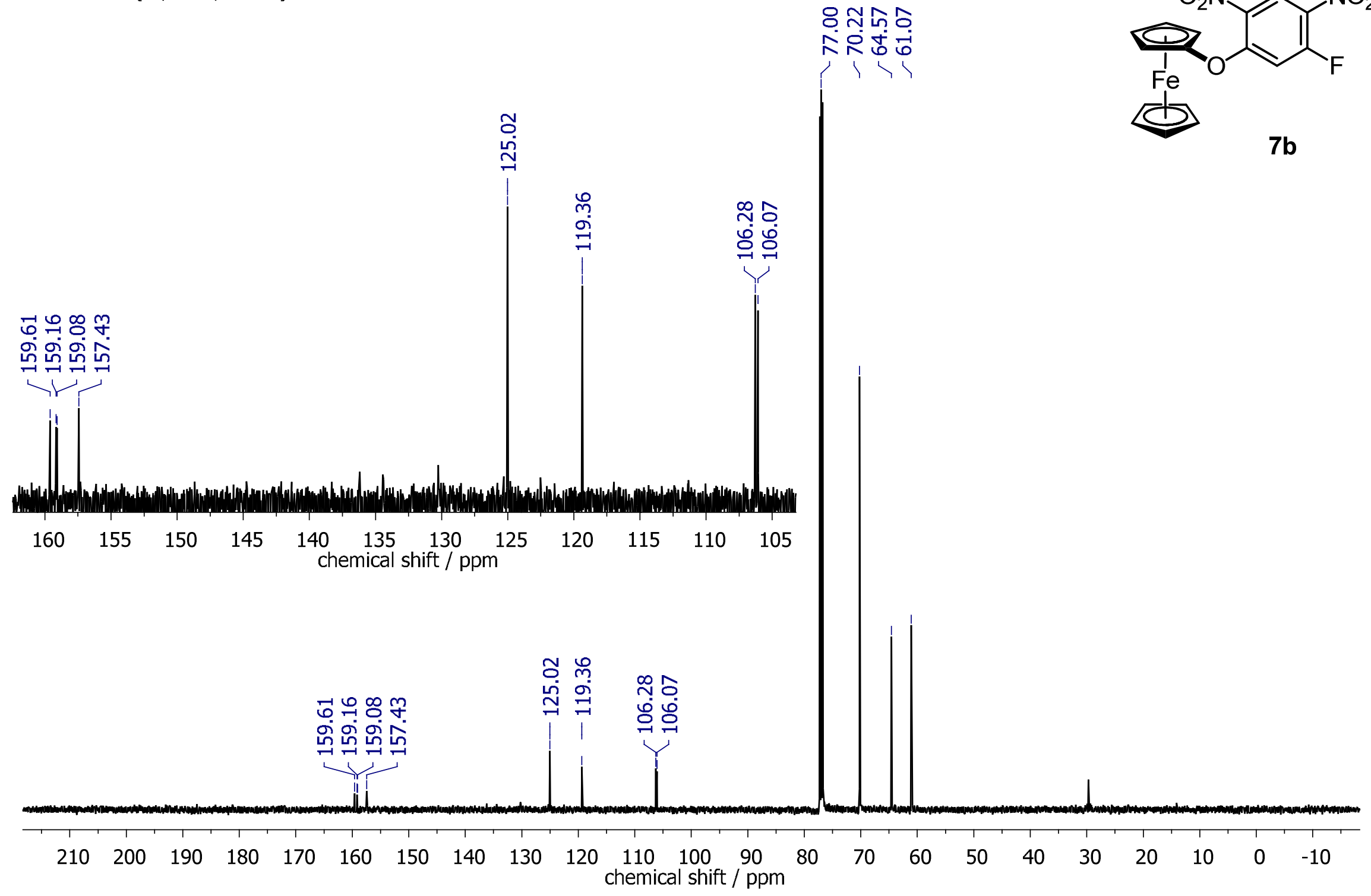




\section{Figure SI32. ${ }^{1} \mathrm{H}$ NMR spectra of $7 \mathrm{c}$}

MK-384-F3

PROTON CDCl3 \{C:\Bruker\TOPSPIN\} korbm 43

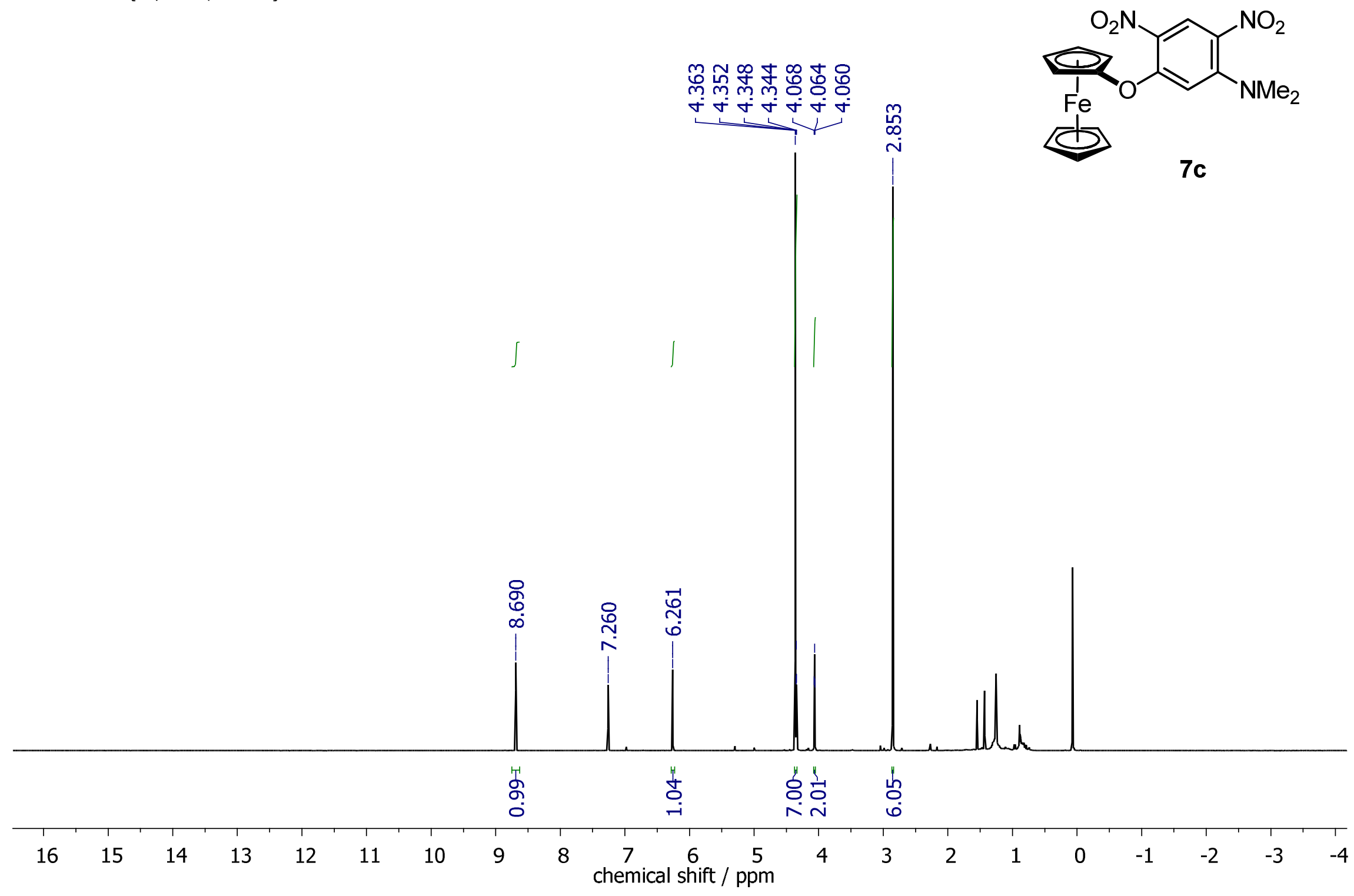




\section{Figure SI33. ${ }^{13} \mathrm{C}\left\{{ }^{1} \mathrm{H}\right\}$ NMR spectra of $7 \mathrm{c}$}

MK-384-F3

C13CPD CDCI3 \{C:|Bruker〈TOPSPIN\} korbm 32

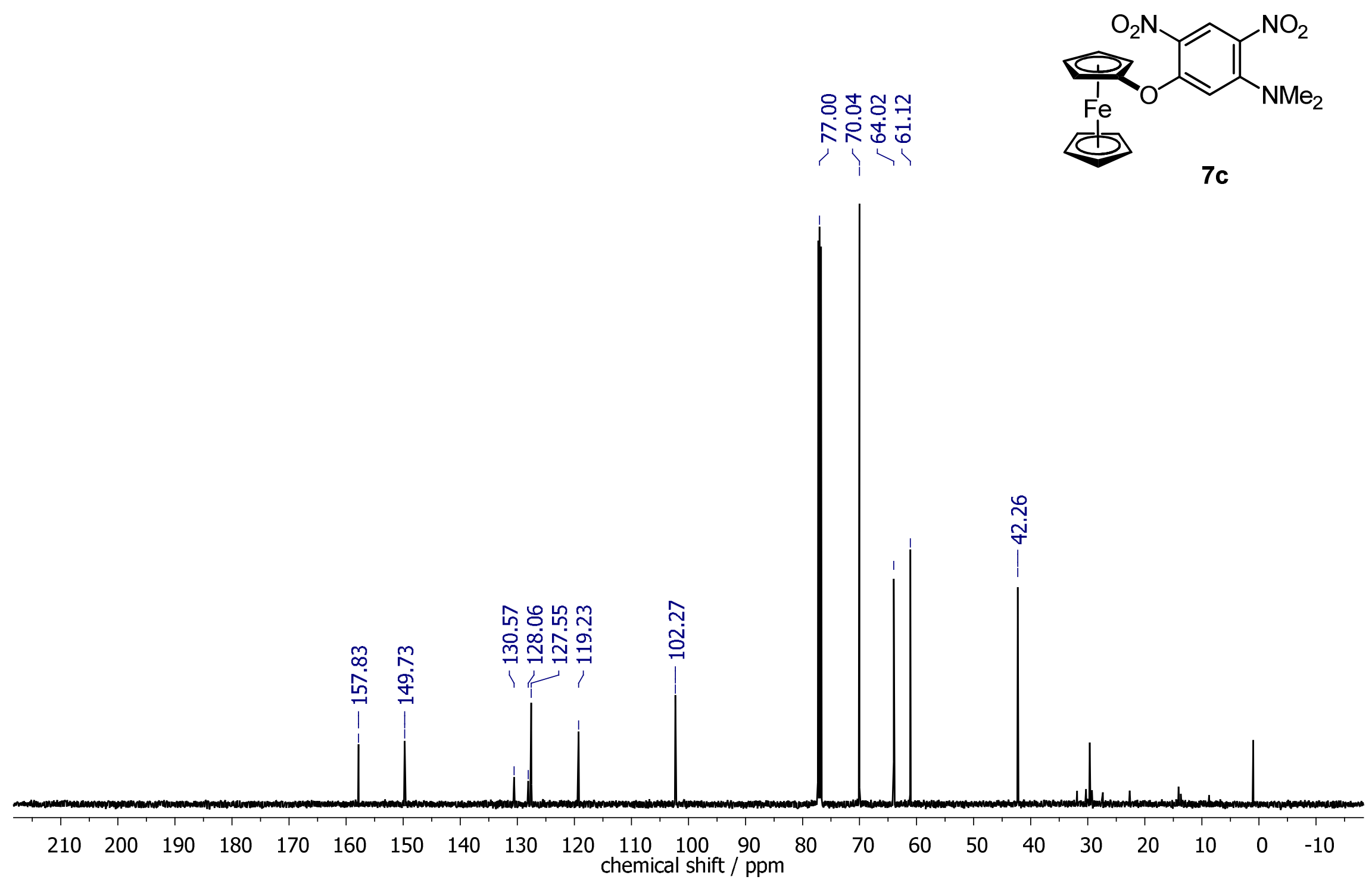




\section{Figure SI34. ${ }^{1} \mathrm{H}$ NMR spectra of 8}

MK-386-F1-cryst

PROTON CDCl3 \{C:|Bruker\TOPSPIN\} korbm 55

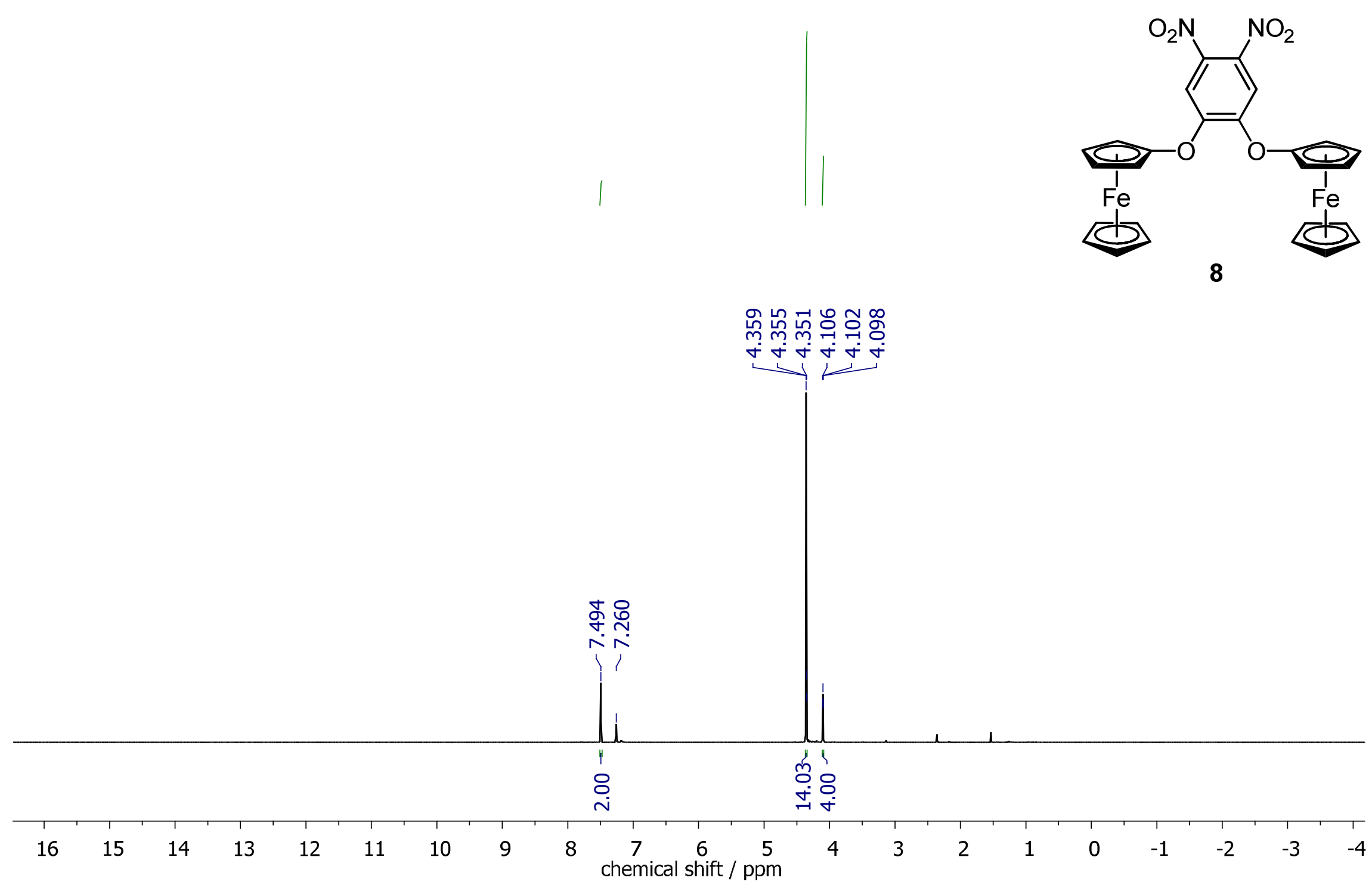




\section{Figure SI35. ${ }^{13} \mathrm{C}\left\{{ }^{1} \mathrm{H}\right\}$ NMR spectra of 8}

MK-386-F1-cryst

C13CPD CDCl3 \{C:|Bruker|TOPSPIN\} korbm 55
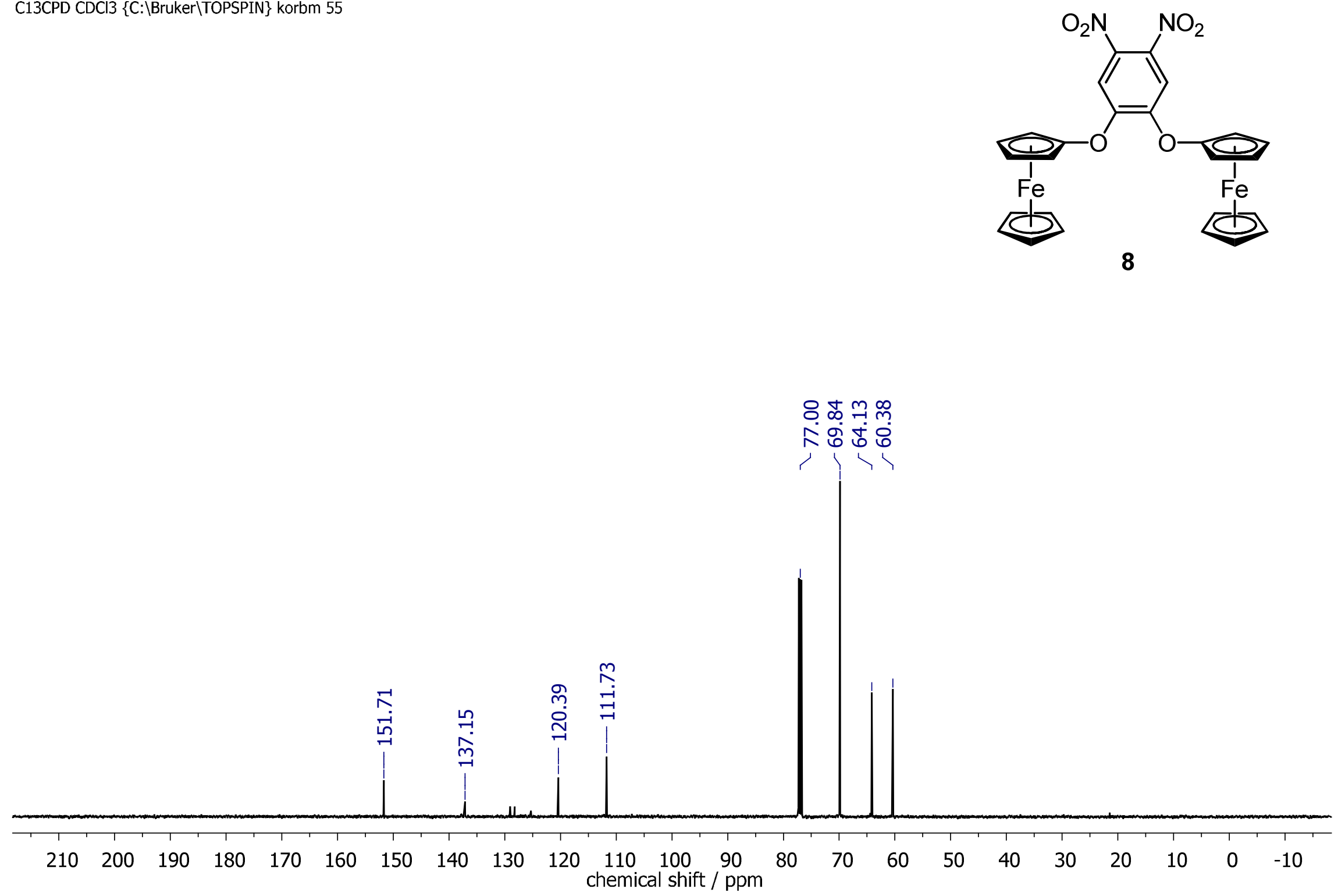


\section{Figure SI36. ${ }^{1} \mathrm{H}$ NMR spectra of $r a c-11 \mathrm{a}$}

MK-391-A-F6

PROTON CDCl3 \{C:|Bruker\TOPSPIN\} korbm 46

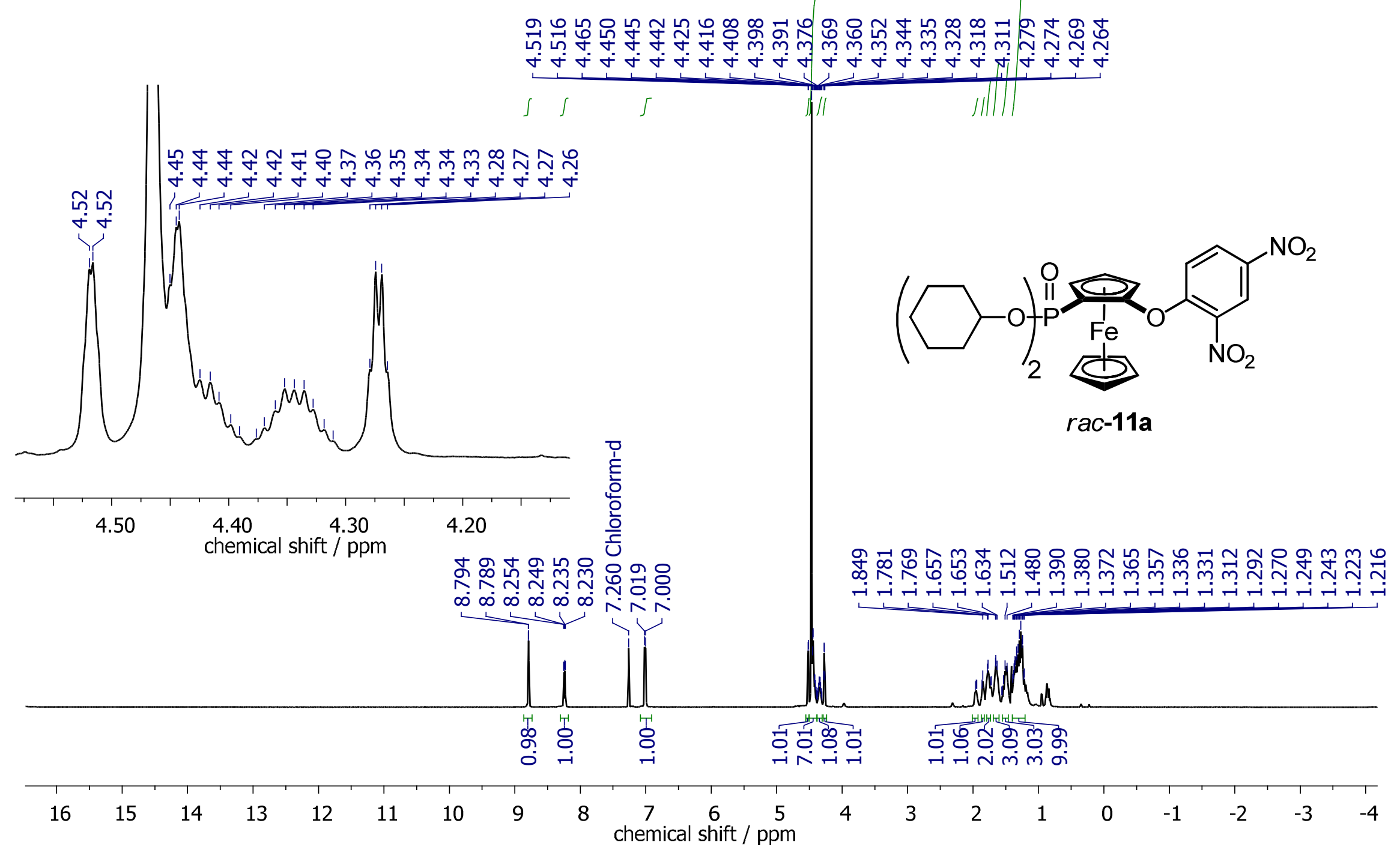




\section{Figure SI37. ${ }^{13} \mathrm{C}\left\{{ }^{1} \mathrm{H}\right\}$ NMR spectra of rac-11a}

MK-391-A-F6

C13CPD CDCl3 \{C:|Bruker|TOPSPIN\} korbm 46

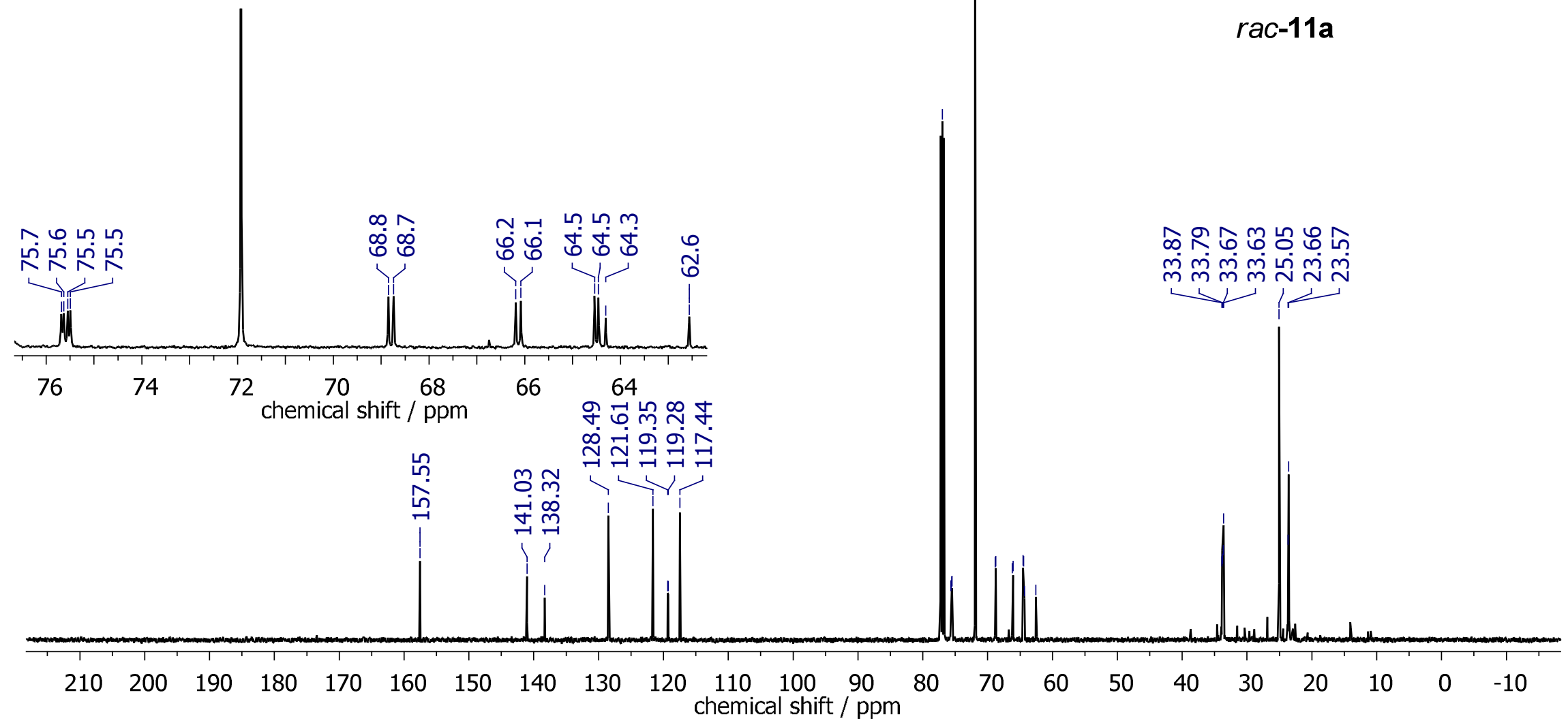

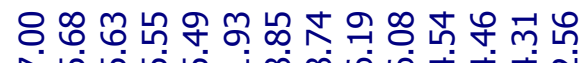

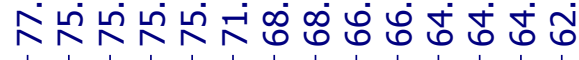

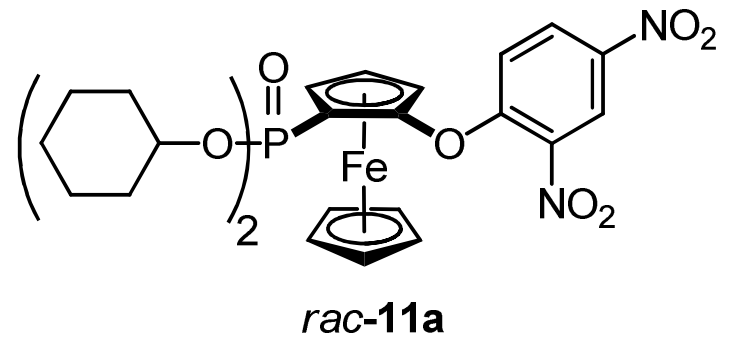

कิ

mm m N N 


\section{Figure SI38. ${ }^{31} \mathbf{P}\left\{{ }^{1} \mathrm{H}\right\}$ NMR spectra of rac-11a}

MK-391-A-F6

P31CPD CDCl3 \{C:|Bruker|TOPSPIN\} korbm 46

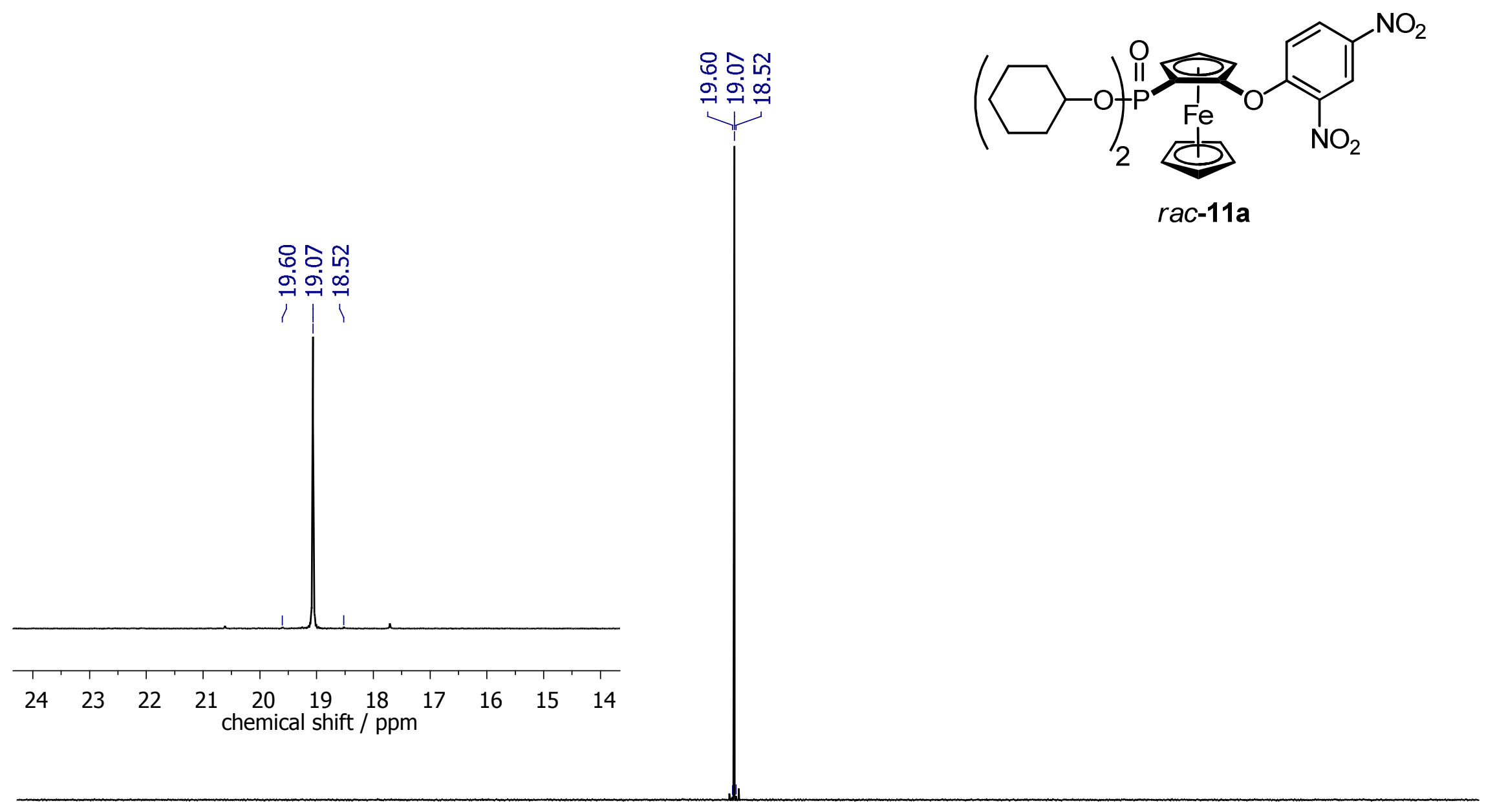

$\begin{array}{lllllllll}220 & 200 & 180 & 160 & 140 & 120 & 100 & 80 & 60\end{array}$

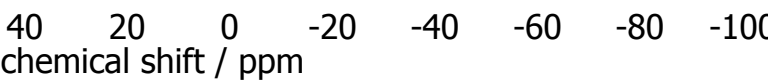

$-140$

$-180$ 


\section{Figure SI39. ${ }^{1} \mathrm{H}$ NMR spectra of rac-11b}

MK-391-B-F3

PROTON CDCl3 \{C:|Bruker|TOPSPIN\} korbm 10
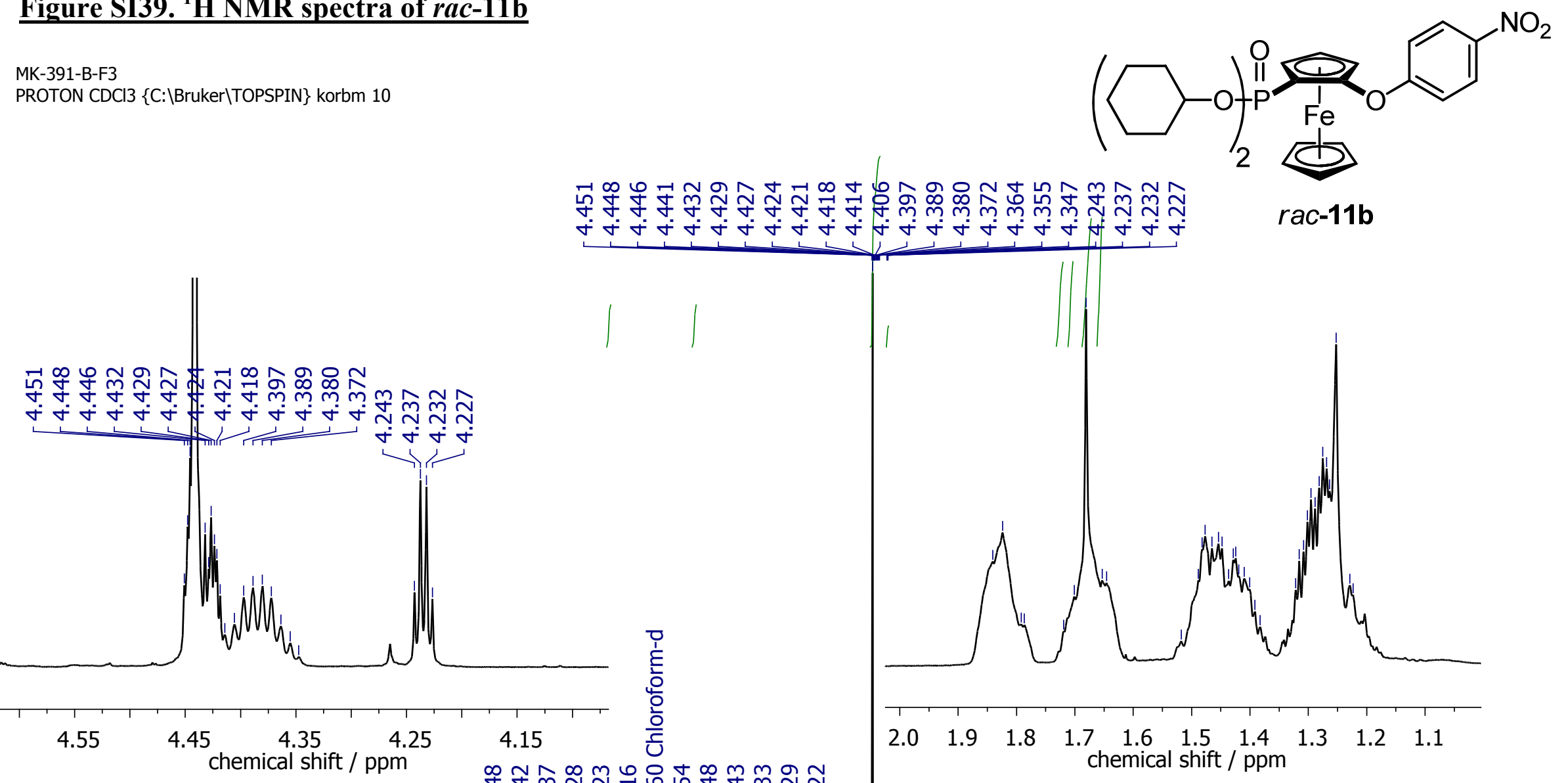

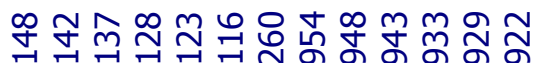

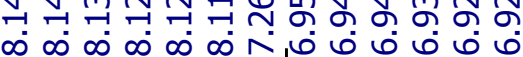

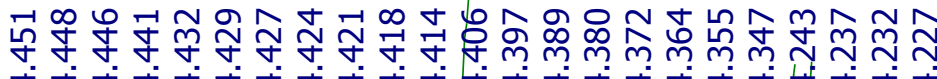

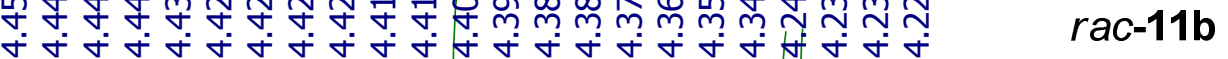

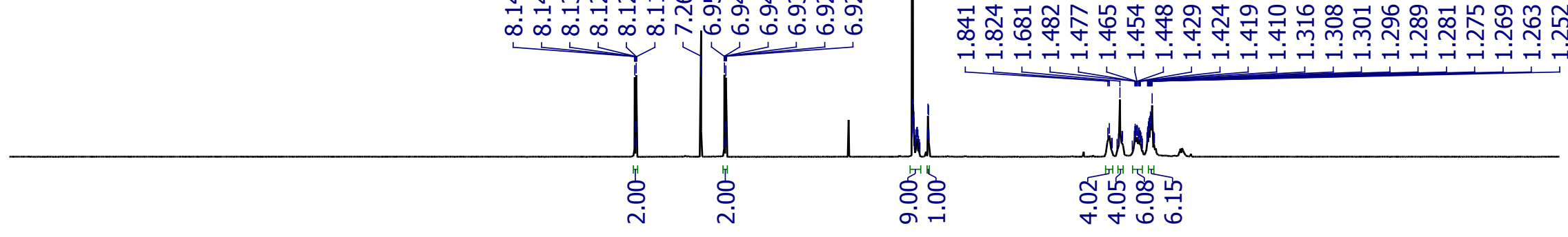

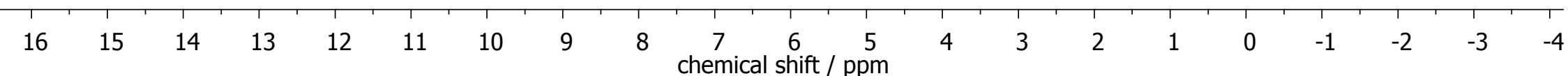


Figure SI40. ${ }^{13} \mathrm{C}\left\{{ }^{1} \mathrm{H}\right\}$ NMR spectra of rac-11b

MK-391-B-F3

C13CPD CDCl3 \{C:|Bruker|TOPSPIN\} korbm 10

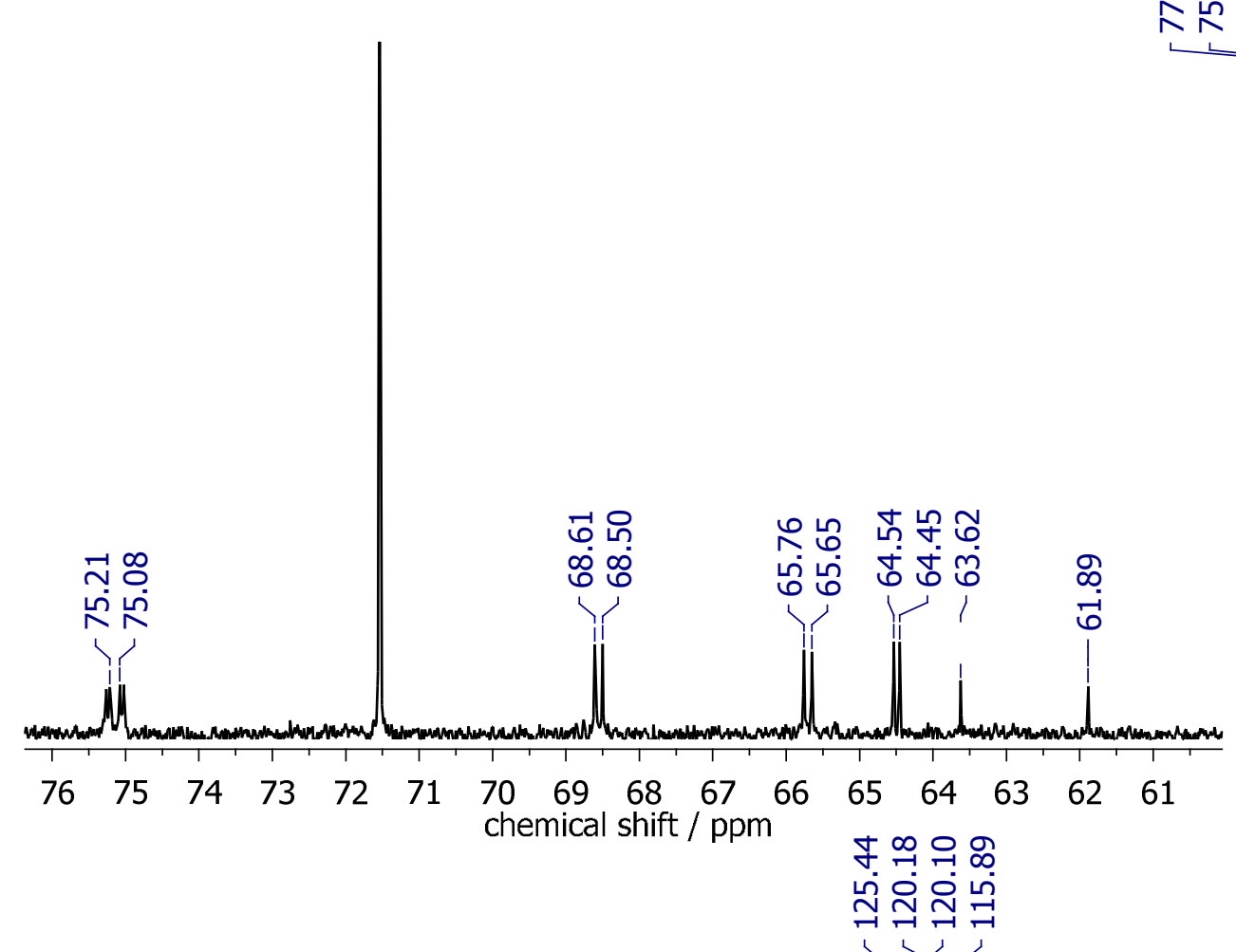

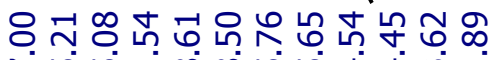

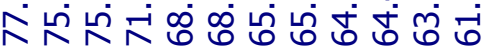
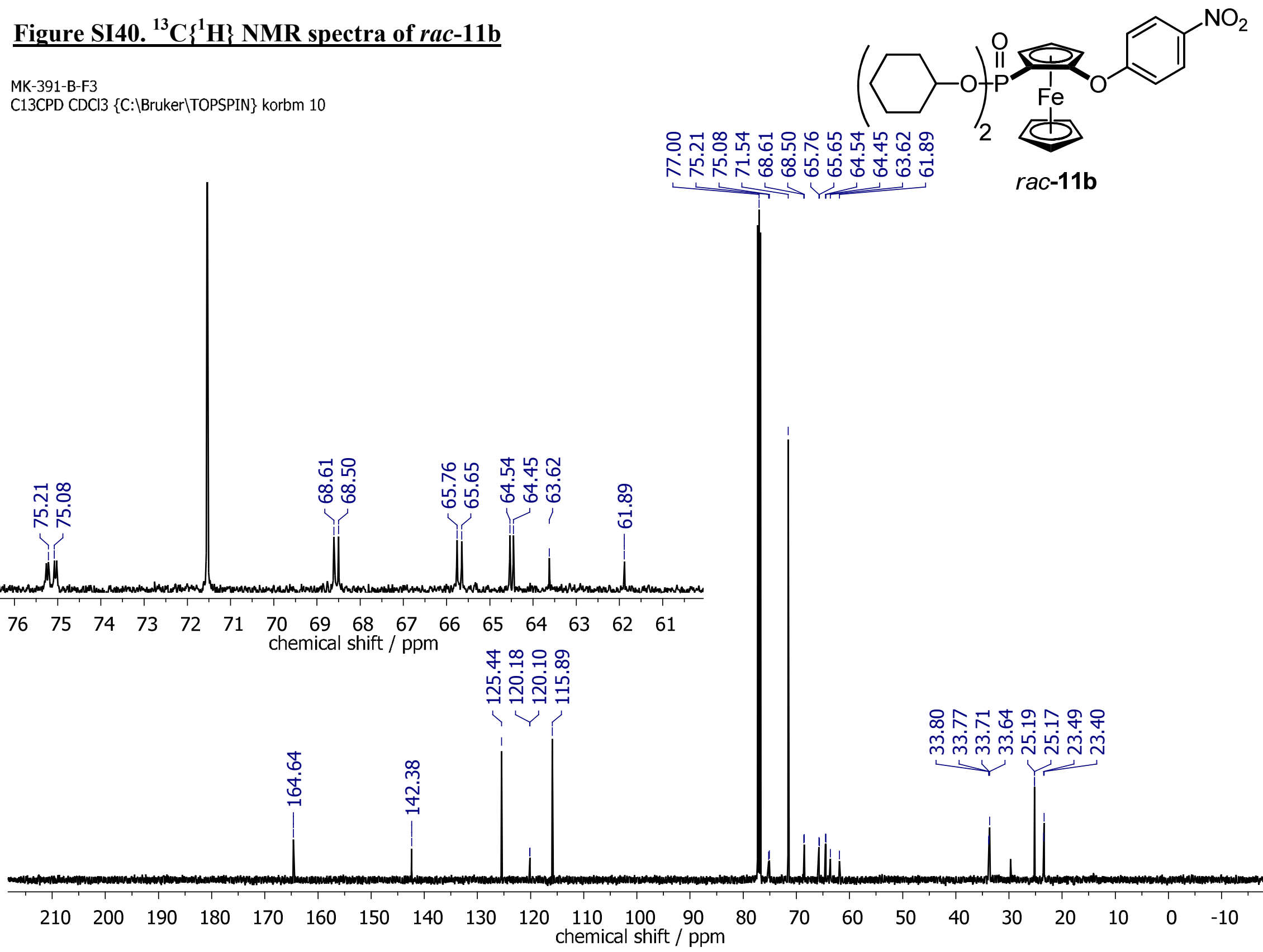


\section{$\underline{\text { Figure SI41. }{ }^{31} \mathrm{P}\left\{{ }^{1} \mathrm{H}\right\} \text { NMR spectra of } \mathrm{rac}-11 \mathrm{~b}}$}

MK-391-B-F3

P31CPD CDCl3 \{C:|Bruker|TOPSPIN\} korbm 10
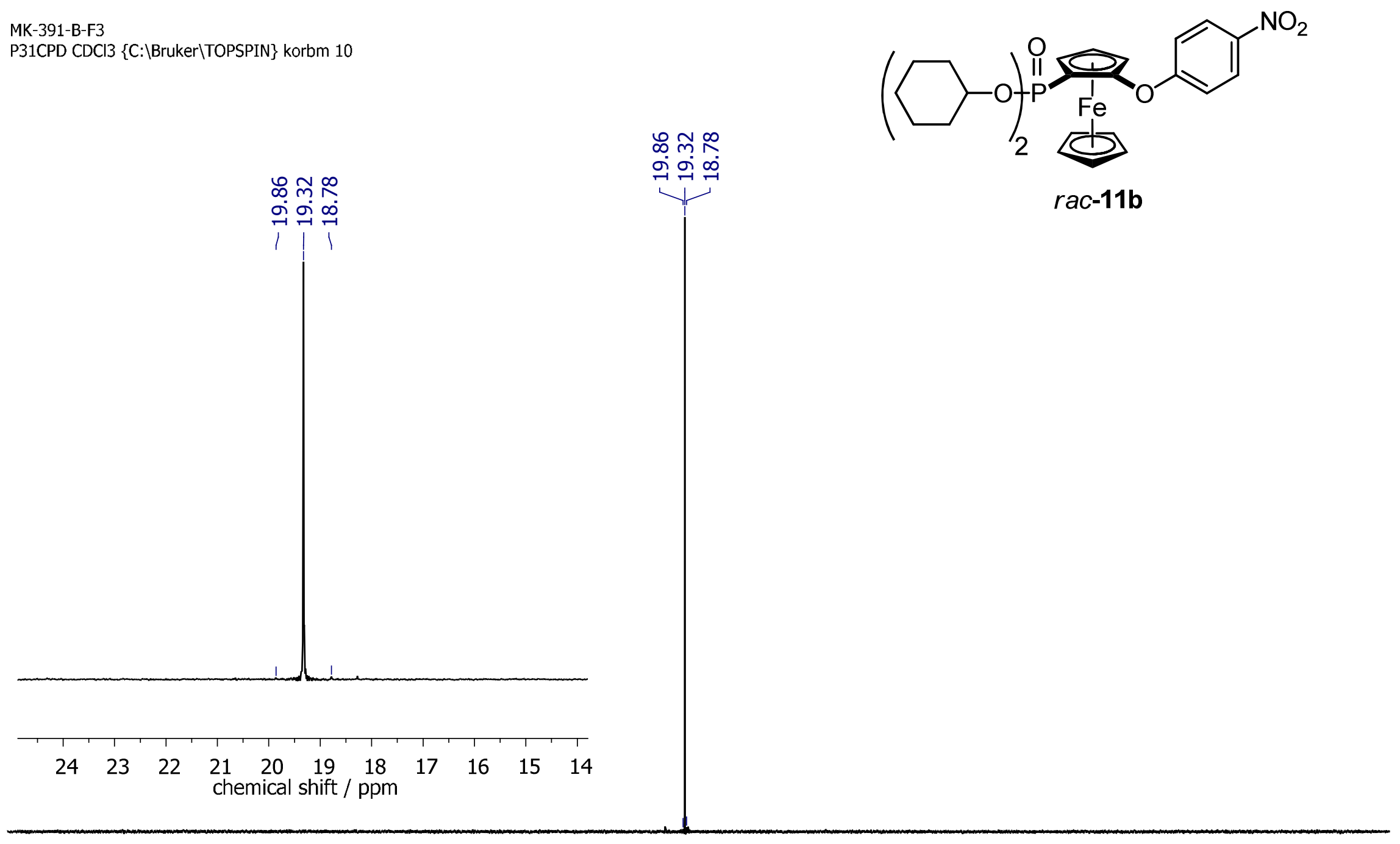


\section{Figure SI42. ${ }^{1}$ H NMR spectra of rac-12a}

MK-390-A-F3

PROTON CDCl3 \{C:|Bruker|TOPSPIN\} korbm 43
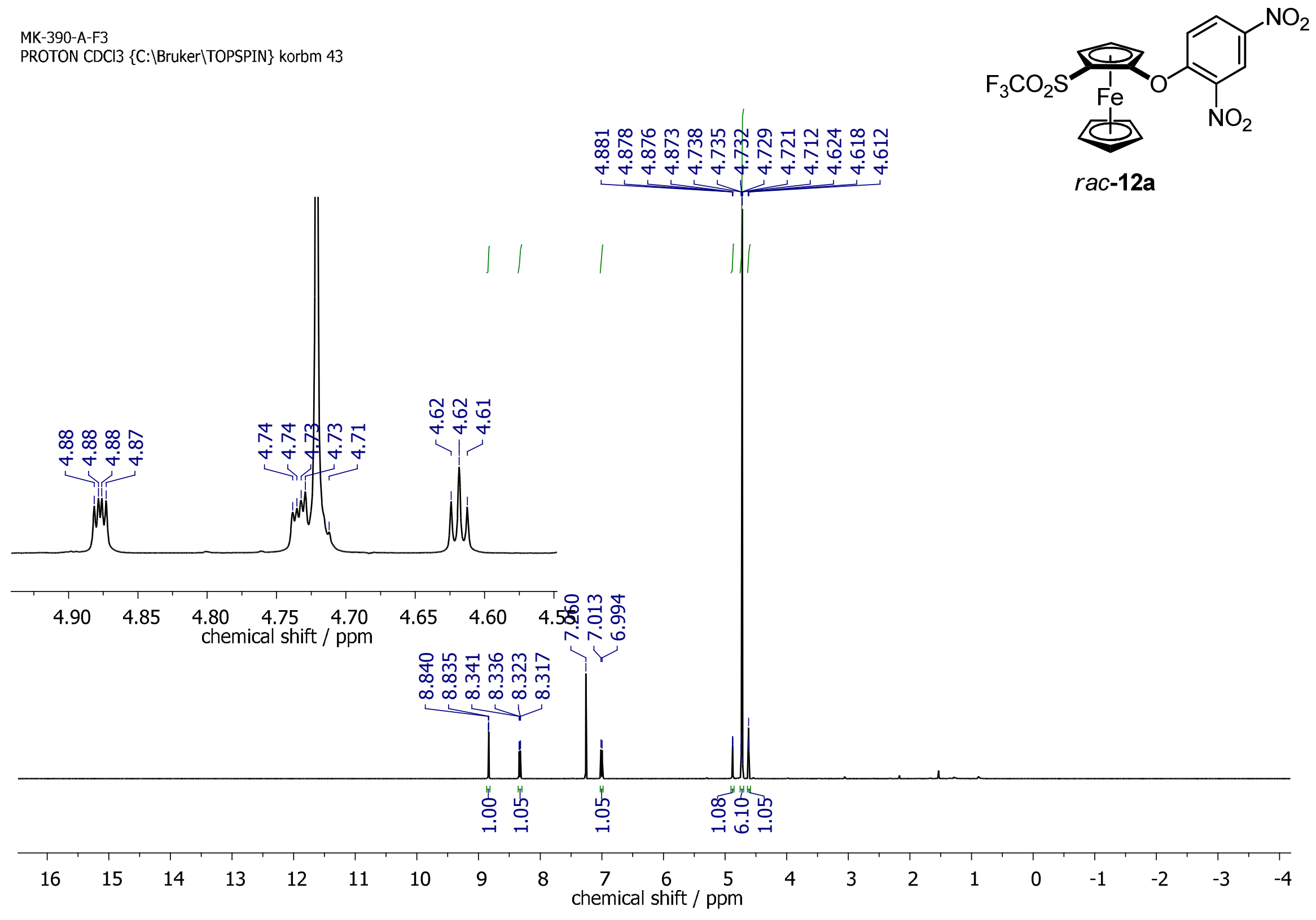


\section{Figure SI43. ${ }^{13} \mathrm{C}\left\{{ }^{1} \mathrm{H}\right\}$ NMR spectra of rac-12a}

MK-390-A-F3

C13CPD CDCl3 \{C:|Bruker\TOPSPIN\} korbm 43
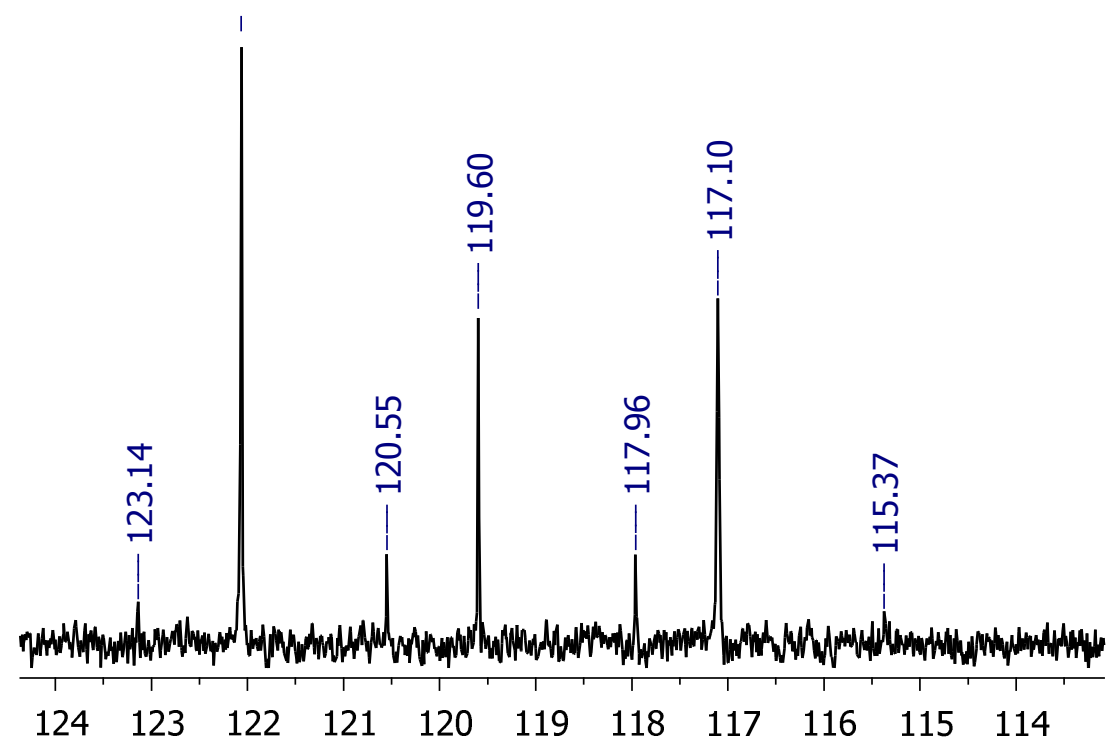

$\begin{array}{lllllll}124 & 123 & 122 & 121 & \begin{array}{l}120 \\ \text { chemical shift / ppm }\end{array}\end{array}$

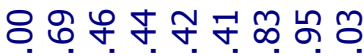

ヘิ

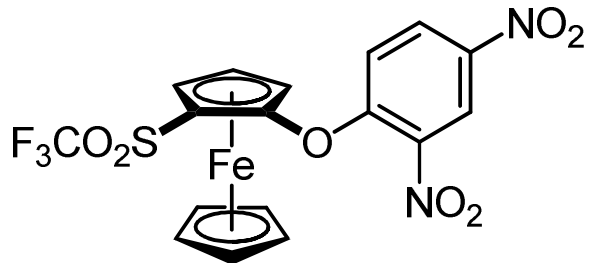

rac-12a

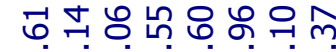

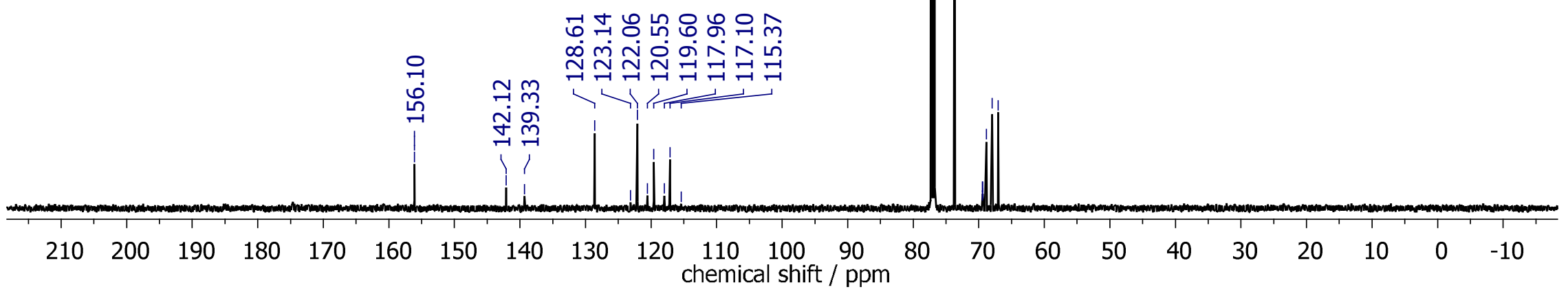




\section{Figure SI44. ${ }^{1} \mathrm{H}$ NMR spectra of rac-13a}

MK-391-F

PROTON

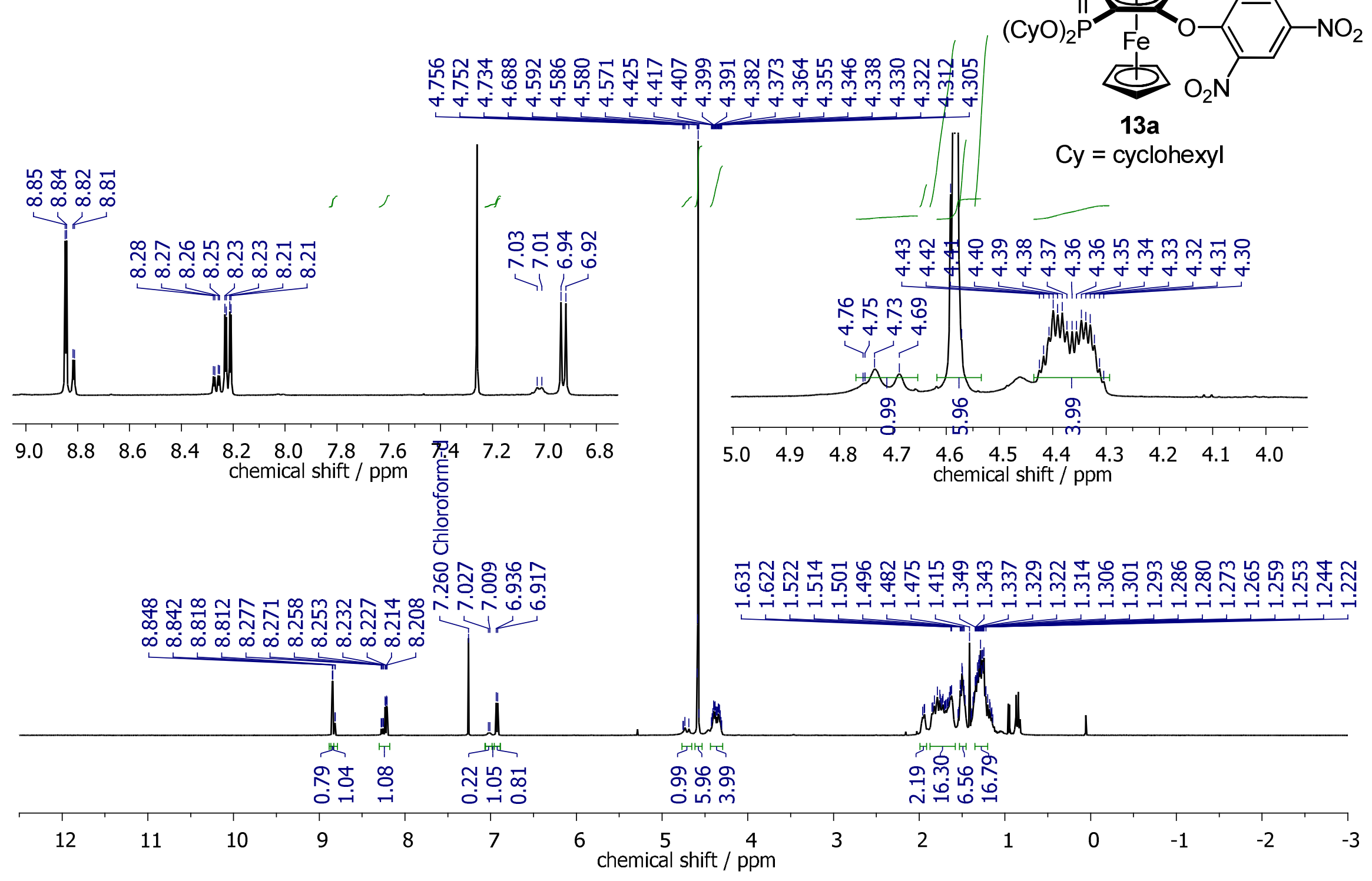




\section{Figure SI45. ${ }^{13} \mathrm{C}\left\{{ }^{1} \mathrm{H}\right\}$ NMR spectra of $\mathrm{rac}-13 \mathrm{a}$}

MK-391-F

C13CPD CDCl3 \{C:|Bruker|TOPSPIN\} korbm 27

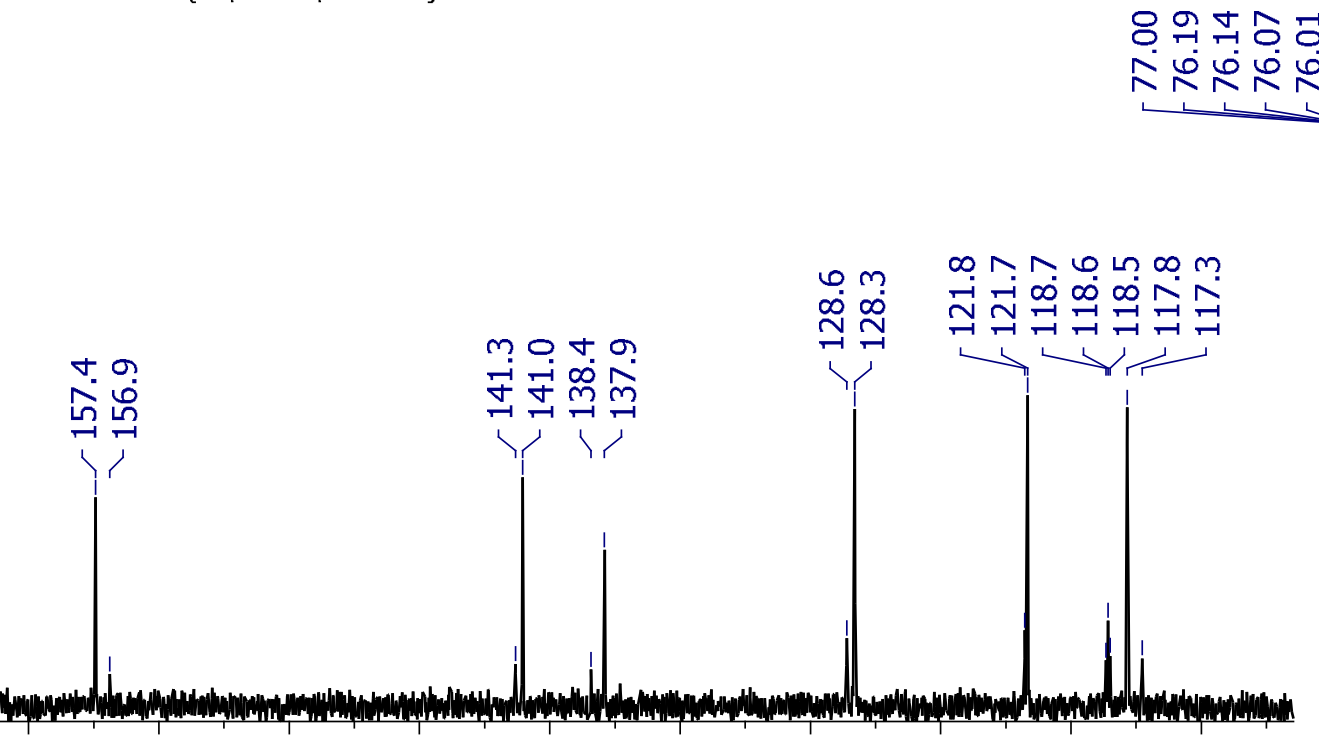

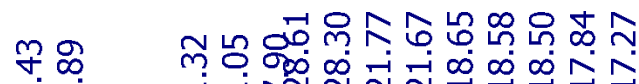

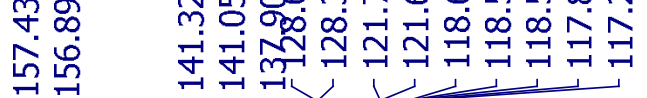
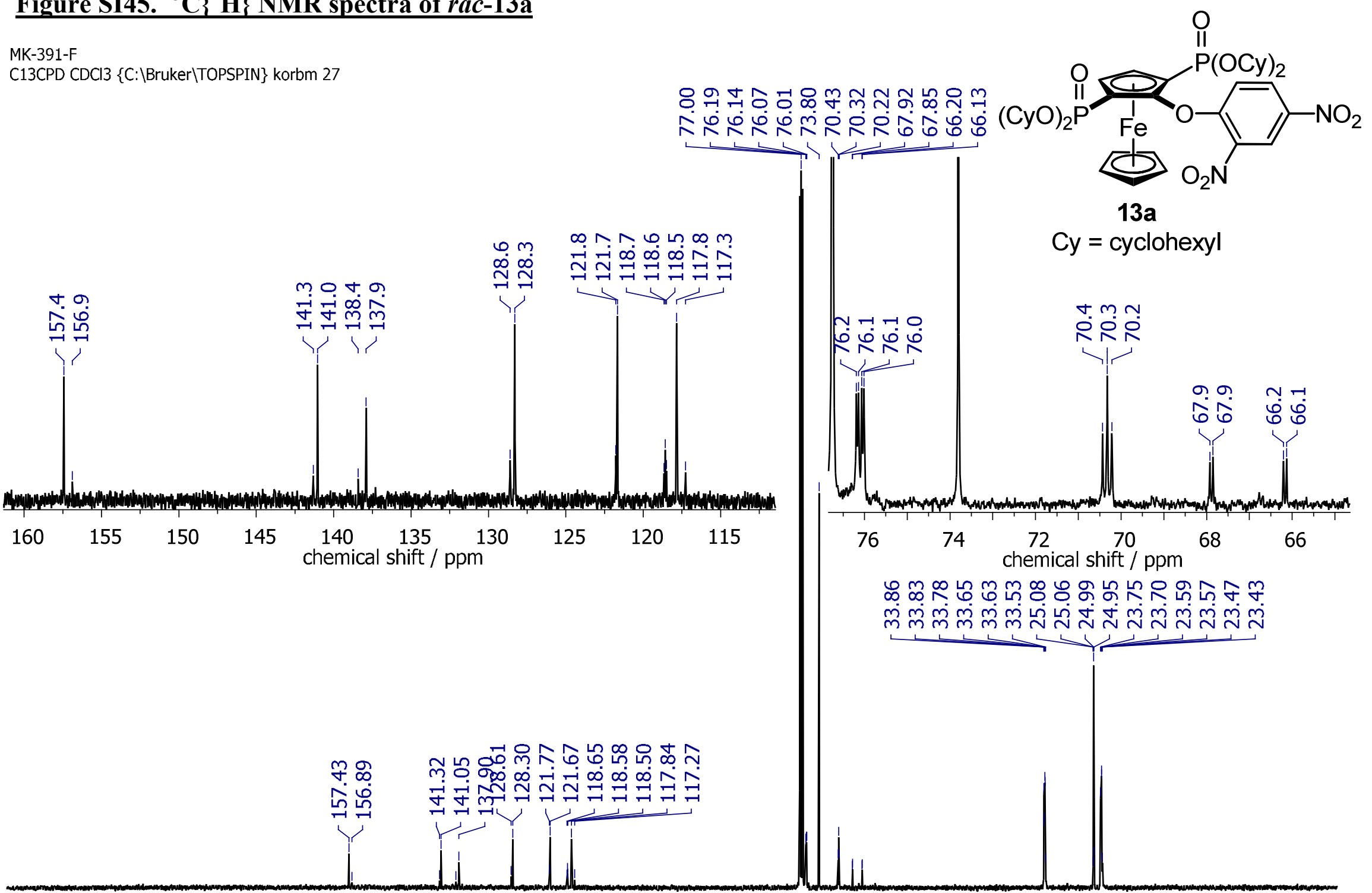

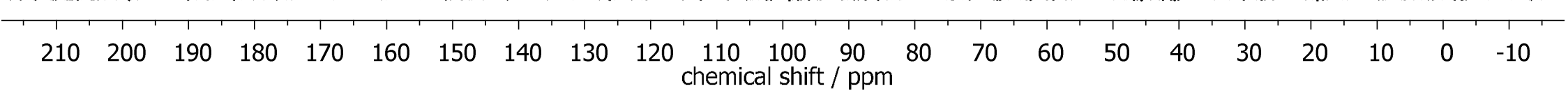




\section{Figure SI46. ${ }^{31} \mathrm{P}\left\{{ }^{1} \mathrm{H}\right\}$ NMR spectra of rac-13a}

MK-391-F

P31CPD CDCl3 \{C:|Bruker|TOPSPIN\} korbm 27

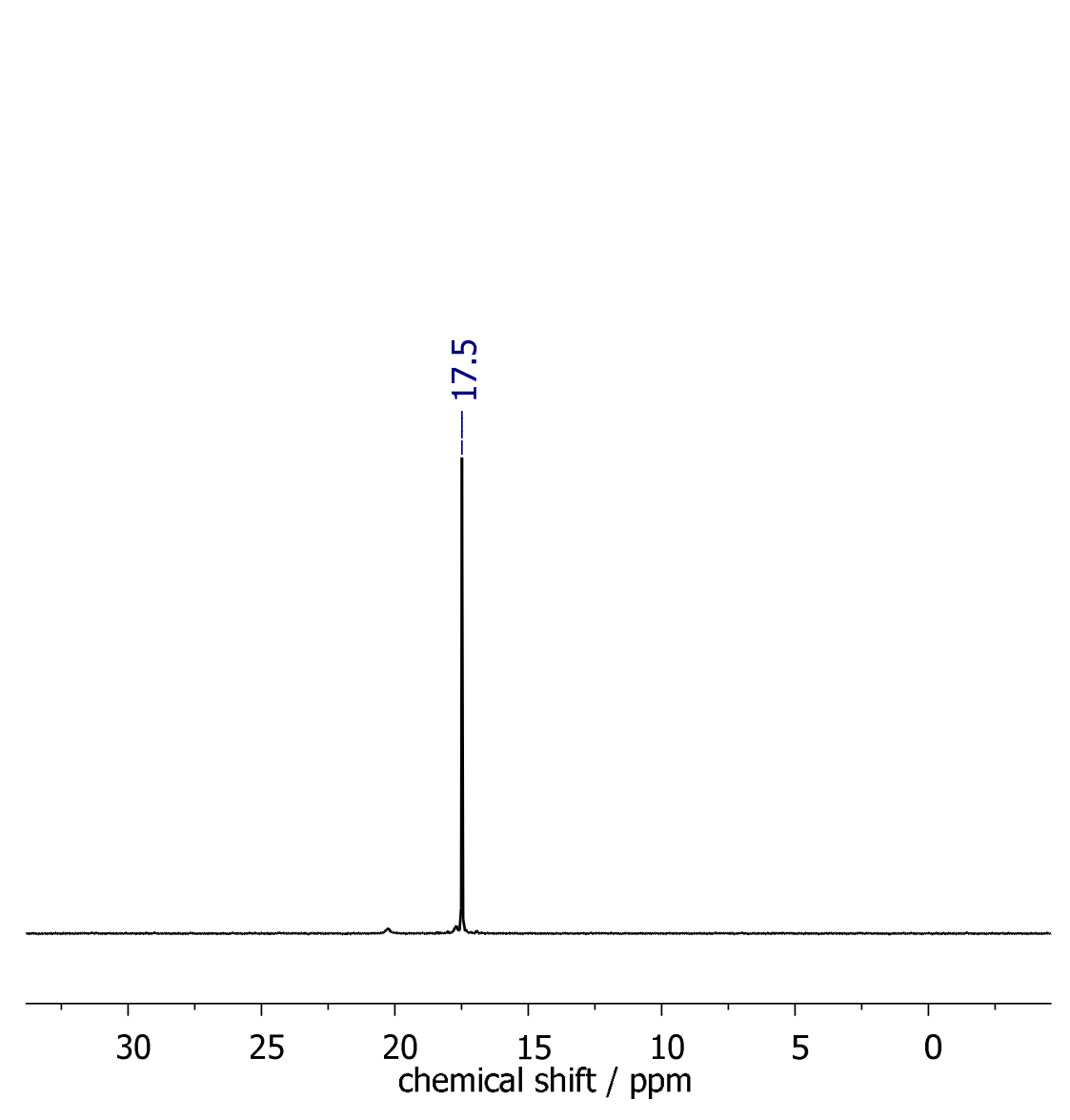

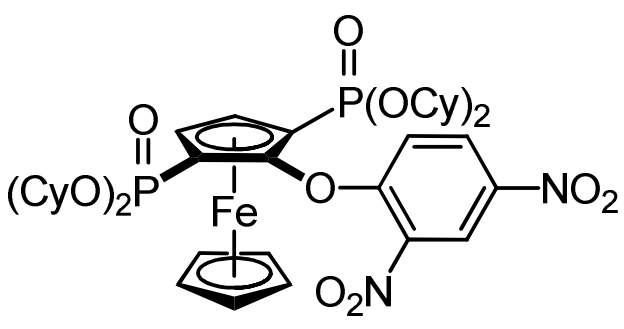

$13 a$

Cy = cyclohexyl 


\section{Figure SI47. ${ }^{1} H$ and ${ }^{31} P\left\{{ }^{1} H\right\}$ NMR spectra of $\left(R_{D}\right)-16$ a}

MK-381-F3

PROTON CDCl3 \{C:|Bruker|TOPSPIN\} korbm 57
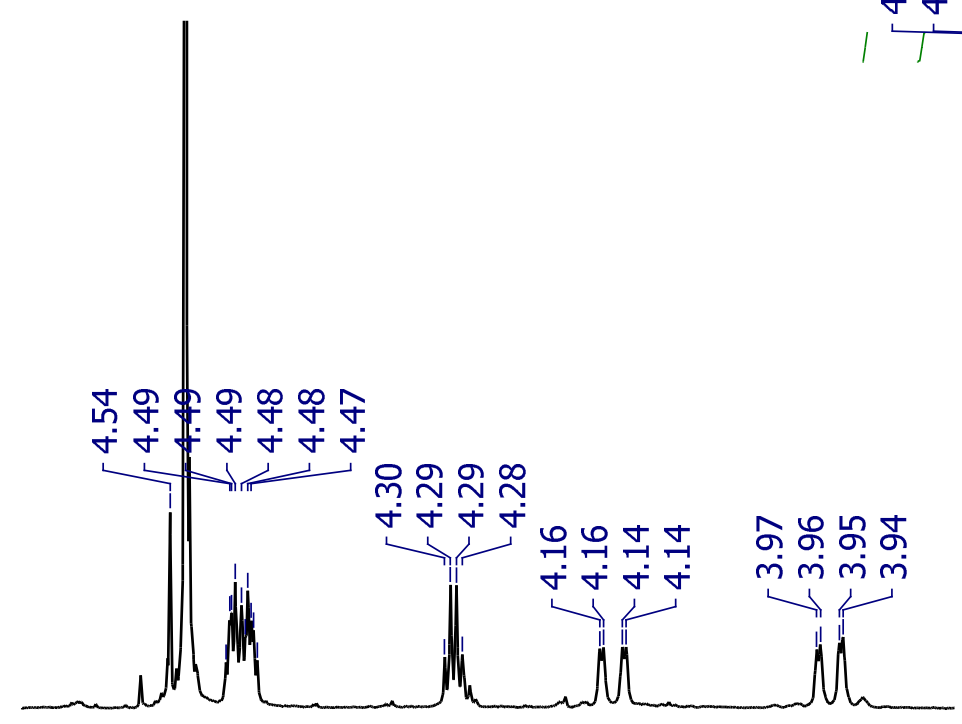

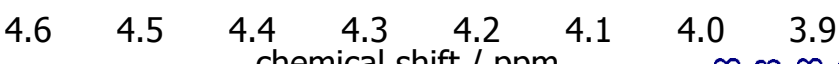
chemical shift / ppm $\quad$ 요

$\infty$

4

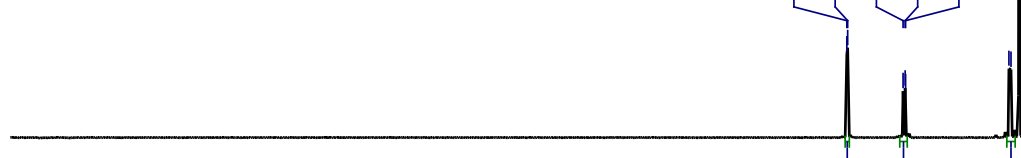

둥

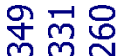

sin

Nn

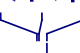

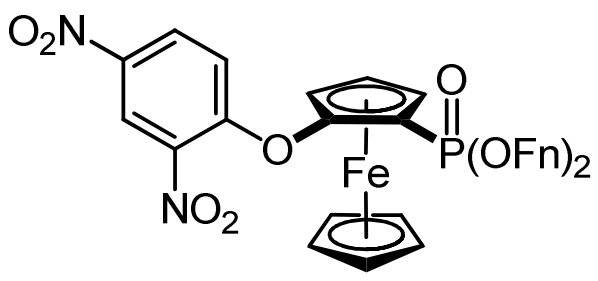

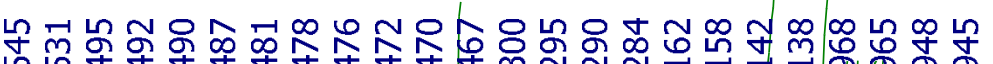

MK-381-F3

P31CPD CDCl3 \{C:|Bruker|TOPSPIN\} korbm 57

寓

$\mathrm{Fn}=$

$\left(R_{\mathrm{p}}\right)-16 \mathrm{a}$
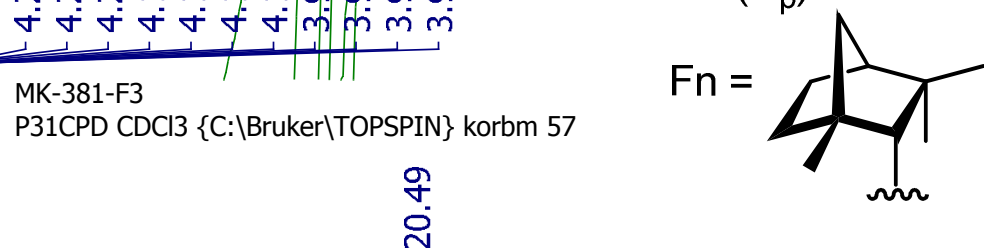

120

$\begin{array}{llllll}80 & 60 & 40 & 20 & 0 & -20\end{array}$

chemical shift $/ \mathrm{ppm}$

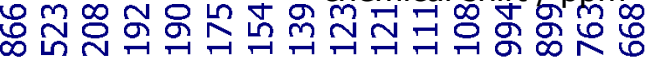

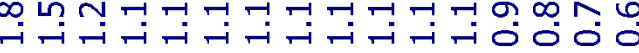

$-60$

\section{2}
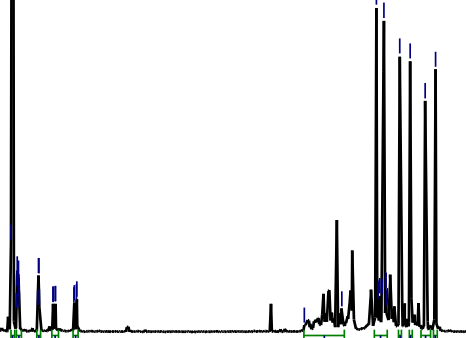

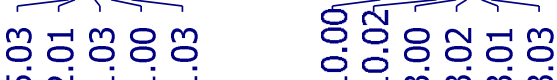

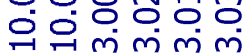

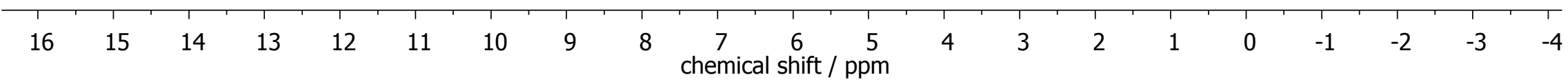


Figure SI48. ${ }^{13} C\left\{{ }^{1} H\right\}$ NMR spectra of $\left(R_{p}\right)$-16a

MK-381-F3

C13CPD CDCl3 \{C:|Bruker|TOPSPIN\} korbm 36

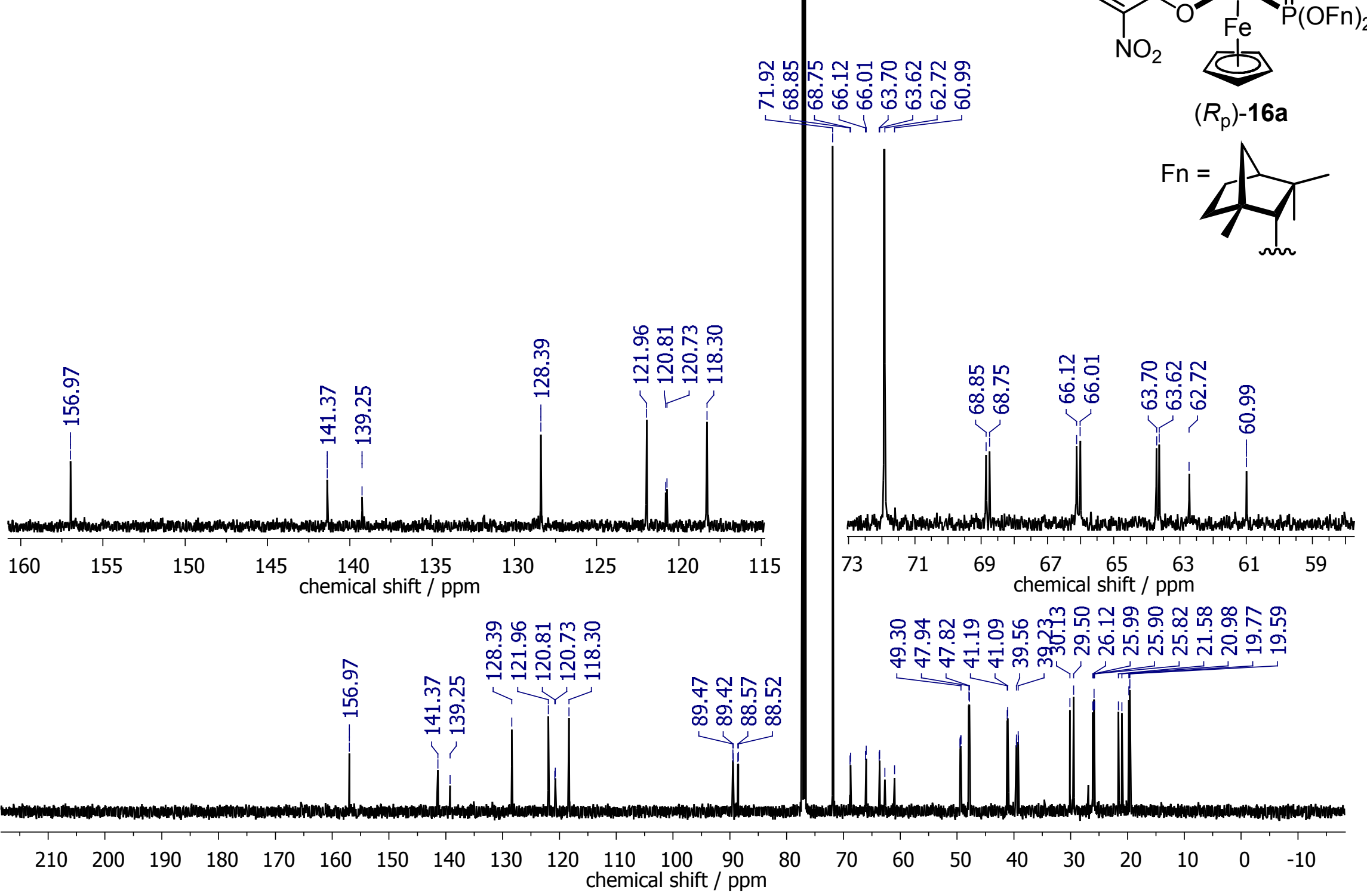




\section{Figure SI49. ${ }^{1} \mathrm{H}$ NMR spectra of $\left(R_{p}\right)-16 \mathrm{~b}$}

MK-401-N-F2-N

PROTON CDCl3 \{C:|Bruker|TOPSPIN\} korbm 42

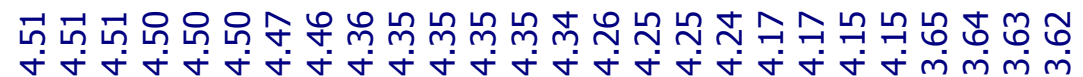

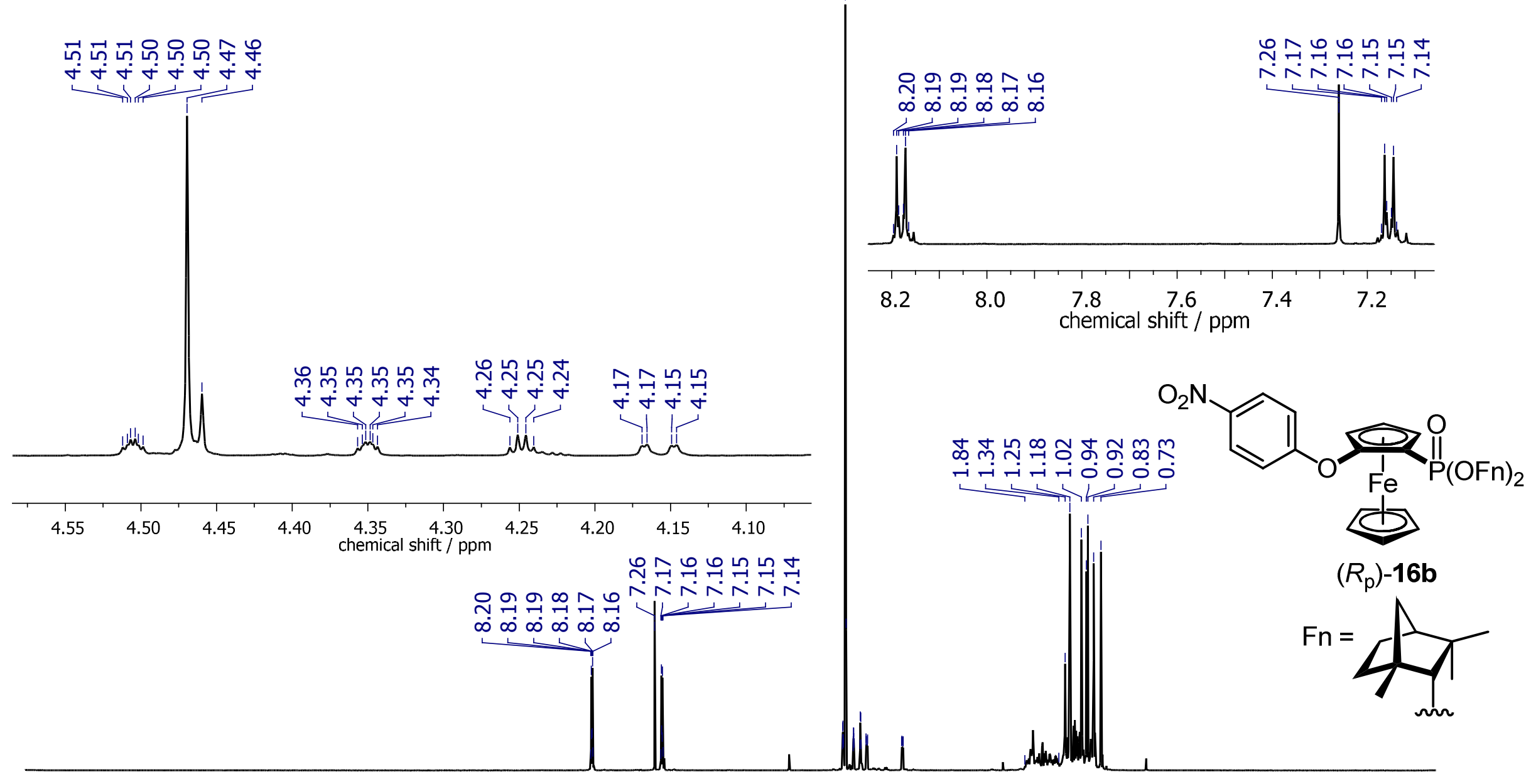


Figure SI50. ${ }^{13} \mathrm{C}\left\{{ }^{1} \mathrm{H}\right\}$ and ${ }^{31} \mathrm{P}\left\{{ }^{1} \mathrm{H}\right\}$ NMR spectra of $\left(R_{p}\right)-16 \mathrm{~b}$

MK-401-N-F2-N

C13CPD CDCl3 \{C:|Bruker|TOPSPIN\} korbm 42

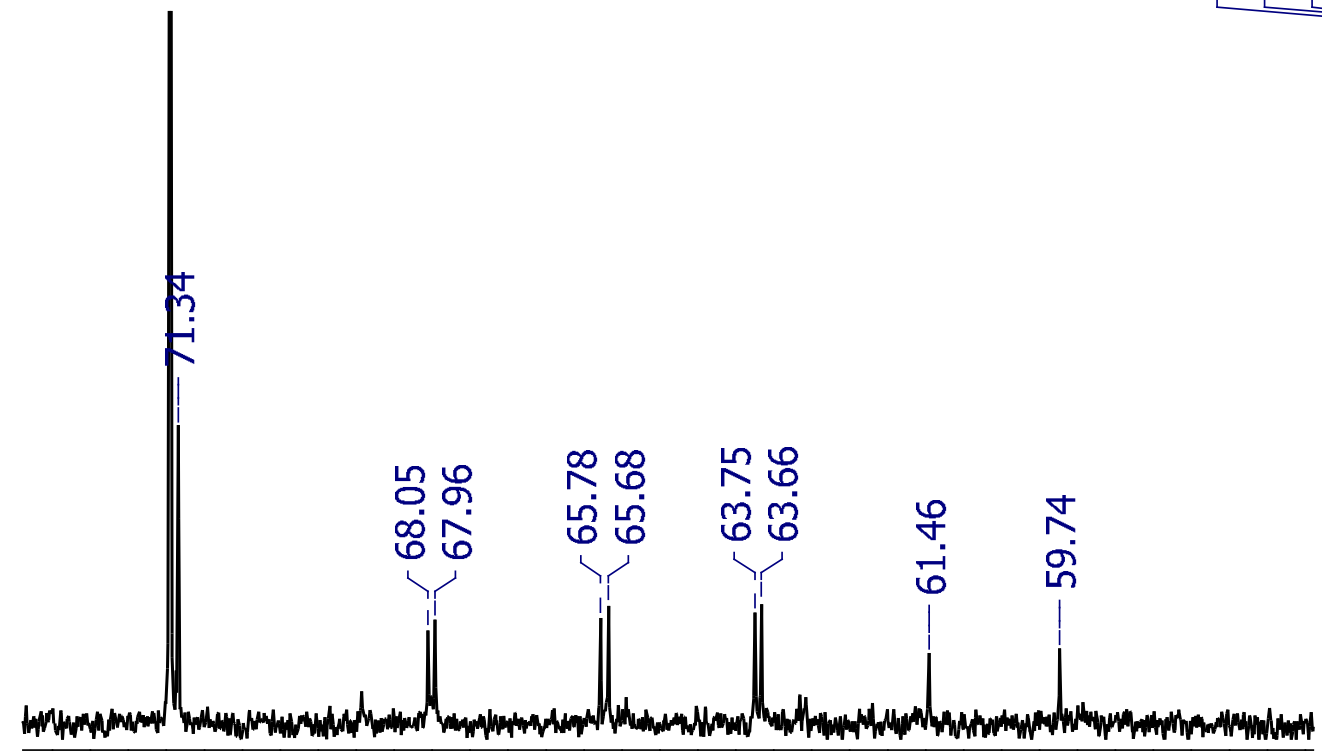
$\begin{array}{lllllllllll}73 & 72 & 71 & 70 & 69 & 68 & 67 & 66 & 65 & 64 & 63 \\ \text { chemical shift / ppm }\end{array}$

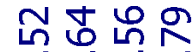
กำ

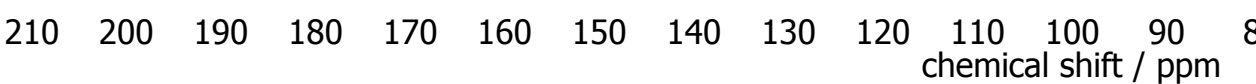

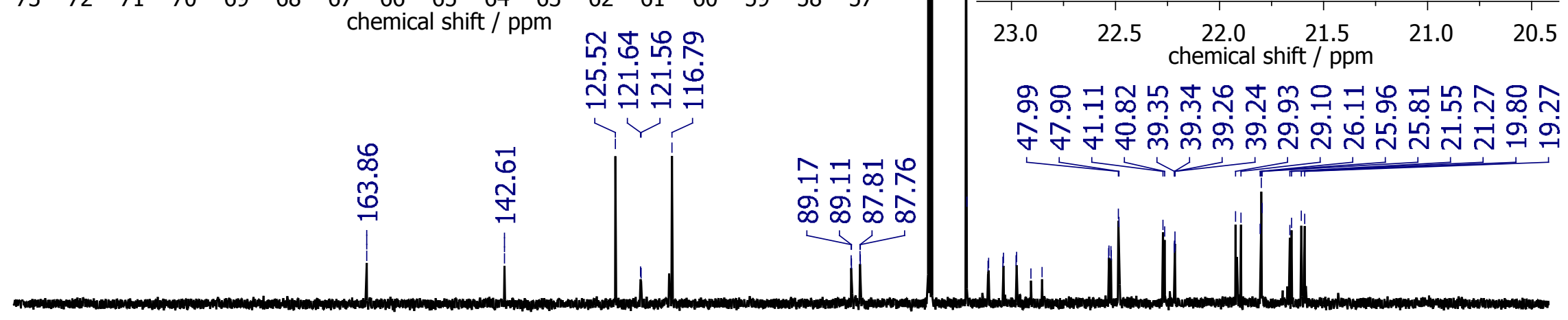

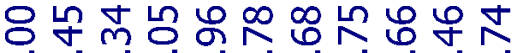

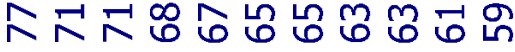

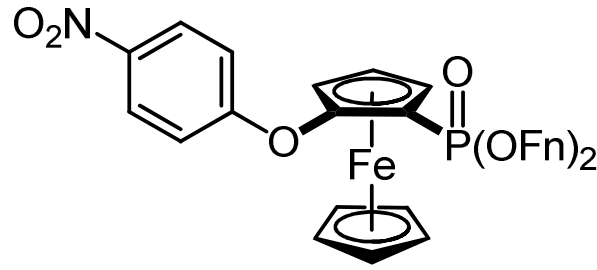

MK-401-F2

P31CPD CDCl3 \{C:|Bruker|TOPSPIN\} korbm 33

$\left(R_{\mathrm{p}}\right)-16 b$

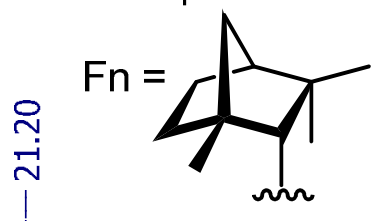

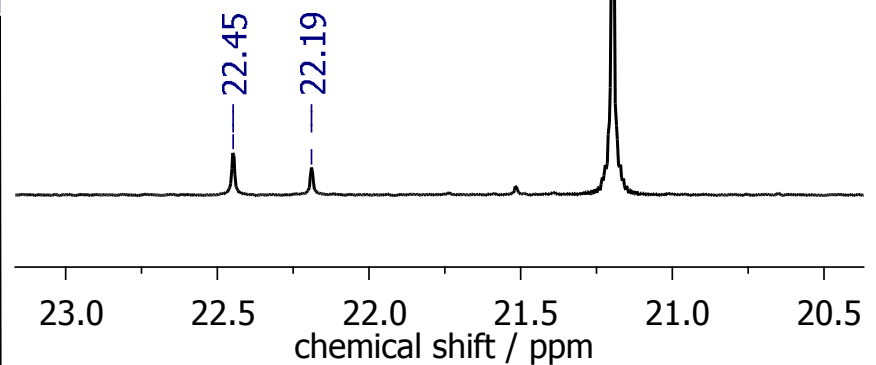

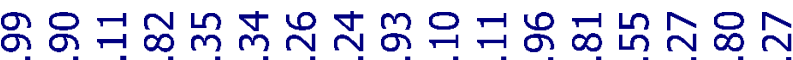
₹ 